\title{
Which narrative strategies durably reduce prejudice? Evidence from field and survey experiments supporting the efficacy of perspective-getting*
}

\author{
Joshua L. Kalla ${ }^{\dagger} \quad$ David E. Broockman ${ }^{\ddagger}$ \\ Forthcoming, American Journal of Political Science
}

Running title: Which narrative strategies durably reduce prejudice?

Keywords: Prejudice reduction, narrative persuasion, perspective-taking, immigration attitudes

\footnotetext{
${ }^{*}$ We thank Geoff Cohen, Tal Eyal, Dave Fleischer, Don Green, Dan Hopkins, Michael Kraus, Betsy Levy Paluck, Adeline Lo, Matt Lowe, Vincent Pons, Takuya Sawaoka, and Gabor Simonovits as well as participants at the Yale University Social/Personality Psychology Colloquium and the InterGroup Relations Workshop for helpful feedback. All errors are our own. Study 1 was conducted by affiliates of People's Action Institute: We Are Down Home, Michigan United, and Pennsylvania Stands Up Education Fund. Studies 2 and 3 were conducted by the Orange County Congregation Community Organization and the Tennessee Immigrant and Refugee Rights Coalition. The California Immigrant Policy Center provided operational support. The New Conversation Initiative provided training and implementation support for all three studies. All studies were reviewed by the Yale University IRB.

${ }^{\dagger}$ Assistant Professor, Department of Political Science and Department of Statistics and Data Science, Yale University. josh.kalla@yale.edu, https: / / joshuakalla.com, PO Box 208301 New Haven, CT 06520-8301.

¥Associate Professor, Travers Department of Political Science, University of California, Berkeley. dbroockman@berkeley.edu, https://polisci.berkeley.edu/people/person/ david-broockman, 210 Social Sciences Building, Berkeley, CA 94720-1950.
} 


\begin{abstract}
Exclusionary attitudes towards outgroups contribute to social and political challenges worldwide. Previous field experiments found that interpersonal conversations employing multiple narrative strategies can durably reduce exclusionary attitudes. We theoretically distinguish between three of these narrative strategies: narratives which promote analogic perspective-taking, vicarious perspective-giving, and perspective-getting. Previous research has assigned these strategies together in a compound treatment, leaving open important theoretical and practical questions about each's effectiveness. We present results from three field studies and a survey experiment that individually manipulate their presence. Across the field studies, we find omitting prompts to engage in analogic perspective-taking and vicarious perspective-giving does not diminish effects; conversations employing only perspectivegetting narratives durably reduce exclusionary attitudes. Results from within-subject analyses and a survey experiment similarly show that perspective-getting consistently reduces exclusionary attitudes and activates multiple mechanisms. These results refine theoretical understandings of prejudice reduction and support facilitating perspective-getting in conversations intended to reduce exclusionary attitudes.
\end{abstract}

The data and materials required to verify the computational reproducibility of the results, procedures and analyses in this article are available on the American Journal of Political Science Dataverse within the Harvard Dataverse Network, at https://doi.org/10.7910/DVN/ MMYAOY. 


\section{Which Narrative Strategies Reduce Exclusionary Attitudes?}

Exclusionary attitudes—intergroup prejudices and opposition to policies that promote outgroups' wellbeing - contribute to significant challenges worldwide. A growing number of Americans express a desire to take action to combat these attitudes (e.g., the movement to be "anti-racist"). Unfortunately, social science research does not offer clear guidance about how to do so. In particular, most strategies for reducing exclusionary attitudes have never been shown effective in the field; or, to the extent they have, often have effects that rapidly decay (Paluck et al. 2020). However, recent field and natural experiments have uncovered several strategies that organizations and individuals can use to durably reduce exclusionary attitudes towards stigmatized groups (e.g., Lowe 2021; Broockman and Kalla 2016). One line of research has shown that exchanging narratives that encourage individuals to consider an outgroup's perspective in interpersonal conversations can durably reduce exclusionary attitudes towards that outgroup (Broockman and Kalla 2016; Kalla and Broockman 2020). Moreover, it has found that these narratives are responsible for the effects of these conversations, as removing this exchange of narratives extinguishes their effects (Kalla and Broockman 2020, Study 1).

But which narrative strategies effectively reduce exclusionary attitudes? In this paper, we theoretically distinguish between several distinct narrative strategies to encourage individuals to consider an outgroup's perspective that previous research has deployed. Table 1 summarizes these strategies, which differ by the source of the narrative (whether self-generated, recalled, or received from another) and the topic of the narrative (an outgroup's experience or one's own experience). First, lab- and survey-based research has studied traditional perspective-taking, wherein individuals imagine a narrative as if they themselves were the outgroup member experiencing it (e.g. Galinsky and Moskowitz 2000; Simonovits, Kezdi and Kardos 2018; Adida, Lo and Platas 2018; Williamson et al. 2021). Next, Broockman and Kalla (2016) consider "analogic perspectivetaking," a form of perspective-taking in which "perceivers try to understand the target's experience 
by recalling a different situation from their own experience that is presumed to parallel the target's situation" (Gehlbach and Brinkworth 2012). However, that study's intervention, and interventions in other studies of analogic perspective-taking, also contain what we term vicarious perspectivegiving and perspective-getting. Vicarious perspective-giving involves recounting the experiences of an outgroup member. By contrast, perspective-getting involves hearing a narrative about an outgroup member's perspective (e.g., Bruneau and Saxe 2012). ${ }^{1}$

These narrative strategies are conceptually distinct and evidence supporting their efficacy would have different theoretical and practical consequences. Unfortunately, existing research does not offer clear guidance about the efficacy of these strategies in real-world contexts. For instance, previous field studies have always employed multiple of these strategies simultaneously in compound treatments (Broockman and Kalla 2016; Kalla and Broockman 2020). This has left unclear to what extent each of these narrative strategies effectively reduces exclusionary attitudes. This leaves open important theoretical questions. It also means practical questions remain-given that prejudice reduction interventions are often expensive and difficult to scale, which components of these interventions should practitioners focus their scarce resources on implementing ${ }^{2}$

In this paper, we present evidence from three original field studies and a survey experiment that seek to disentangle the impacts of these narrative strategies. Our field studies consider interventions that sought to reduce Americans' exclusionary attitudes towards a highly stigmatized group, unauthorized immigrants. ${ }^{3}$ Stigma against immigrants and hostile elite rhetoric contribute to hostile government policies that negatively impact immigrants (e.g., Hainmueller, Hangartner and Pietrantuono 2017). Unfortunately, previous research also suggests that attitudes towards immi-

\footnotetext{
1 "Perspective-getting" is most associated with studies of person perception, not exclusionary attitudes (e.g., Eyal, Steffel and Epley 2018). However, Bruneau and Saxe (2012) have a condition where a "responder" listens to and summarizes the experience of an outgroup member, and, consistent with our findings, this reduces exclusionary attitudes under some conditions. They call this "perspective-taking" but we call it "perspective-getting" to distinguish it from traditional perspective-taking.

${ }^{2}$ If the effects of different narrative strategies are additive, it could be optimal to deploy all of them, but if they are non-additive, it could be optimal to focus on the strategy that is easiest to implement.

${ }^{3} \mathrm{We}$ use the term unauthorized instead of undocumented or illegal because it is considered a neutral term. Our survey instruments rotate between using all three terms.
} 
Table 1: Narrative Strategies for Considering Outgroups' Perspective

(a) Definition and Examples

\begin{tabular}{lll}
\hline Strategy & Definition & Example \\
\hline $\begin{array}{l}\text { Traditional Perspective- } \\
\text { Taking }\end{array}$ & $\begin{array}{l}\text { Imagining an experience from the } \\
\text { perspective of an outgroup member. } \\
\text { (e.g., Galinsky and Moskowitz (2000)) }\end{array}$ & $\begin{array}{l}\text { Imagining what it would be like to } \\
\text { experience a story if one were the } \\
\text { outgroup member in that story. }\end{array}$ \\
\hline $\begin{array}{l}\text { Analogic Perspective- } \\
\text { Taking }\end{array}$ & $\begin{array}{l}\text { Recalling a similar situation } \\
\text { from one's own experience. } \\
\text { (e.g., Gehlbach and Brinkworth (2012), } \\
\text { Broockman and Kalla (2016) })\end{array}$ & $\begin{array}{l}\text { Thinking about a time when one was } \\
\text { discriminated against to help understand } \\
\text { what it is like for outgroup members } \\
\text { when they face discrimination. }\end{array}$ \\
\hline Perspective-Getting & $\begin{array}{l}\text { Hearing about the experiences of an } \\
\text { outgroup member (from them or } \\
\text { others). (e.g., Bruneau and Saxe (2012), } \\
\text { Eyal, Steffel and Epley (2018)) }\end{array}$ & $\begin{array}{l}\text { Listening to an ingroup friend tell a } \\
\text { story about the experiences of } \\
\text { their friend in the outgroup. }\end{array}$ \\
\hline $\begin{array}{l}\text { Vicarious Perspective- } \\
\text { Giving }\end{array}$ & $\begin{array}{l}\text { Recounting the experiences } \\
\text { of an outgroup member. }\end{array}$ & $\begin{array}{l}\text { Desing the experiences of a friend } \\
\text { or family member in the outgroup. }\end{array}$ \\
\hline
\end{tabular}

(b) Key Differences

\begin{tabular}{lll}
\hline Strategy & Source of Narrative & Topic of Narrative \\
\hline $\begin{array}{l}\text { Traditional Perspective- } \\
\text { Taking }\end{array}$ & Self-generated (imagined) & $\begin{array}{l}\text { Outgroup Member's } \\
\text { Experiences }\end{array}$ \\
\hline $\begin{array}{l}\text { Analogic Perspective- } \\
\text { Taking }\end{array}$ & Self-generated (recalled) & Own Experiences \\
\hline Perspective-Getting & Received from another & $\begin{array}{l}\text { Outgroup Member's } \\
\text { Experiences }\end{array}$ \\
\hline $\begin{array}{l}\text { Vicarious Perspective- } \\
\text { Giving }\end{array}$ & Self-generated (recalled) & $\begin{array}{l}\text { Outgroup Member's } \\
\text { Experiences }\end{array}$ \\
\hline
\end{tabular}

grants are typically durable and resistant to lasting change (e.g., Hopkins, Sides and Citrin 2019).

What narrative strategies might effectively reduce exclusionary attitudes against highly stigmatized groups such as unauthorized immigrants? Our original field studies consider three of the narratives strategies we identified in prior field experiments on interpersonal conversations: narratives promoting perspective-getting, vicarious perspective-giving, and analogic perspective-taking (see Table 1 for definitions). Across a variety of evidentiary strategies, we marshal consistent evidence in favor of the efficacy of narratives that promote perspective-getting, or hearing about the experiences of an outgroup member. This stands in contrast to how some prior research has 
interpreted its findings. We also find that these narratives are similarly effective whether delivered directly by an outgroup member or shared by a third-party discussing the experiences of an outgroup member.

Table 2 summarizes how our new studies relate to and build upon existing field experiments on these narrative strategies, organizing prior studies' interventions into our typology of narrative strategies. Broockman and Kalla (2016) contained only one treatment condition which involved all three narrative strategies (perspective-getting, vicarious perspective-giving, and analogic perspective-taking) and found durable reductions in transphobia. Broockman and Kalla (2016) speculated that analogic perspective-taking was chiefly responsible for the effects, but did not separately randomize its presence. Kalla and Broockman (2020, Study 1) replicated these effects in the context of unauthorized immigrants, and also found that removing all three narrative strategies extinguished the effects. Existing work has therefore shown that these three narrative strategies are effective in combination, but has not established to what extent each of them is individually effective.

To disentangle the effects of the three strategies, we first present two original field experiments on door-to-door canvassing interventions that build on this work.

Study 1 presents results from a field experiment on a door-to-door canvassing intervention that aimed to reduce prejudice against unauthorized immigrants and increase support for including them in government health insurance programs. Study 1's Full Intervention condition mirrors prior studies by deploying all three narrative strategies. As compared to a Placebo condition, this Full Intervention durably reduced prejudice for at least several months and increased support for including unauthorized immigrants in Medicaid. However, in an Intervention without Analogic Perspective-Taking condition, the conversations omitted analogic perspective-taking and had effects that were similar to, if not slightly larger than, the Full Intervention. This result suggests that narratives promoting Analogic Perspective-Taking are not necessary for interpersonal conversations to reduce exclusionary attitudes. 
Table 2: Summary of differences between conditions in previous studies and this study

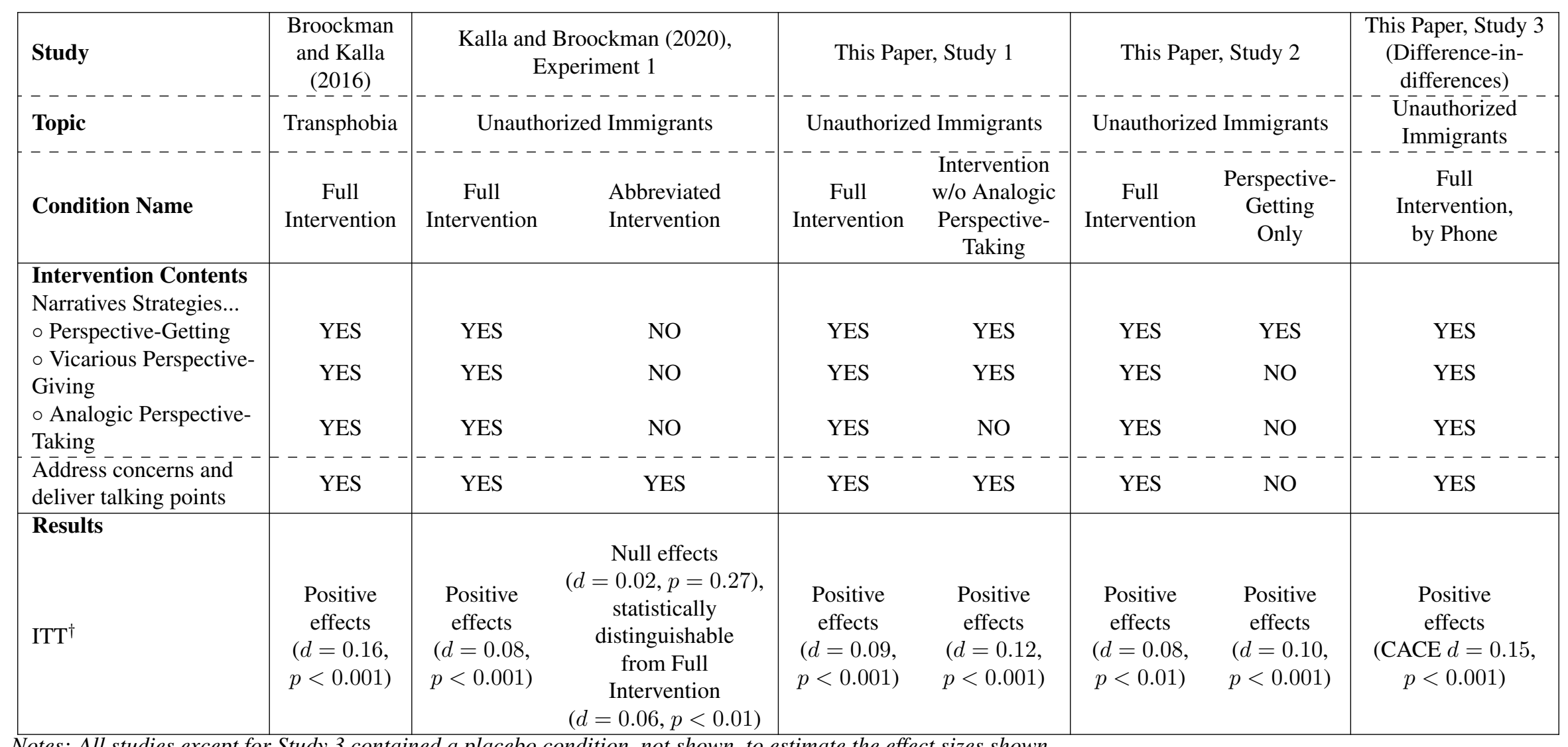

Notes: All studies except for Study 3 contained a placebo condition, not shown, to estimate the effect sizes shown.

$\dagger$ Results are intent-to-treat (ITT) estimates from an Overall Index averaged across survey waves. Because the studies use different survey items, the estimates are not directly comparable across studies. Study 3 is a difference-in-differences without an uncontacted control group, so the estimate is most comparable to a Complier Average Causal Effect (CACE), as it describes the effects among the subset of individuals who completed the conversation. 
Next, in Study 2, we present results from another field experiment conducted by a separate organization. This study's Full Intervention condition again mirrors the previous studies and involved exchanging all three forms of narratives. However, a second Perspective-Getting Only condition only deployed narratives promoting Perspective-Getting, omitting both Analogic PerspectiveTaking and Vicarious Perspective-Giving narratives. The Full Intervention condition had significant effects on reducing exclusionary attitudes, but the Perspective-Getting Only condition had similar effects. These results support the efficacy of conversations that focus on sharing narratives about outgroup members (Perspective-Getting), as including Vicarious Perspective-Giving and Analogic Perspective-Taking narratives does not appear to increase effects.

We then present several additional results that are further consistent with the efficacy of perspective-getting.

First, we conduct a meta-analysis of our new studies and previous field experiments which confirms their collective implications with respect to the efficacy of perspective-getting.

Next, we present within-subject analyses from our two original field experiments and a third original field study, a difference-in-differences design that evaluated a version of the Full Intervention conducted by phone. Using records canvassers kept about what occurred during each conversation, we compare pre-post differences across individuals who had conversations that did and did not involve each of the intended narrative approaches. Across all three studies, we consistently find that participants were more supportive after conversations in which they heard a story about an outgroup member (perspective-getting), but were no more supportive if participants also told a story of their own (vicarious perspective-giving and analogic perspective-taking).

Finally, we present a survey experiment that tests these approaches and traditional perspectivetaking. We again find that perspective-getting consistently reduces exclusionary attitudes, whereas the other approaches have less reliable effects.

We close by discussing the theoretical implications of our findings and presenting data from our field- and survey-based studies on the mechanisms that these narratives activated. We find 
that in both field and survey contexts, perspective-getting activates multiple mechanisms that have been found to reduce prejudice. However, our work cannot determine to what extent the effects of the interventions we study operate through these mechanisms, and we discuss how future research could examine this.

\section{Theoretical Perspectives}

Exchanging narratives in interpersonal conversation represents a promising paradigm for reducing exclusionary attitudes for several reasons (Kalla and Broockman 2020). First individuals often "transport" themselves into narratives they find interesting, reducing motivation to counter-argue and heightening emotional responses (Green and Brock 2000). Second, interpersonal conversation represents a natural setting to encourage individuals to effortfully process the implications of a narrative. Finally, interlocutors can approach the conversation non-judgmentally, showing respect to an individual and listening to their views without counter-arguing, which could reduce resistance to persuasion by reducing threat to the self (e.g., Kalla and Broockman 2020).

Consistent with these expectations, Kalla and Broockman (2020) find that removing the nonjudgmental exchange of narratives from interpersonal conversations extinguishes their effects on exclusionary attitudes. However, this research does not establish which narrative strategies produce the effects in the first place. This is important to understand for two reasons. First, on a practical level, existing approaches with multiple narratives require intensive training and long conversa-

tions. Second, on a theoretical level, understanding to what extent these narratives are effective in the field would help elucidate the underpinnings of successful prejudice reduction efforts and can help guide the development of future interventions.

In this paper, we draw theoretical distinctions between four specific kinds of narratives that appear in prior studies (Table 1).

Traditional Perspective-Taking. Perspective-taking is one of the most common approaches 
studied to reduce prejudice in lab and survey settings (e.g., Adida, Lo and Platas 2018; Galinsky and Moskowitz 2000; Simonovits, Kezdi and Kardos 2018). When engaging in traditional perspective-taking, individuals self-generate a narrative about an outgroup member's experience, in particular imagining themselves as if they were another person, seeing what they see and experiencing what they experience. This has often been found to make the outgroup seem more similar to the perspective-taker ("self-other merging" or "self-other overlap") (Todd and Galinsky 2014).

There are two challenges with deploying traditional perspective-taking in a field context. First, on a practical level, while volunteers for experiments may be willing to imagine a narrative from another person's perspective, it may be difficult to prompt a stranger encountered as part of a political campaign to do the same. Second, prior research on perspective-taking has found that potential perspective-takers may resist taking the perspective of stigmatized outgroups (Todd and Galinsky 2014), such as unauthorized immigrants, precisely the outgroups where interventions to reduce exclusionary attitudes are most necessary. Consistent with this, some studies find that perspective-taking can fail to produce attitude change (e.g., Adida, Lo and Platas 2018, who also find effects on behavior).

Analogic Perspective-Taking. Other narrative strategies may overcome these challenges. Analogic perspective-taking involves the perspective-taker recalling an experience from their own life (self-generating a narrative they recall about their own experiences), which they are then encouraged to use to assist them in better understanding the perspective of a target. For example, in Broockman and Kalla (2016), canvassers asked voters to think about a time when they had felt judged as a way to help them better understand the discrimination that transgender people face. Analogic perspective-taking could then reduce prejudice by increasing self-outgroup overlap (by increasing perceived similarity between oneself and the outgroup) and reactive empathy (by seeing parallels between the outgroup's emotions and one's own).

Analogic perspective-taking may be more practical to employ in a field context than traditional perspective-taking, as individuals may be more willing to recount an experience from their own 
life than to imagine themselves as a member of a highly stigmatized group. Even if an analogy is available, the potential perspective-taker may still resist admitting that their life experiences are similar to those of a highly stigmatized outgroup.

Perspective-Getting. Perspective-getting involves hearing a narrative about the experiences of an outgroup member (not necessarily from an outgroup member first-hand). It is the only of the three strategies we study where the source of the narrative is another person and the narrative is not self-generated.

Perspective-getting has not received a great deal of direct attention in the study of prejudice reduction (Bruneau and Saxe 2012; Audette, Horowitz and Michelitch 2020), but is also supported by a long tradition of psychological literature. First, literature on the identifiable victim effect (e.g., Redelmeier and Tversky 1990) has found that identifying particular individuals instead of a larger group can trigger stronger emotional responses, promoting reactive empathy. Second, narratives may also combat the fundamental attribution error, changing attributional thinking by allowing individuals to realize that disadvantaged outgroup members may face hardships due to external, situational challenges, not negative personal attributes. Third, it could lead individuals to see the outgroup more as a collection of individuals, and less as an overall group (so-called "entitativity"). Finally, such narratives may also promote self-outgroup merging if individuals feel they can relate to the outgroup member in the narrative. The mechanisms activated would likely depend on the content of the narratives.

At the same time, perspective-getting may be a less active cognitive process since it does not involve self-generating a narrative, and so could result in less durable reductions in prejudice than either analogic or traditional perspective-taking. Individuals might also engage in subtyping and avoid generalizing a positive narrative to their views about a stigmatized outgroup at large (Richards and Hewstone 2001).

Vicarious Perspective-Giving. The final narrative strategy we consider is vicarious perspective-giving. In this strategy, people self-generate a narrative about an outgroup member 
that they recall-i.e., they are asked to share a story about an outgroup member they know. For example, Broockman and Kalla's (2016) intervention also asked individuals if they knew any transgender or LGBTQ people and, if so, to tell a story about them.

Vicarious perspective-giving could activate the same mechanisms as perspective-getting (reactive empathy, changing attributional thinking, and promoting self-outgroup merging), again depending on the content of the narratives. But it may be more effective than analogic or traditional perspective taking because the subject does not need to be willing to see themselves as similar to the outgroup, which as noted above, may backfire or be resisted if the outgroup is stigmatized. Instead, the subject can recall an experience of an outgroup member that promotes understanding or empathy while still maintaining a distance from the outgroup. However, vicarious perspectivegiving may fail in practice if the receiver of the conversation does not know an outgroup member well enough to recount an experience that outgroup member had, or engages in subtyping that leads them to resist generalizing to the outgroup at large.

Given the competing expectations of the various narrative strategies, we present evidence from multiple field studies and a survey experiment attempting to disentangle the different impacts of deploying these strategies in interpersonal conversations.

\section{Study 1: Door-to-door Canvassing Experiment}

In the fall of 2019, we conducted a pre-registered, randomized, placebo-controlled experiment to measure the effects of a door-to-door canvassing intervention. This experiment was conducted in Michigan, Pennsylvania, and North Carolina.

The canvass intervention in Study 1 attempted to increase public support for including unauthorized immigrants in government health care programs such as Medicaid and to reduce prejudice against unauthorized immigrants. When the intervention was deployed in late 2019, the issue of including unauthorized immigrants in public programs had recently become salient; many candi- 
dates for the Democratic Presidential nomination had announced they supported the policy and then-President Trump criticized their support.

\section{Canvass Intervention}

The canvass intervention had several steps.

1. Establish contact. The canvasser knocks on the door and says, "Hi, are you [subject's name]?" If the subject identifies themself, the canvasser marks "Voter came to door" on their walk list. This qualifies the voter to be targeted for resurveying. Note that this first step is identical in the placebo and treatment conditions.

2. Inform subject about policy being discussed. The canvassers began by engaging in a series of strategies to elicit participants' opinions in a non-judgmental manner. First, canvassers informed voters that they were at the door to discuss universal healthcare. Canvassers then asked voters about their opinion on the policy and asked them to explain their position. They then did the same about including unauthorized immigrants in universal healthcare. Canvassers were trained to ask these questions in a non-judgmental manner, not indicating they were pleased or displeased with any particular answer, but rather to appear genuinely interested in the subject's opinions.

3. Vicarious Perspective-Giving. The canvasser then asked the voter if they know anyone who is an immigrant and, in particular, an unauthorized immigrant. If the voter knew someone, the canvasser asked the voter to talk about how they knew this person, their story, and how it must feel to be an immigrant.

4. Perspective-Getting. The canvasser would share a story about an immigrant. This might be their own story or a story about a friend or family member (most of the canvassers were not themselves immigrants). 


\section{Analogic Perspective-Taking - removed in Intervention Without Analogic Perspective-Taking.}

The intervention also attempted to encourage analogic perspective-taking towards unauthorized immigrants. To do this, canvassers asked voters to share a time when they needed care or support. In particular, they were prompted to share about "a time when you or a loved one had to pay for or access healthcare in the past." Canvassers would also share their own stories of struggling in order to make voters feel comfortable sharing a story of their own.

Canvassers' goal was for this non-judgmental exchange of narratives to end with individuals self-generating and explicitly stating aloud implications of the narratives that ran contrary to any exclusionary attitudes individuals previously stated.

6. Provide arguments and information. The canvasser would then reiterate for the voter why they hoped the voter would become more supportive of including unauthorized immigrants in a universal healthcare system.

7. Discuss. The canvasser would note any contradictions in the voter's opinions and talk through them.

8. Address concerns. The canvasser would return to any concerns about unauthorized immigrants and universal healthcare that the voter may have mentioned earlier. The canvasser would talk through these concerns and provide talking points in response to them.

9. Encourage active processing. The intervention ended with canvassers asking voters if and why the conversation changed their attitudes towards including unauthorized immigrants in a universal healthcare system. The canvasser then thanked the subject and left.

The experiment had a placebo condition and two treatment conditions.

The first treatment condition contained all the steps above ("Full Intervention" condition). The second treatment removed the analogic perspective-taking step ("Intervention without Analogic Perspective-Taking" condition), allowing us to assess the marginal effect of including analogic 
perspective-taking by comparing this condition with the Full Intervention condition. Everything else was the same between these two treatment conditions.

In the placebo condition, canvassers initially established contact in a manner identical to the treatment conditions (see step 1), but then had a short conversation about an unrelated topic (a brief one-question survey about rent control in North Carolina and the minimum wage elsewhere). The purpose of this condition is to identify voters who could have been delivered the treatment (but were not due to their random assignment).

\section{Experimental Design}

We measured the effects of these conversations with an ostensibly unrelated survey, using the design in Broockman, Kalla and Sekhon (2017). The experiment began by recruiting registered voters $(n=369,317)$ via mail for an online survey, presented as the first in a series of surveys not specifically about immigration or health care and which made no reference to any potential canvassing. We gathered voters' mailing information from public lists of registered voters. We also collected respondents' email addresses in this baseline survey so that we could email follow-up survey invitations. We next randomly assigned baseline survey respondents to the Full Intervention $(n=2,973)$, Intervention without Analogic Perspective-Taking $(n=2,975)$, or Placebo conditions $(n=2,977)$. Blocked random assignment was conducted at the household level, such that participants within the same household were always assigned to the same condition.

To deliver the intervention, staff and volunteers affiliated with the partner organizations went door-to-door from September - November, 2019 to visit individuals' homes at their addresses in the voter registration database. Canvassers began by knocking on voters' doors unannounced. Before revealing the purpose of the conversations, canvassers asked to speak with the person on their list who had enrolled in the study and confirmed the person's identity. Next, canvassers implemented the experimental condition corresponding with the person's random assignment. We define those individuals who confirmed their identities as compliers who are eligible for recruitment to the 
post-treatment surveys.

Among those who began the conversation, the conversations took an average of 18.5 minutes in the full intervention group and 15.5 minutes in the group without analogic perspective-taking.

One week, 7 weeks, and 4.5 months after the conversation took place, we emailed ostensibly unrelated invitations to participate in post-treatment surveys to all individuals who identified themselves at the door before the intervention began. The post-treatment surveys contained several dependent variables of interest but also many unrelated items intended to disguise the connection between the survey and the intervention.

The post-treatment surveys contained several survey items to gauge the effects. We preregistered that we would combine these items into two primary outcome indices: a policy index gauging support for including unauthorized immigrants in government programs and a prejudice index. As we pre-registered, we formed these indices at each wave by taking the first factor from a factor analysis of all the items in the index and then standardizing the index to standard deviation one. Online Appendix B contains the survey items (p. 5-6 and 16-17), tests of design assumptions, and a link to the pre-registration and intervention scripts and training materials.

\section{Results}

We estimate the effects of the intervention by comparing post-treatment survey responses among those assigned to the two treatment conditions to those assigned to the placebo condition who identified themselves at the door before the conversation began (Nickerson 2005). ${ }^{4}$ We use OLS with pre-treatment covariates and standard errors clustered by household. The results on the prejudice and policy indices are shown in Figure 1. As shown, both interventions were similarly effective - if anything, the intervention without analogic perspective-taking may have been slightly more effec-

\footnotetext{
${ }^{4}$ Effects are among those who came to the door. Of these, $81 \%$ of voters in the treatment conditions entered into the conversation, as measured by providing a "first rating" where they initially told canvassers how they felt about the policy. The estimates presented here should therefore be multiplied by $\approx 1.23$ to compute the effect among those who enter into the conversation.
} 
tive. These effects also persisted at least 4.5 months, at which point we stopped fielding additional surveys.

The intervention did not merely strengthen existing support but created new support for policies to include undocumented immigrants in government programs. To demonstrate this, we dichotomize variables capturing support for these policies such that the variables are set to 1 if the participant expressed any support and 0 otherwise (either not sure or disagreed). We find that both interventions caused a large number of people to become supporters of these policies, even months after the interventions took place. Figure 2 shows that when dichotomizing the health-care policy items, we find increases of 5-9 percentage points. Notably, the effects of the Intervention Without Analogic Perspective-Taking are always similar, if not slightly larger, than the Full Intervention. Table OA20 shows effects across all the policy outcomes.

Online Appendix B presents the results on all the individual items of interest we had preregistered, representativeness assessments, and heterogenous treatment effects (p. 5 and 8-14). Of particular interest, Table OA19 (p. 13) shows that weighting the survey sample to match the sampling frame produces estimates that are larger. This indicates that any unrepresentativeness of our sample, if anything, appears to lead us to underestimate the size of the effect in the population we attempted to recruit, perhaps because of the high levels of education and political engagement in our sample. Importantly, Table OA12 (p. 12) presents results finding similar effects regardless of whether the canvasser is personally an immigrant or not, meaning the results cannot be attributed to direct contact with outgroups. Last, Table OA18 (p. 13) finds that the intervention had similar effects among those who did and did not approve of Donald Trump at baseline.

In summary, Study 1 replicated the effect of interpersonal conversations involving the exchange of narratives about outgroup's perspectives. However, we found that the conversations had these effects regardless of whether they included analogic perspective-taking, contrary to Broockman and Kalla's (2016) interpretation that analogic perspective-taking narratives drive the effects of these conversations. We also found that these effects persisted, again regardless of the presence of 
Figure 1: Study 1: Main Results

Effect of Full Intervention vs. Placebo

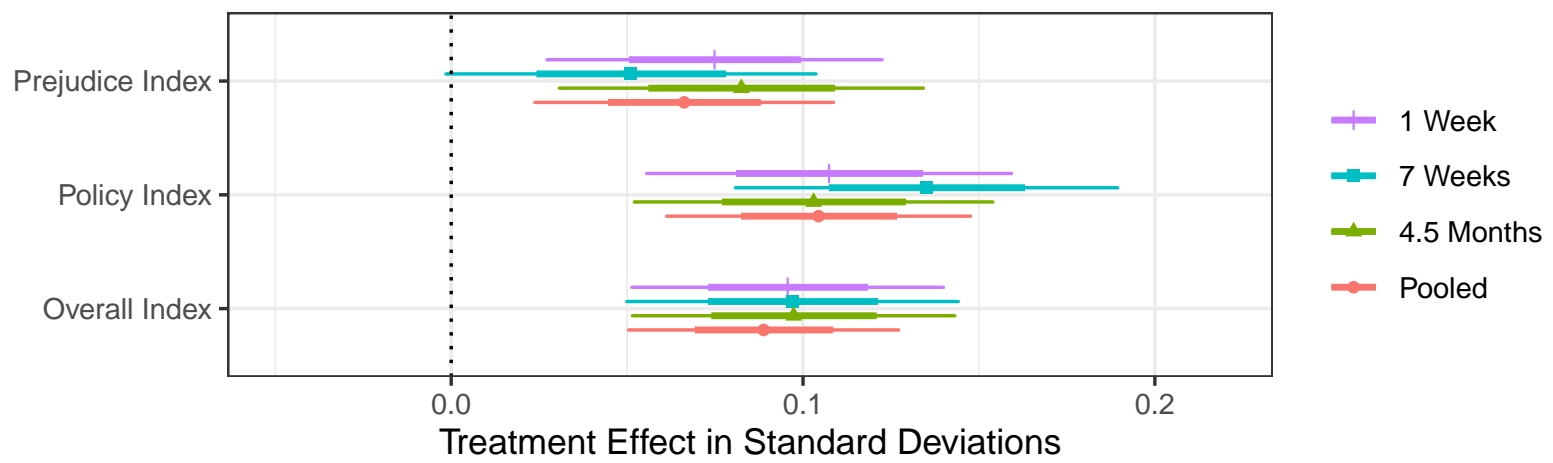

Effect of Intervention without Analogic Perspective-Taking vs. Placebo

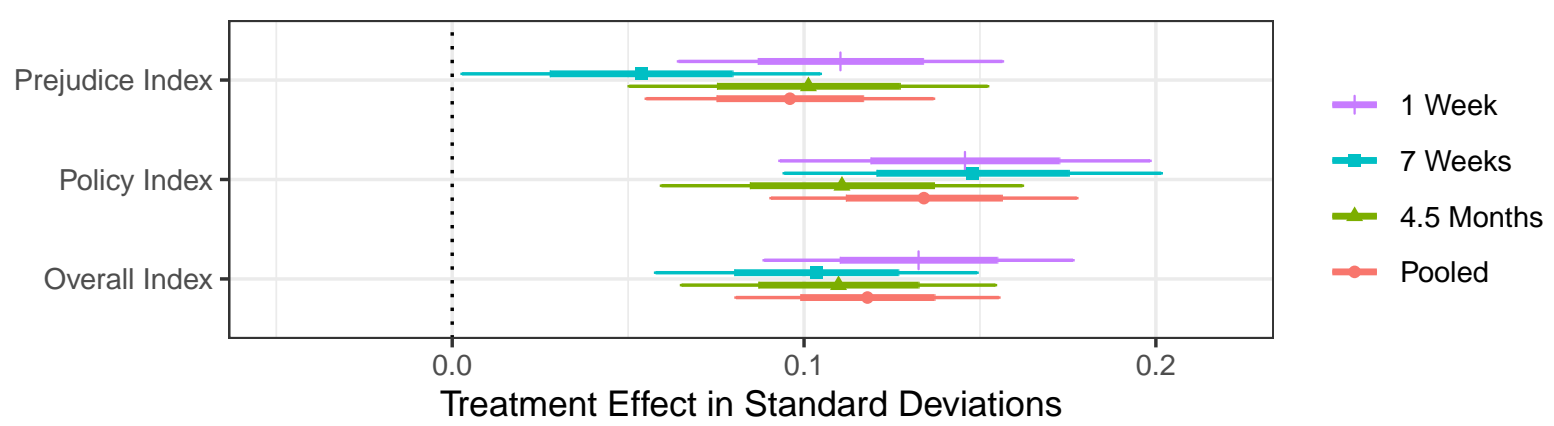

Effect of Full Intervention vs.

Intervention without Analogic Perspective-Taking

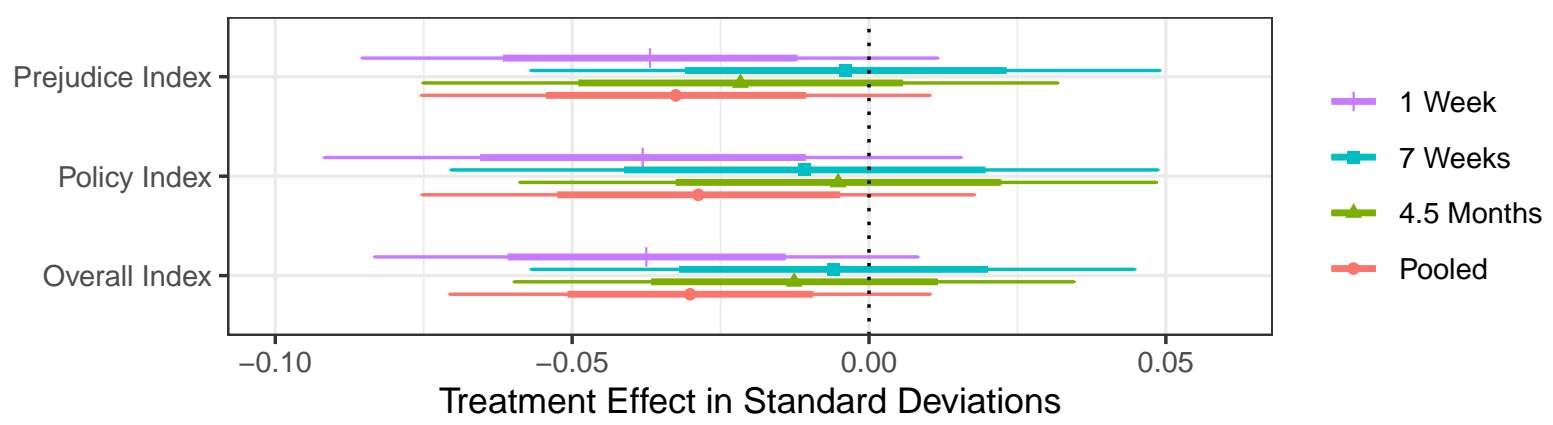

Notes: Thick lines are one standard error (household clusters), thin lines are 95\% confidence intervals. 
Figure 2: Study 1: Effects on Dichotomized Policy Items

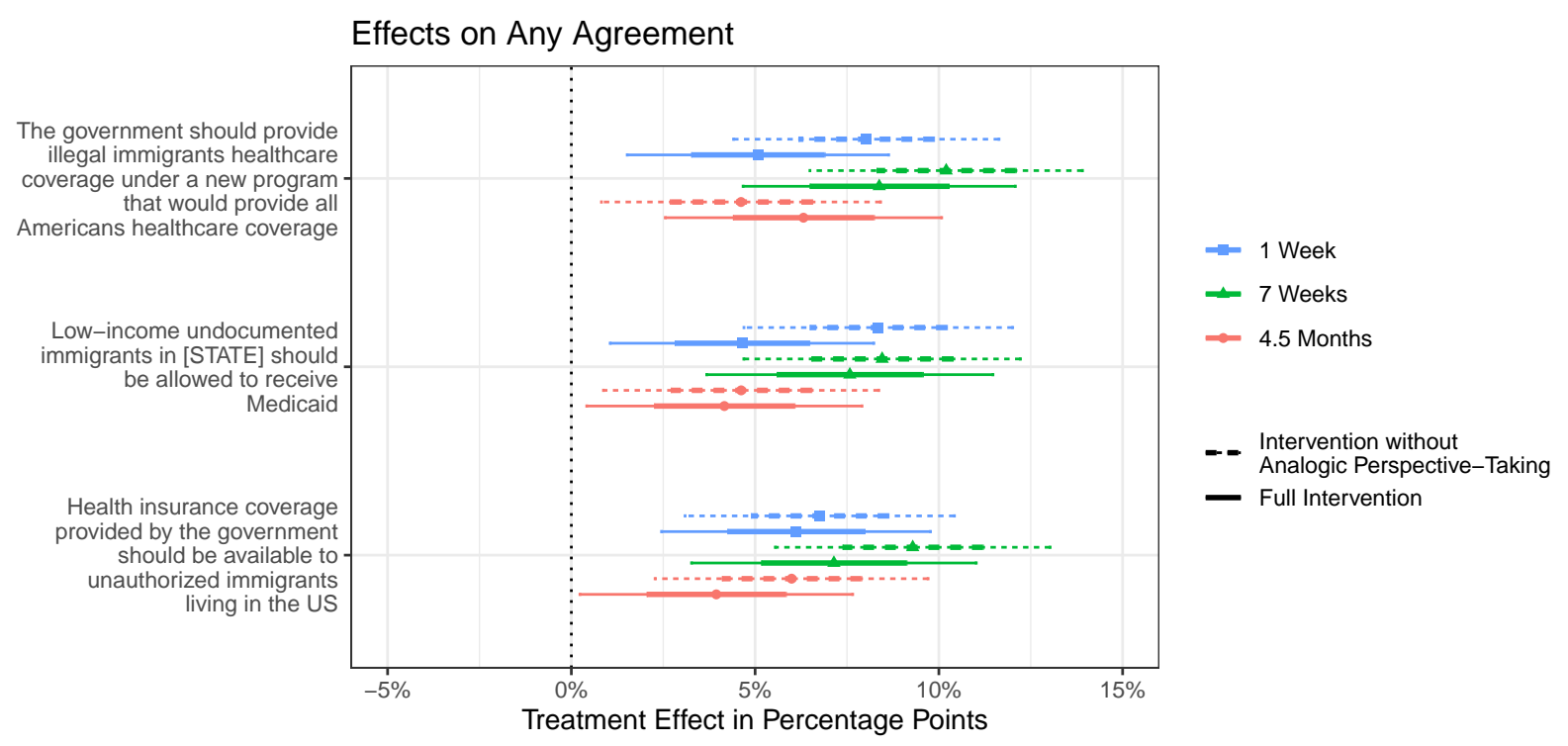

Notes: Thick lines are one standard error (household clusters), thin lines are 95\% confidence intervals. Outcome is set to 1 if the individual agreed with the policy and 0 otherwise.

the analogic perspective-taking prompt.

\section{Study 1: Within-Subject Results}

Study 1's research design only randomly manipulated whether canvassers attempted to encourage analogic perspective-taking, but did not separately manipulate the presence of perspective-getting or vicarious perspective-giving; nor, within the full intervention condition, did it separately manipulate the presence of canvassers or voters actually sharing an analogic narrative. However, canvassers from Study 1 maintained detailed records about which narratives were exchanged during the canvassing interactions. These records allow us to further probe the effects of each of the narratives in the framework we developed in Table 1.

In particular, to explore which of these narratives might have driven the effects we observed in Study 1, we conducted a non-pre-registered within-subject analysis. We first formed an overall 
index of all of the items in both the prejudice and policy index, using factor loadings estimated from the pre-treatment wave of survey data. We then estimated a difference-in-differences regression within both treatment groups with this index as the outcome. This regression includes fixed effects for survey wave and for each individual respondent and clustered the standard errors at the individual respondent level. To estimate the change in the overall index associated with each narrative being exchanged, we estimated an interaction between an indicator for whether the survey wave was conducted post-treatment with the presence of each narrative strategy. Note that in this analysis the presence of a narrative strategy is determined by whether the voter engages in it and is not randomly assigned.

Figure 3 shows the results. First, we find that individuals who shared a story about an immigrant they knew (vicarious perspective-giving) had similar values on the overall index in follow-up surveys to those who did not; the point estimate is negative and insignificant. Second, however, we find that individuals who heard a narrative about an immigrant (perspective-getting) had significantly higher values on the overall index than those who did not. Finally, respondents who either told or were told an analogic story did not have significantly larger changes in their overall index.

In summary, the experimental results suggested that a condition with both vicarious perspective-giving and perspective-getting could produce the same effects as a condition also including analogic perspective-taking. Observational, within-subjects results suggest that attitude change in the treatment group only occurs among those who were told a story about an immigrant (perspective-getting), and regardless of whether subjects shared their own story about an immigrant (vicarious perspective-giving) or a related topic (analogic perspective-taking and analogic perspective-getting). This supports perspective-getting as the "key ingredient" responsible for the effects. However, as these are within-subject results and not randomized, they are open to alternative interpretations; Study 2 therefore presents a randomized field experiment of whether conversations which use no other narrative strategies but perspective-getting would have similar effects. 
Figure 3: Study 1: Within-Subject Results (Not Randomly Assigned)

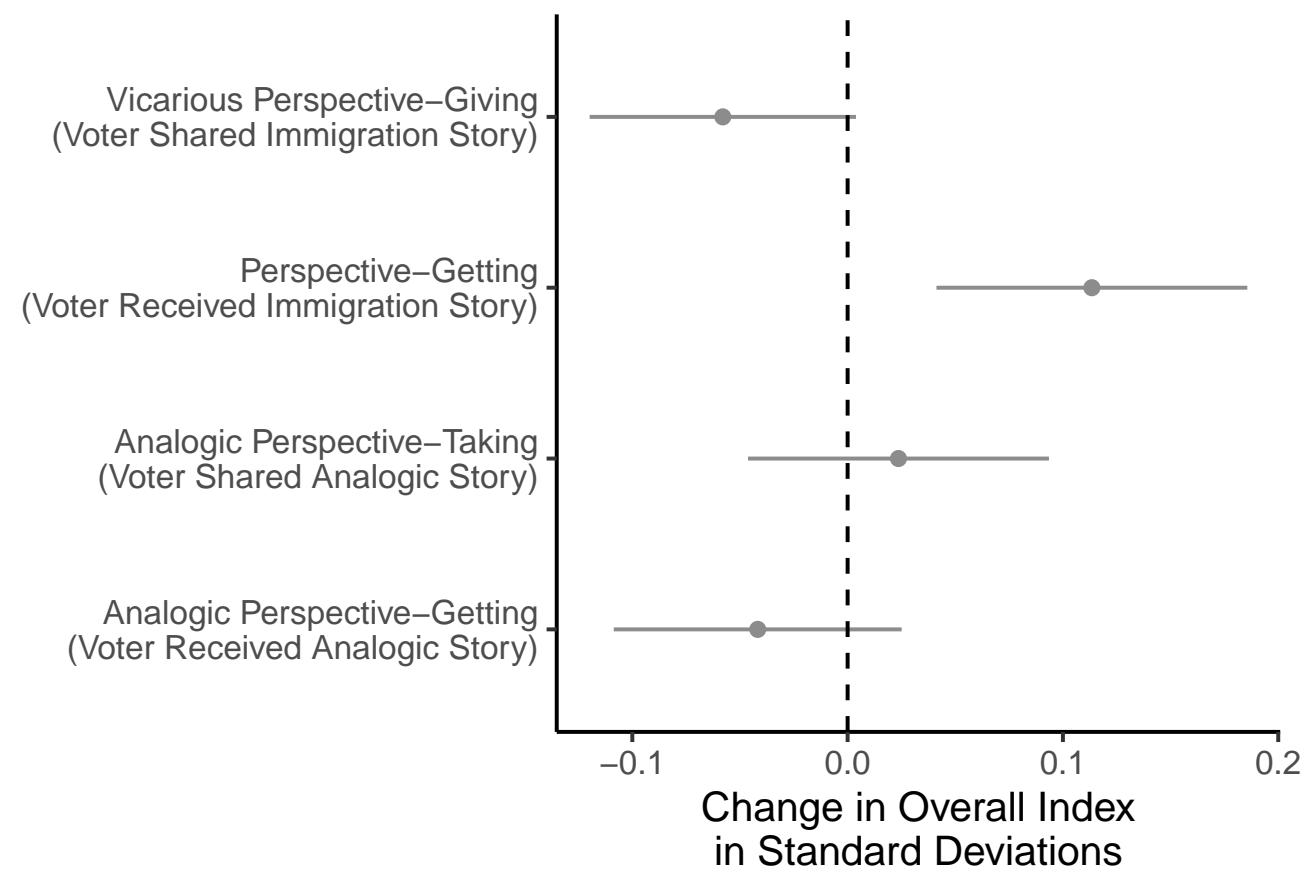

Notes: Tails are $95 \%$ confidence intervals.

\section{Study 2: Door-to-door Canvassing Experiment}

In the winter and spring of 2020, we conducted a second pre-registered, randomized, placebocontrolled field experiment to measure the effects of a door-to-door canvassing intervention in California and Tennessee. The canvass attempted to reduce prejudice towards immigrants and increase public support for including unauthorized immigrants in government programs: in-state college tuition (Tennessee) and Medicaid (California).

\section{Canvass Intervention}

We designed Study 2 to conduct a more focused test on the efficacy of perspective-getting alone by including a new condition that included perspective-getting only and no other narrative strategies. In particular, in addition to a Full Intervention condition similar to Study 1's, Study 2 contained a 
Perspective-Getting Only condition that omitted all narratives except perspective-getting, as well as many of the other conversational elements. This condition followed steps similar to the steps in Study 1's Full Intervention (see above), but omitted the "Vicarious Perspective-Giving," "Analogic Perspective-Taking," "Provide arguments and information", "Discuss" and "Address concerns" steps (steps 4-8 noted above). In this condition, canvassers focused on asking the voter their current view, telling a narrative about an immigrant (perspective-getting), and making their case based on the narrative.

Whereas the Full Intervention took an average of 17.1 minutes among those who began the conversation, the Perspective-Getting Only Intervention took an average of only 7.3 minutes-less than half as long.

In the Perspective-Getting Only Intervention, canvassers did not usually do all of the talking for over 7 minutes. Although many of the parts of the script that encouraged a two-way exchange were removed (e.g., the canvassers no longer asked voters to rate their opinion or to tell a story of their own), canvassers reported in debriefs that it was still very common for voters to spontaneously respond with their views and reactions, and canvassers had been trained to engage with these. Therefore, it would be inaccurate to conceive of this interaction as involving only perspective-getting; rather, perspective-getting was the only narrative that was typically shared in the conversations, but this narrative was still embedded in a two-way conversation with a "non-judgmental" tone (Kalla and Broockman 2020).

\section{Experimental Design}

Similar to Study 1, we measured the effects of these conversations in an experiment with a parallel survey measurement. The experiment began by mailing registered voters $(n=336,023)$ an invitation to an ostensibly unrelated online baseline survey, presented as the first in a series of surveys not specifically about immigration, college tuition, or health care and which made no reference to any potential canvassing. $n=9,340$ voters completed the first baseline survey and provided 
a valid email address. We then conducted a second baseline survey, to which $n=6,163$ voters responded. We next randomly assigned the people who had responded to both the first and second baseline surveys to the Full Intervention ( $n=2,053)$, Perspective-Getting Only Intervention ( $n=2,054)$, or Placebo conditions $(n=2,056)$. Blocked random assignment was conducted at the household level.

As in Study 1, to deliver the intervention, canvassers affiliated with the partner organizations went door-to-door to visit individuals' homes at their addresses in the voter registration database. Canvassing was originally scheduled to continue through May 2020, but was cancelled in March due to the COVID-19 pandemic.

As in Study 1, canvassers began by knocking on voters' doors unannounced. Canvassers then asked to speak with the person on their list who had enrolled in the study and confirmed the person's identity. Next, canvassers implemented the experimental condition corresponding with the person's random assignment, using the approach described above.

One week, 11 weeks, and 4.5 months after the conversation took place, we sent ostensibly unrelated invitations to participate in post-treatment surveys to all individuals who identified themselves at the door before the intervention began. The post-treatment surveys contained several dependent variables of interest but also many unrelated items intended to disguise the connection between the survey and the intervention.

As in Study 1, the post-treatment surveys contained several survey items to gauge the effects. We pre-registered that we would combine these items into two primary indices: one gauging support for including unauthorized immigrants in government programs and another on prejudice. As we pre-registered, we formed these indices at each wave by taking the first factor from a factor analysis of all the items in the index and then rescaling the index to mean zero standard deviation one. Online Appendix B contains the full survey items, intervention scripts, tests of design assumptions, and a link to the pre-registration (p. 15 and 18-25). Treatment effects are estimated using OLS with pre-treatment covariates and clustered standard errors. 


\section{Results}

The results on the overall prejudice and policy indices are shown in Figure 4. As shown, both interventions had similar, statistically significant effects. In particular, in the one-week follow-up survey, the Perspective-Getting Only intervention is estimated to be most effective. In the followup surveys, the effects of the Full Intervention are slightly (but not significantly) larger on the policy index, while on the prejudice index, the effects of the Perspective-Getting Only intervention remain larger. On the overall index pooling all items and pooling across all three follow-up survey waves, the point estimates of the two interventions are nearly identical, with the point estimate of the Full Intervention being only very slightly larger, although the confidence intervals are wide enough that they may include meaningful differences (the $95 \%$ confidence interval on the comparison of the Full to Perspective-Getting Only intervention ranges from 0.09 to -0.05 standard deviations). Given that Study 1 found the Full Intervention had slightly lower point estimates, we expect this is due to statistical noise, but this comparison warrants replication. Although the standard errors are slightly larger than in Study 1 because Study 2 had to be stopped early due to COVID-19, the results suggest that the two conditions were both essentially equally effective at durably reducing exclusionary attitudes. While the treatment effects for both interventions clearly persist for at least 11 weeks, the effects are somewhat smaller and fall short of conventional levels of statistical significance 4.5 months after the conversation. (Table OA30 reports that the effects at 4.5 months are associated with a $p$-value of 0.07 for the Full Intervention and 0.24 for the Perspective-Getting Only Intervention.) However, the comparison between treatment effects at 11 weeks and 4.5 months is not sufficiently powered due to the early stopping.

As in Study 1, dichotomizing the individual policy items shows that the intervention created large increases in support, and not simply strengthen existing support: Figure A1 and Table OA43 shows effects across several dichotomized policy outcomes (finding increases in the proportion of individuals who support rather than do not support various pro-immigrant policies). For example, in the first post-treatment survey, we find a 12.7 percentage point increase in support for making 
Figure 4: Study 2: Main Results

Full Intervention vs. Placebo

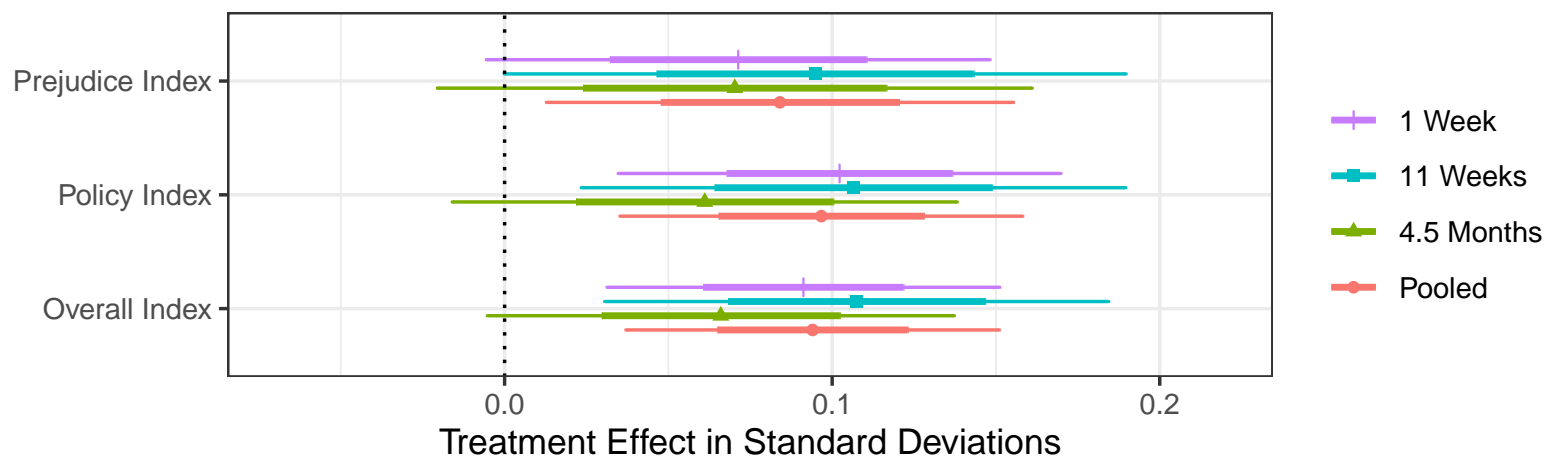

Perspective-Getting Only vs. Placebo

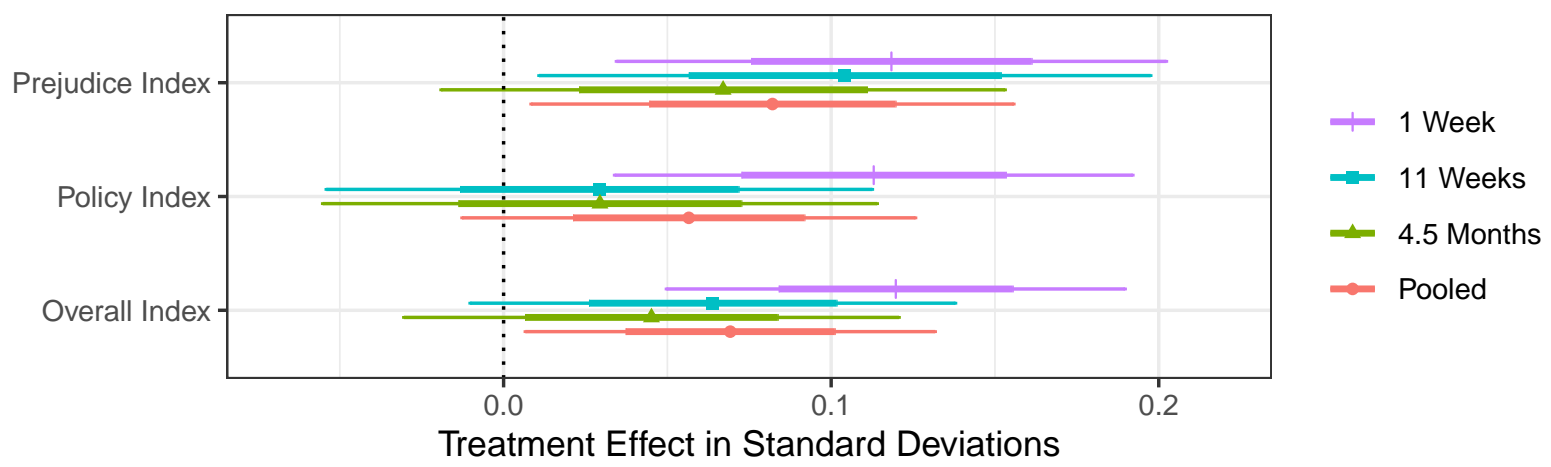

Effect of Full Intervention vs. Perspective-Getting Only

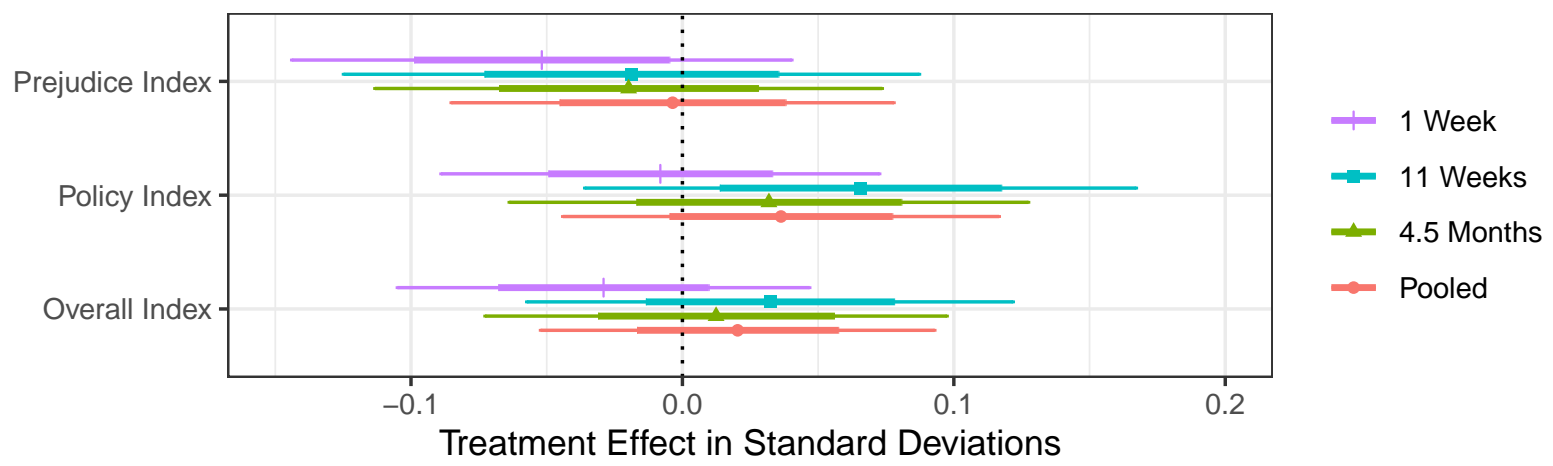

Notes: Thick lines are one standard error (household clusters), thin lines are $95 \%$ confidence intervals. 
unauthorized immigrants eligible for college scholarships at state colleges, and a 7.4 percentage point increase in support for offering them in-state tuition at state colleges. ${ }^{5}$

Online Appendix B presents the results on all the individual items of interest we had preregistered, representativeness assessments, and heterogeneous treatment effects (p. 15 and 18-25). Of particular interest, Table OA42 (p. 24) shows that weighting the survey sample to match the sampling frame produces estimates that are if anything larger. This indicates that any unrepresentativeness of our sample, if anything, appears to lead us to underestimate the size of the effect in the population we attempted to recruit. Importantly, Table OA33 (p. 22) presents results finding similar effects regardless of whether the canvasser is personally an immigrant or not, indicating that contact with outgroup members is not responsible for the effects. Last, Table OA37 (p. 23) finds that the intervention had similar effects among those who did and did not indicate they planned to vote for Donald Trump in the 2020 election at baseline.

In summary, the results of Study 2 further support the efficacy of perspective-getting. Even when removing many other elements of the intervention besides perspective-getting, including both of the other narrative strategies in the Full Intervention condition, the effects of the conversations remain statistically significant and substantively similar. This result suggests that a perspective-getting exercise is a key condition for the efficacy of interpersonal conversations to reduce exclusionary attitudes. Moreover, underscoring the practical implications of these findings, the Perspective-Getting Only intervention took half as long to implement as the Full Intervention despite having similar effects.

\footnotetext{
${ }^{5}$ Estimates are among those who came to the door. Of these, $\approx 82 \%$ of voters in the treatment conditions entered into the conversation. The estimates should therefore be multiplied by $\approx 1.22$ to compute the effect among those who enter into the conversation.
} 


\section{Further Evidence Supporting Perspective-Getting}

\section{Meta-analysis of Existing and Original Field Experiments}

First, the pattern of studies across Table 2 suggests that perspective-getting is a "key ingredient" for the effects of interpersonal conversations that seek to reduce prejudice: across existing studies and our new studies, all conditions with perspective-getting have statistically significant effects, but conditions without it (e.g., Kalla and Broockman 2020, Study 1) do not. To more formally test this, we conduct a meta-analysis using the results of all of the treatment arms involving narrative exchange in all of the experiments reported in Broockman and Kalla (2016), Kalla and Broockman (2020), and this paper $(n=9)$. We code whether each arm included each of the three narratives and use these indicators as independent variables in a meta-regression. The dependent variable is the estimate of the treatment effect as compared to placebo on an index of all of the items preregistered as primary outcomes, pooled across all of the post-treatment survey waves. We cluster the standard errors at the study level and use a random-effects model.

Figure 5 reports the results. As the Figure shows, the base condition including perspectivegetting has a large and statistically significant effect. The second two coefficients can then be interpreted as the marginal effect of adding additional narrative strategies. We find that conditions which add vicarious perspective-getting or analogic perspective-taking do not have effects that are greater; in fact, both point estimates are negative (but insignificant). The body of results produced by these studies therefore does indeed support the efficacy of perspective-getting.

\section{Within-Subject Evidence from Studies 1, 2 and 3 (New study)}

We next present further within-subject evidence that supports the efficacy of perspective-getting.

In doing so, we introduce results from a new Study, Study 3. Study 3 is reported in full in the Online Appendix (p. 27-30) and briefly reviewed here. After Study 2 was ended early due 
Figure 5: Meta-regression on data from Broockman and Kalla (2016), Kalla and Broockman (2020), and This Paper

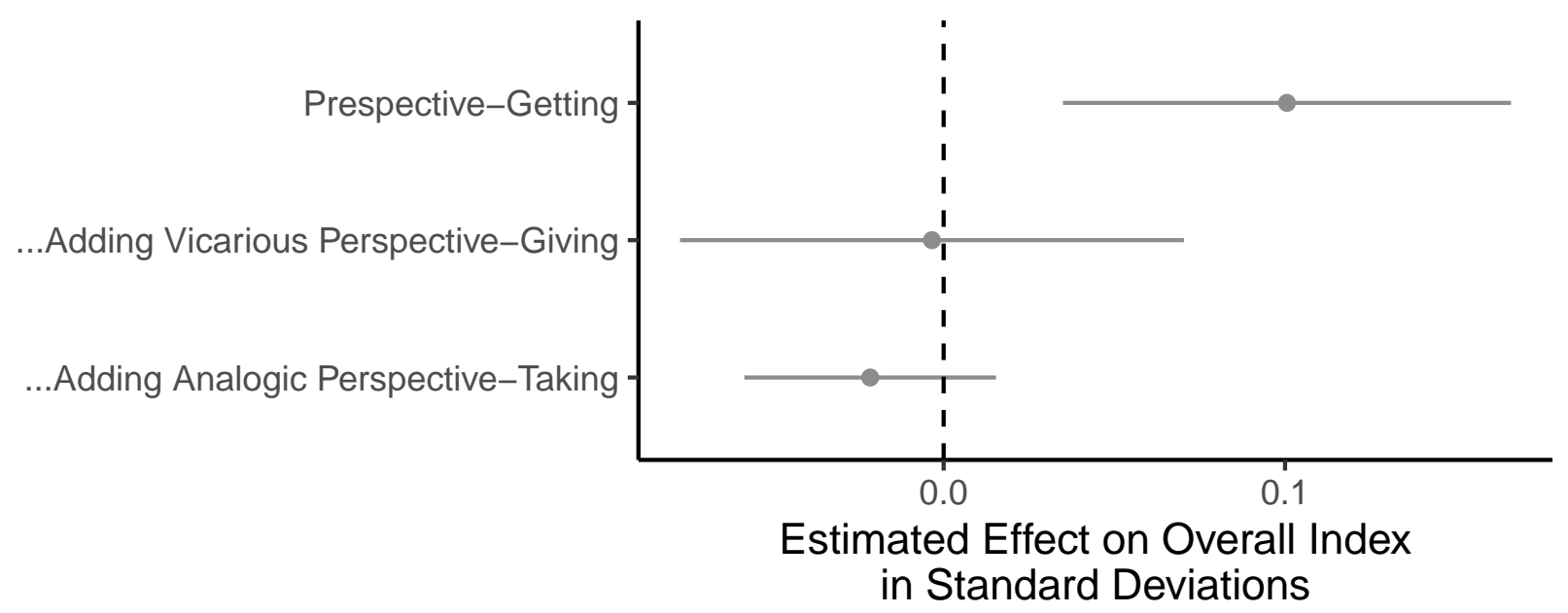

to the COVID-19 pandemic precluding in-person canvassing, the organizations that implemented Study 2 switched to delivering the intervention by phone. The organizations sought to use the sample recruited for Study 2 who had not yet been canvassed to evaluate the impacts of these phone calls. Power calculations revealed that a randomized experiment would not have sufficient statistical power due to the limited number of individuals in Study 2 with known phone numbers. In the Study, the organizations attempted to reach everyone with a phone number from the Study 2 sample who had not been reached at their doors. We then surveyed everyone who could have been attempted (whether reached or not) and conducted a comparison of the change over time in attitudes among those who were and were not successfully reached on the phone using a differencein-differences analysis. The results of Study 3 again replicate the effects of the intervention, finding effects of approximately 0.12 standard deviations on an overall index of policy and prejudice items $(p<0.01$, see Table OA46).

In order to disentangle the impacts of the different narratives present in the conversations in Studies 1, 2, and 3, we conduct observational (i.e., non-randomized) within-subjects analyses with the data from these studies. In particular, in all three studies we gathered records canvassers kept during the conversations that recorded whether voters and whether canvassers shared a story during 
the conversations. The data from Study 2 and 3 does not record which narratives were shared, only who shared them, so in this analysis we cannot distinguish between analogic perspective-taking narratives voters shared and vicarious perspective-giving narratives voters shared. (See Figure 3 for within-subject results from Study 1 that do allow us to distinguish between types of narratives.) When canvassers share narratives, though, this nearly always means that canvassers shared a story about an immigrant (producing perspective-getting), since this is the very first story on the script in all three studies. Note that the presence of a narrative strategy is not randomly assigned. Instead, voters chose whether to engage in each strategy.

To estimate how the changes in exclusionary attitudes differed based on the presence of canvasser narratives (perspective-getting) or voter narratives (either analogic perspective-taking or vicarious perspective-giving), we estimate a difference-in-differences model for each study. Each model uses an index of all post-treatment items pre-registered as outcomes asked in all posttreatment survey waves as the outcome variable. The regressions include individual and survey wave fixed effects, as well as coefficients on an interaction between the survey wave occurring post-treatment and whether canvassers and voters shared a story, the coefficients of interest. The standard errors are clustered at the individual level. We include data from the treatment groups only. This analysis was not pre-registered.

Figure 6 shows the results. In all three studies, we find that individuals' attitudes change much more when canvassers share stories (perspective-getting) than when they do not. However, in all three studies, we find little evidence that the changes are larger if voters shared a story (i.e., engaged in either analogic perspective-taking or vicarious perspective-giving). The final row shows a precision-weighted average of the results of the three studies. We again find strong evidence that the conversations had much larger effects when canvassers shared stories, but that the effects do not differ based on whether voters also shared stories.

In summary, within-subject changes support the efficacy of voters hearing the perspective of immigrants (perspective-getting), and suggest there is little added benefit from voters engaging in 
Figure 6: Within-Subject Results (Not Randomly Assigned): Studies 1, 2, and 3

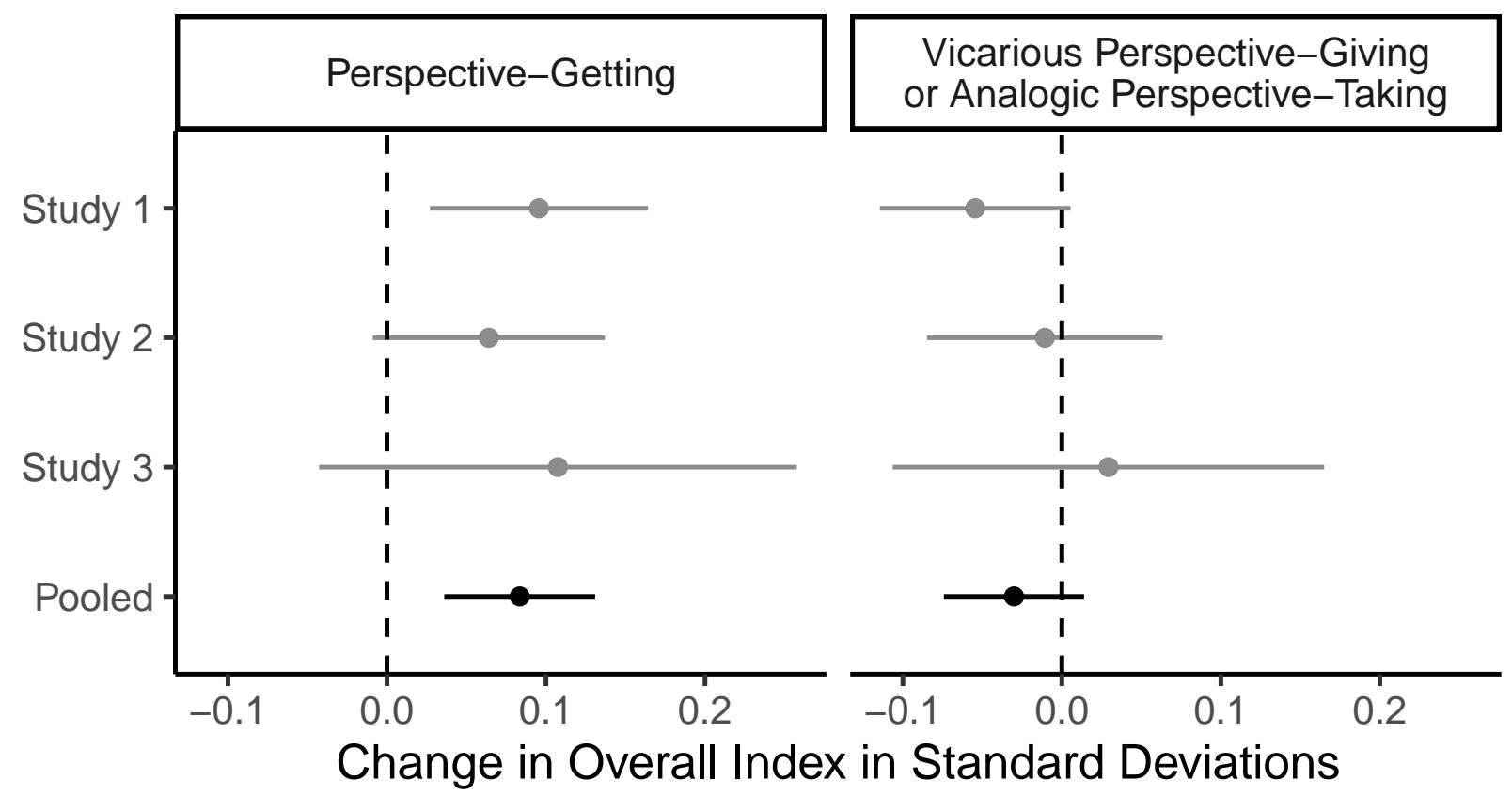

Notes: Each study's data is from a separate model. The pooled row is a precision-weighted average of the first three coefficients. Tails are $95 \%$ confidence intervals.

analogic perspective-taking or vicarious perspective-giving. However, this comes with the caveat that this is an observational (i.e., non-randomized) analysis.

\section{Study 4: Survey-Based Experiment}

The results of our field studies have supported the efficacy of perspective-getting. However, two questions remain open. First, our intervention conditions always contain perspective-getting, leaving open the question of whether analogic perspective-taking might have independent effects, but not effects that are additive to perspective-getting-i.e., it may be that either approach is sufficient to reduce exclusionary attitudes among those whose attitudes can be changed, meaning there is no additive effect of either. Second, our results so far have left relatively open the question of what mechanisms these narrative approaches engage due to limited survey space and concerns about sus- 
picion on post-treatment surveys in the field studies. We therefore conducted survey experiments that separately manipulated the presence of these narrative strategies.

To investigate the conditions under which various forms of encouraging the consideration of outgroup's perspectives are effective at reducing prejudice, and through what mechanisms they might operate, we conducted a follow-up, large-N survey experiment on Lucid. ${ }^{6}$

\section{Experimental Conditions}

The experiment was a $6 \times 2$ factorial design. The first factor was the prejudice reduction strategy, with a placebo and five treatment conditions. The second factor randomly assigned whether the experiment concerned attitudes towards transgender people or undocumented immigrants.

The treatment conditions are summarized in Table 3. We began by showing all subjects a picture of an outgroup member. We then gave respondents instructions that generally followed the strategies used in the field experiments in Table 2.

- Our baseline condition is the Identified Photo condition, in which respondents saw a photo of an outgroup member and were told that this person was a member of the outgroup. ${ }^{7}$

- We then included a second placebo condition, the Write Essay About Photo condition, in which respondents were instructed to write an essay about what they saw in the photo. This was intended as an additional placebo which would hold constant the presence of writing prompts.

- The third condition was Traditional Perspective-Taking, in which we gave respondents a prompt similar to Galinsky and Moskowitz's (2000).

\footnotetext{
${ }^{6}$ This study was pre-registered at https://osf.io/58j7w/?view_only=

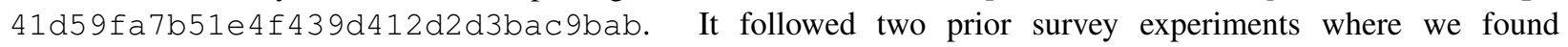
evidence of demand effects. This study added the "Identified Photo" placebo in an attempt to reduce demand.

${ }^{7}$ There was also a pure control condition containing an unidentified photo. However, we found that the Identified Photo condition appeared to have its own effects, which we interpreted as consistent with demand. We therefore use the Identified Photo condition as the baseline condition.
} 
- In the Analogic Perspective-Taking condition, we asked people to tell a story about a time when they were showed compassion (unauthorized immigration arm) or were discriminated against (transgender people arm) and what this made them think about how members of the outgroup should be treated, mirroring the tasks in Broockman and Kalla (2016) and our studies.

- Finally, there were two perspective-getting arms in which people read a story about an outgroup member, drawn from Broockman and Kalla (2016) (transgender arm) or adapted from a story that a canvasser told in our studies (unauthorized immigrant arm). There were two versions of this condition, one where respondents were asked to summarize the story and one in which they were not, in order to hold constant the presence of a writing task. ${ }^{8}$

After the outgroup perspective task, we asked a series of filler questions about subjects' personality. We then moved on to ask the DVs. We created a separate scale for both outgroups (transgender people, undocumented immigrants). ${ }^{9}$

\section{Results}

We estimate the effects of each condition using a linear regression with a series of pre-registered pre-treatment covariates included to increase precision. The Identified Photo condition is used as the baseline. The dependent variable is the prejudice index, with higher values being coded as lower prejudice.

Figure 7 gives the main results by outgroup and then pooling across the outgroups. We find that traditional perspective-taking did not appear to have effects in our survey experiments (similar to Adida, Lo and Platas's (2018) findings for effects on attitudes, but not behavior). Future research should attempt to replicate and investigate this result further, including in the field (which our study

\footnotetext{
${ }^{8}$ We did not include a vicarious perspective-giving condition because in pre-tests we found few respondents told such a story.

${ }^{9}$ Study materials are available at https://osf.io/pyzcd/?view_only= c1f01a3d53c749b2bd5a83aaff3bad80.
} 
Table 3: Conditions in survey experiment

\begin{tabular}{|c|c|c|}
\hline Condition Name & Perspective Received & $\begin{array}{c}\text { Essay Task } \\
\text { (Perspective Given) }\end{array}$ \\
\hline Identified Photo (Placebo) & - & - \\
\hline $\begin{array}{c}\text { Write Essay About } \\
\text { Photo (Additional Placebo) }\end{array}$ & - & $\begin{array}{l}\text { Write essay about } \\
\text { what is in photo }\end{array}$ \\
\hline $\begin{array}{c}\text { Traditional Perspective- } \\
\text { Taking }\end{array}$ & - & Write essay from outgroup perspective \\
\hline $\begin{array}{c}\text { Analogic Perspective- } \\
\text { Taking }\end{array}$ & - & $\begin{array}{c}\text { Transgender group: Time when other } \\
\text { showed self compassion, what this } \\
\text { suggests for how outgroup } \\
\text { should be treated } \\
\text { Undocumented immigrant group: } \\
\text { Time when other discriminated } \\
\text { against self, what this suggests for } \\
\text { how outgroup should be treated }\end{array}$ \\
\hline $\begin{array}{l}\text { Perspective-Getting } \\
\text { (Essay) }\end{array}$ & $\begin{array}{c}\text { Story about } \\
\text { outgroup member }\end{array}$ & $\begin{array}{c}\text { Summarize story about } \\
\text { outgroup member } \\
\text { just read in survey }\end{array}$ \\
\hline $\begin{array}{c}\text { Perspective-Getting } \\
\text { (No Essay) }\end{array}$ & $\begin{array}{c}\text { Story about } \\
\text { outgroup member }\end{array}$ & - \\
\hline
\end{tabular}

does not). However, analogic perspective-taking appears to be effective for both groups, as does perspective-getting.

These results suggest a slightly less pessimistic take-away with respect to analogic perspectivetaking in particular. Study 1 and 2's results seem to suggest analogic perspective-taking is ineffective, since adding it does not increase effect sizes. However, in Study 4 we found that on its own, it does have effects, at least in a survey context when outcomes are measured immediately. This suggests that analogic perspective-taking and perspective-getting (both done in the full intervention in Studies 1-3) may both be effective but that there may be no additional effect of doing both. However, we emphasize that there is no evidence that analogic perspective-taking is better than perspective-getting, and in fact our field studies consistently find evidence that, if anything, 
Figure 7: Study 4 (Survey Experiment) Results

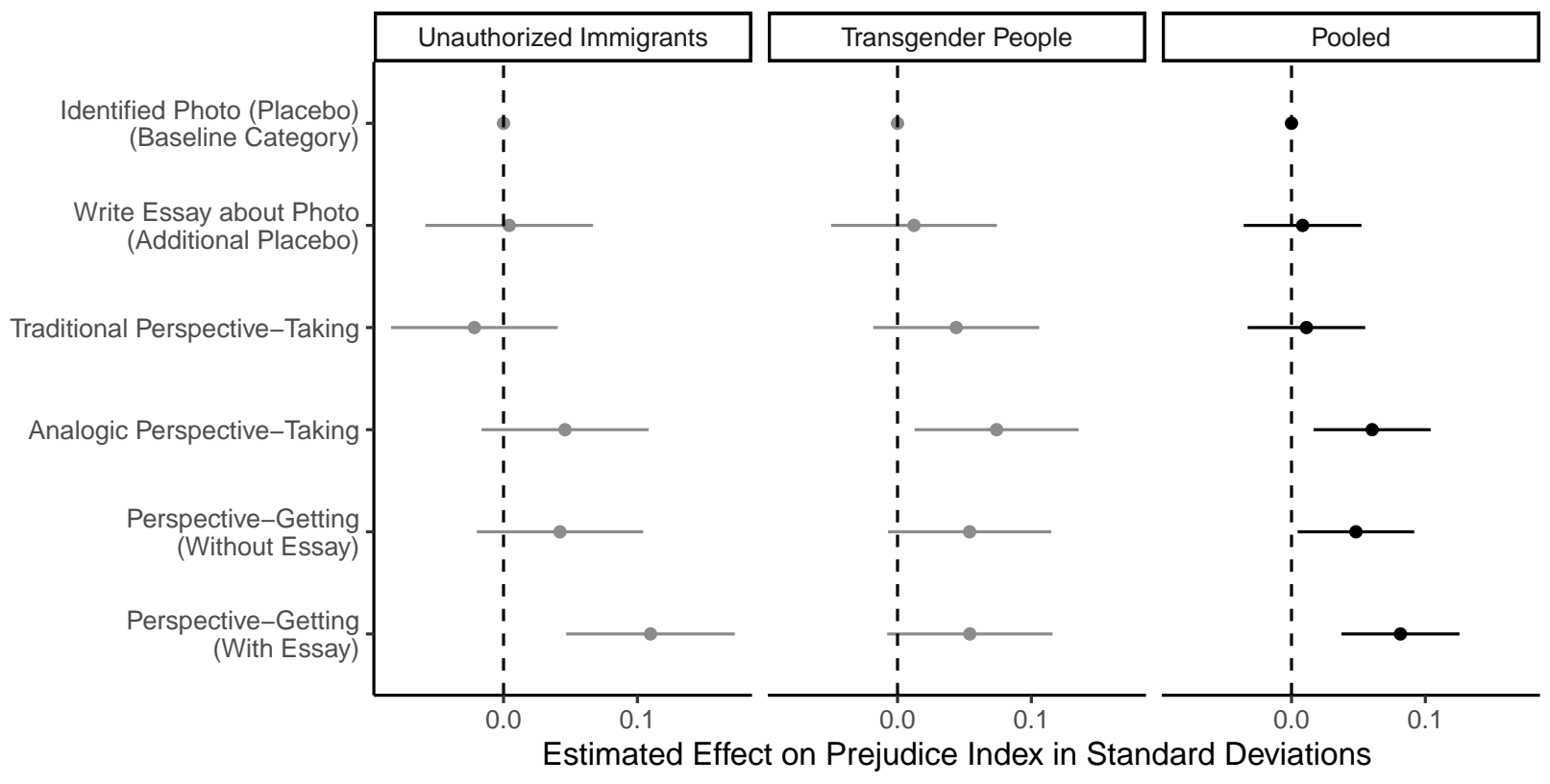

Notes: Positive coefficients correspond with decreased prejudice. 95\% confidence intervals surround point estimates.

the conversations may be more effective if they focus on perspective-getting alone. In all, then, the evidence supports the efficacy of perspective-getting.

Another suggestive finding is that perspective-getting with an additional essay task may have been more effective, although this result is not statistically significant. Our field experiments did not contain conditions that specifically sought to alter the presence of active processing and instead always contained efforts to encourage active processing, but these results suggest active processing could bolster the size of the effects of perspective-getting, even as it does not appear necessary for them. 


\section{Evidence on Mechanisms}

Why does perspective-getting reduce exclusionary attitudes? In both Studies 1 and 4, we asked several survey questions to measure potential mechanisms identified in prior literature and discussed above: attributional thinking, entitativity (in Study 4 only), reactive empathy, and self-outgroup merging. ${ }^{10}$

Figure 8 shows the effects of the treatments on these potential mediators. In this section we focus on the evidence provided by the survey experiments as these separately manipulate each narrative strategy and so are less ambiguous.

First, as reported in Figure 7, our survey experiments largely found null effects on prejudice of an Additional Placebo that involved writing an essay about a photo and of Traditional PerspectiveTaking (consistent with the null results on attitudes, but not behavior, documented by Adida, Lo and Platas (2018)). However, as reported in Figure 8b, these two conditions had effects on selfoutgroup merging and, in the case of traditional perspective-taking, on attributional thinking. This suggests that the effects of the other interventions on reducing prejudice are unlikely to be due to self-outgroup merging or changing attributional thinking, as two conditions (Additional Placebo and Traditional Perspective-Taking) that successfully manipulated these potential mediators had no effect on prejudice. In summary, although we hypothesized in line with prior literature in psychology that traditional perspective-taking would reduce prejudice primarily through self-outgroup merging, we found it did lead to self-outgroup merging but did not reduce prejudice. And, although it unexpectedly changed attributional thinking, this still did not decrease prejudice in our survey experiments either.

Next, we hypothesized that analogic perspective-taking would activate the mechanisms of selfoutgroup merging and reactive empathy, but found that it only activated self-outgroup merging-

\footnotetext{
${ }^{10}$ The question wordings were: Self-outgroup merging: "I think I have a lot in common with [GROUP]." Reactive empathy: "The suffering of some [GROUP] concerns me." Attributional thinking: "[GROUP] face big challenges that are no fault of their own." Entitativity: "When you think about the term [GROUP], do you think about individual people or do you think about a group of people?"
} 
Figure 8: Evidence on Potential Mechanisms: Effects on Potential Mediators in Studies 1 and 4

(a) Study 1 (Door-to-door Canvassing Field Experiment)

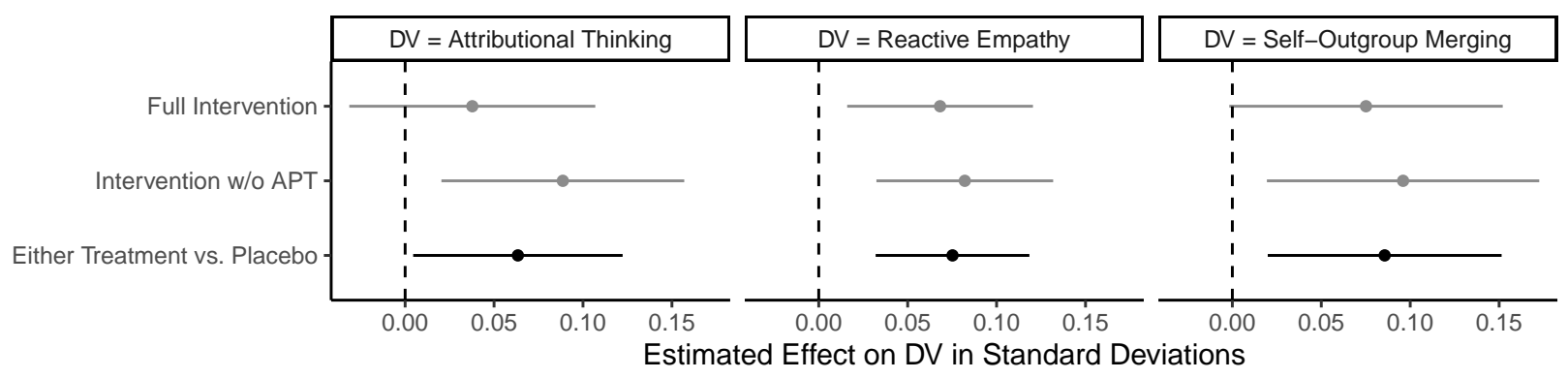

(b) Study 4 (Survey Experiments)

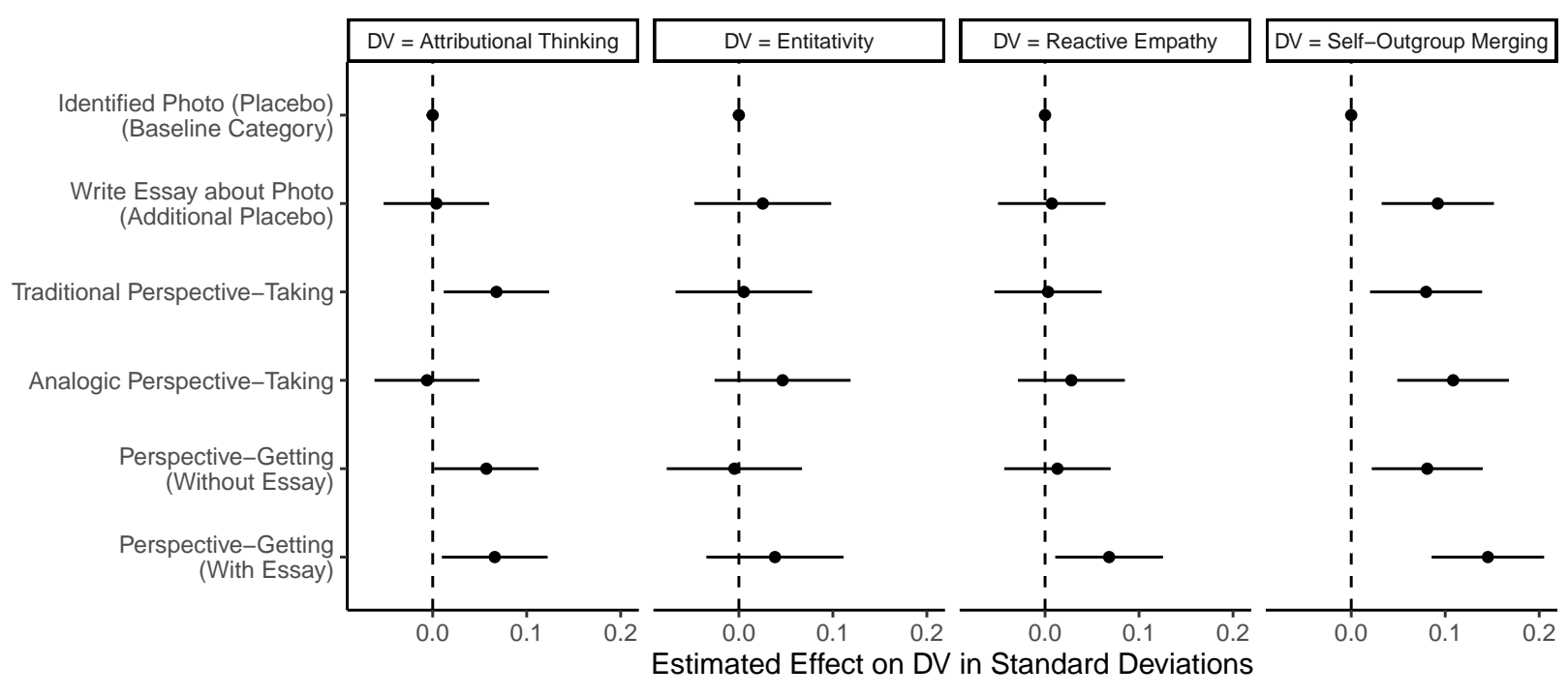

Notes: $95 \%$ confidence intervals surround point estimates.

the same mechanism which our Additional Placebo and Traditional Perspective-Taking conditions suggest were ineffective. This suggests that it activated an additional mechanism we did not measure, which future research could investigate.

Third, we hypothesized that perspective-getting could activate all four of the mechanisms we considered. Our results are consistent with this hypothesis for all but entitativity, where our results are null. Especially when perspective-getting is accompanied by a prompt for respondents 
to actively process the implications of the perspective (by writing a short essay), there is evidence that the mechanisms of attributional thinking, reactive empathy, and self-outgroup merging are activated. Together with our prior result about the likely non-effects of self-outgroup merging and attributional thinking, this suggests that perspective-getting reduces prejudice by prompting empathy towards that group or through other unmeasured mediators. But our finding that a more passive form of perspective-getting (Perspective-Getting Without Essay) did not appear to engage reactive empathy even though it did appear to have effects on prejudice (at the borderline of statistical significance) suggests that unmeasured mediators not considered as central mechanisms by the literature are most likely responsible.

Overall, these results point toward our survey-based treatments likely working through mediators that existing related literature has not previously pinpointed as central; although our treatments affected many of our hypothesized mediators, none of them appear to be sufficient for reducing prejudice in our experiments.

This suggests that the next step for future research might be to take an inductive approach. In particular, research investigating the mechanisms underpinning perspective-getting could proceed by crafting or sourcing a number of different perspective-getting narratives that seek to engage different mechanisms. Then, researchers could generate and test hypotheses about mechanisms based on which of these narratives is most effective. For instance, are narratives that focus more on making emotional appeals or in providing new information more effective? Another possibility is that multiple of these mechanisms are jointly necessary.

In investigating these questions, future research can also address questions such as what contextual, individual, or outgroup-level attributes represent scope conditions for its effects. For instance, are fictionalized or entertaining narratives more effective than documentaries? To what extent does the quality of the delivery (e.g., canvasser quality or actor quality) matter? 


\section{Discussion}

In this paper, we first presented a framework to theoretically distinguish between different narrative strategies intended to encourage individuals to consider outgroups' perspectives that had been used in prior research. We then presented results from a series of field studies and a survey experiment. These results were all consistent with the efficacy of one of these strategies in particular-perspective-getting, or hearing the perspective of an outgroup member. In field experiments manipulating the presence of various narrative strategies, within-subject analyses, and survey experiments, we consistently find that perspective-getting effectively reduces exclusionary attitudes, whereas other strategies we considered have less reliable impacts. Importantly, our field studies found that canvassers prompting perspective-getting were effective regardless of whether they were themselves members of the outgroup, indicating our results were not due to contact. Theoretically, these results support the efficacy of perspective-getting and related theoretical perspectives (e.g., Redelmeier and Tversky 1990; Audette, Horowitz and Michelitch 2020). More generally, our consistent finding that perspective-getting can durably reduce attitudes towards a highly stigmatized group suggests that predispositions towards outgroups, often regarded by political scientists as highly durable throughout the life-course, may be more malleable than often thought.

Our findings have several practical implications. Most importantly, they suggest a way forward for individuals who seek to reduce prejudice and exclusionary political attitudes in interpersonal conversations. Prior work has found that changing these attitudes can have important consequences for immigrants (Hainmueller, Hangartner and Pietrantuono 2017). Previous studies would suggest that such conversations require extremely extensive training on how to elicit multiple narratives from voters-it is not easy to knock on a stranger's door and get them to tell a story about their life. Our findings suggest that it may also not be necessary. There still remains great difficulty in talking about sensitive topics with others, but our results do suggest a more feasible and practical 
approach for future interventions: focusing on narratives that facilitate perspective-getting.

Our findings suggest several fruitful inquiries for future research. First, how important is it for perspective-getting narratives to be embedded in non-judgmental conversations or conversations that promote active processing? Might its effects be just as strong in field contexts if delivered passively to individuals in a one-way interaction (e.g., canvassers had simply told a story and left)? Second, these studies were limited to measures of explicit attitudes. What, if any, are the effects on actual voting, prejudicial behavior, or implicit attitudes? Second, although our research did study a highly salient topic at a time when elites were seeking to activate anti-immigrant sentiment, would perspective-getting narratives remain effective when respondents are also faced with more forceful counter-narratives or competing frames? Third, how much does the medium matterwould it be more efficient, for example, to embed narratives in mass media instead of door-to-door campaigns? Future field research, including research on more impersonal modes such as mass media campaigns, could help elucidate these questions. Last, how might the effects of perspectivegetting narratives vary across outgroups and the degree of stigma associated with them?

\section{References}

Adida, Claire L., Adeline Lo and Melina R. Platas. 2018. "Perspective taking can promote shortterm inclusionary behavior toward Syrian refugees." Proceedings of the National Academy of Sciences 115(38):9521-9526.

Audette, Nicole, Jeremy Horowitz and Kristin Michelitch. 2020. "Personal Narratives Reduce Negative Attitudes toward Refugees and Immigrant Outgroups: Evidence from Kenya." Available at https://cpb-us-e1.wpmucdn.com/sites.dartmouth.edu/dist/ 9/452/files/2020/07/Personal-Narratives.pdf.

Broockman, David E. and Joshua L. Kalla. 2016. "Durably reducing transphobia: A field experi- 
ment on door-to-door canvassing." Science 352(6282):220-224.

Broockman, David E., Joshua L. Kalla and Jasjeet S. Sekhon. 2017. "The design of field experiments with survey outcomes: A framework for selecting more efficient, robust, and ethical designs." Political Analysis 25(4):435-464.

Bruneau, Emile G. and Rebecca Saxe. 2012. "The power of being heard: The benefits of 'perspective-giving'in the context of intergroup conflict." Journal of experimental social psychology 48(4):855-866.

Eyal, Tal, Mary Steffel and Nicholas Epley. 2018. "Perspective mistaking: Accurately understanding the mind of another requires getting perspective, not taking perspective." Journal of personality and social psychology 114(4):547.

Galinsky, Adam D. and Gordon B. Moskowitz. 2000. "Perspective-taking: decreasing stereotype expression, stereotype accessibility, and in-group favoritism." Journal of personality and social psychology 78(4):708-724.

Gehlbach, Hunter and Maureen Elizabeth Brinkworth. 2012. "The social perspective taking process: Strategies and sources of evidence in taking another's perspective." Teachers College Record 114:1-29.

Green, Melanie C. and Timothy C. Brock. 2000. "The role of transportation in the persuasiveness of public narratives.” Journal of personality and social psychology 79(5):701-721.

Hainmueller, Jens, Dominik Hangartner and Giuseppe Pietrantuono. 2017. "Catalyst or crown: Does naturalization promote the long-term social integration of immigrants?" American Political Science Review 111(2):256-276.

Hopkins, Daniel J., John Sides and Jack Citrin. 2019. “The muted consequences of correct information about immigration.” Journal of Politics 81(1):315-320. 
Kalla, Joshua L and David E Broockman. 2020. "Reducing exclusionary attitudes through interpersonal conversation: evidence from three field experiments." American Political Science Review 114(2):410-425.

Lowe, Matt. 2021. "Types of contact: A field experiment on collaborative and adversarial caste integration." American Economic Review .

Nickerson, David W. 2005. "Scalable protocols offer efficient design for field experiments.” Political Analysis 13(3):233-252.

Paluck, Elizabeth Levy, Roni Porat, Chelsey S Clark and Donald P Green. 2020. "Prejudice reduction: Progress and challenges.” Annual Review of Psychology 72.

Redelmeier, Donald A and Amos Tversky. 1990. "Discrepancy between medical decisions for individual patients and for groups." Preference, Belief, and Similarity p. 887.

Richards, Zoë and Miles Hewstone. 2001. "Subtyping and subgrouping: Processes for the prevention and promotion of stereotype change." Personality and Social Psychology Review 5(1):5273.

Simonovits, Gábor, Gabor Kezdi and Peter Kardos. 2018. "Seeing the World Through the Other's Eye: An Online Intervention Reducing Ethnic Prejudice.” American Political Science Review 112(1):186-193.

Todd, Andrew R and Adam D Galinsky. 2014. "Perspective-taking as a strategy for improving intergroup relations: Evidence, mechanisms, and qualifications." Social and Personality Psychology Compass 8(7):374-387.

Williamson, Scott, Claire Adida, Adeline Lo, Melina Platas, Lauren Prather and Seth Werfel. 2021. "Family Matters: How Immigrant Histories Can Promote Inclusion.” American Political Science Review. 
Supplementary Information for "Which narrative strategies durably reduce prejudice? Evidence from field and survey experiments supporting the efficacy of perspective-getting"

by Joshua Kalla and David Broockman 


\section{Table of Contents}

Appendix A. Appendix Figures. page 1

Appendix B. Online Appendicies for Studies 1 and 2. page 2

Appendix C. Online Appendix for Study 1, Additional Details. page 5

Appendix D. Online Appendix for Study 2, Additional Details. page 15

Appendix E. Online Appendix for Study 3. page 27 


\section{A Appendix Figures}

Figure A1: Study 2 Results: Dichotomized Policy Items

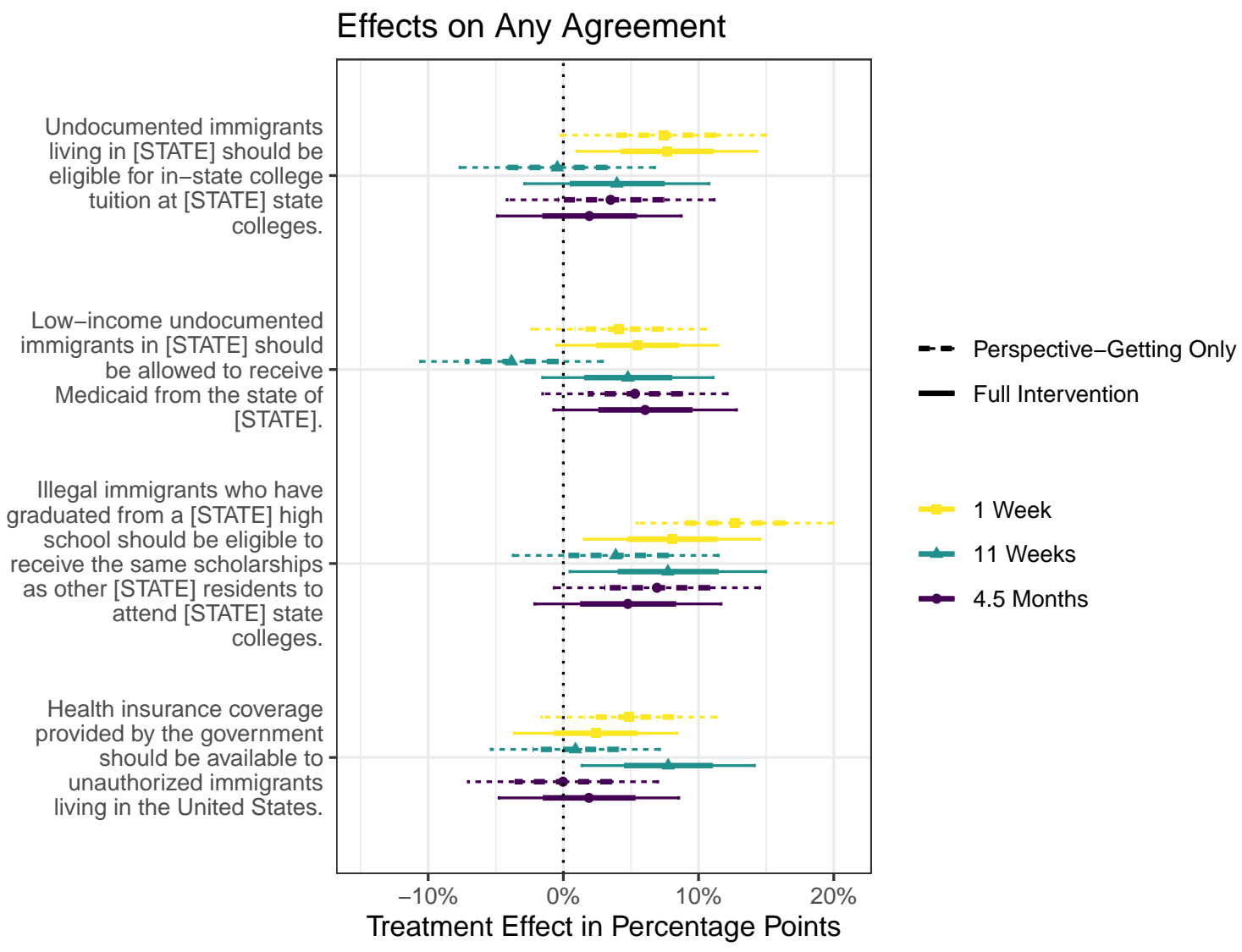




\section{B Online Appendices for Studies 1 and 2}

\section{Survey Recruitment Procedures and Experimental Design}

Studies 1 and 2 used the same experimental design and survey procedures. In this section we describe the survey recruitment procedures and the experimental design. We assess the representativeness of the sample at each step and test design assumptions in other sections.

Baseline Survey. To measure the effects of the intervention, we conducted ostensibly unrelated surveys. To recruit voters to these surveys, the partner organizations first provided us with contact information for voters living in the areas they planned to canvass, acquired from the publicly available list of registered voters. We invited these voters to the baseline survey by mail. The survey was called the "UNIVERSITY-UNIVERSITY [State] Opinion Survey".

The recruitment letter included the survey web URL, a unique login for each voter, and instructions for taking the survey online. To participate, respondents entered the URL from the letter in their computer or smartphone and then their unique login. We mailed letters to households that contained individual logins (213,162 households with 369,317 people in Experiment 1; 181,253 households with 336,023 people in Experiment 2); when multiple eligible voters lived in the same household, we sent the household one letter that contained a unique login for each person.

Voters were offered no incentives for completing the baseline survey but were offered $\$ 5$ for completing each follow-up survey. Voters received these incentives via email (collected during the survey) immediately upon completion of the survey. Voters could redeem these $\$ 5$ incentives as gift-cards to Amazon, iTunes, Starbucks, WalMart, or Home Depot or as donations to Habitat for Humanity, the National Parks Foundation, or Clean Water Fund.

In Study 1, to conserve the partner group's resources, voters with high levels of baseline support were dropped prior to random assignment. Voters who were in or above the 91st percentile on both a baseline immigration prejudice factor and baseline immigration policy factor were removed from the experiment.

Random Assignment of Households. After voters completed the baseline survey and provided a valid email address, we randomly assigned one-third to each treatment condition. Voters were randomly assigned at the household level, ensuring that multiple voters who completed the pre-survey within the same household were always assigned to the same treatment condition. All analyses adjust standard errors to account for this clustered assignment (see details below). This procedure is identical to that used in Broockman and Kalla (2016) and follows the best practices for field experiments with survey outcomes (Broockman, Kalla and Sekhon 2017).

The household-level clustered random assignment took place within blocks of three households. These blocks were formed by matching households on household size and on householdlevel-average values of baseline covariates (a factor measuring baseline views on immigration and a factor measuring baseline views on partisan politics). Within each block, one household (cluster) was assigned to each condition. This pre-treatment blocking reduces the chance of imbalance between conditions and improves precision (Broockman, Kalla and Sekhon 2017).

Random Assignment of Turfs. On the day of each canvass, groups of households were formed into "turfs" by the staff at the partner organizations. "Turfs" are groups of nearby households convenient for two canvassers to visit by walking a short distance. Households were put in groups 
blind to treatment assignment and simply based on the geographic layout of households to be canvassed that day. A route connecting the households in the turf were then drawn, again blind to treatment assignment, such that an efficient route could be followed; half of the households were marked for a Canvasser A and half for a Canvasser B in an order each canvasser could follow. The groups of households (turf) were then randomly assigned to pairs of canvassers by having canvassers pick a number corresponding to a turf out of a hat. Then, canvass leaders flipped a coin to determine which canvasser would knock on A doors and which on B doors. In some cases, Canvasser A and B would be one person. Data-quality checks conducted after the canvass ensured that canvassers all properly canvassed the assigned doors within their turf. This random assignment of canvassers to turf allows us to assess canvasser-level treatment effect heterogeneity, such as by canvasser immigration status.

Placebo Design for Delivering Intervention. Canvassers attempted to have a conversation about unrelated issues with voters in the placebo group and a conversation containing the intervention with voters in the two treatment groups.

These were as follows in Experiment 1: In North Carolina, the placebo was a brief, onequestion survey about support for rent control. In Michigan and Pennsylvania, the placebo was a brief, one-question survey about support for a \$15 minimum wage. In Experiment 2, it was a brief conversation about news consumption.

This placebo-controlled experimental design (Nickerson 2005) is common in studies of doorto-door canvassing interventions and field experiments more generally (Broockman, Kalla and Sekhon 2017). Nickerson (2005) summarizes the placebo design:

Rather than rely upon a control group that receives no attempted treatment, the group receiving the placebo can serve as the baseline for comparison for the treatment group...assuming that (1) the two treatments have identical compliance profiles; (2) the placebo does not affect the dependent variable; and (3) the same type of person drops out of the experiment for the two groups.

The sole purpose of the placebo discussion was to identify subjects who were home and thus with whom a conversation at the door could be attempted (versus subjects who were not home at all or would not even open the door). Identifying this group allows a direct comparison of subjects with whom the intervention actually began to subjects with whom the intervention could have begun but did not because of their random assignment (and thus with whom a conversation about recycling began instead). This design dramatically improves the precision of door-to-door canvassing experiments (Broockman, Kalla and Sekhon 2017).

We implemented the placebo design as follows.

First, the canvassers began by implementing an identical procedure regardless of experimental condition. Canvassers were given walk lists of voters to contact that had been sequentially ordered by voters' addresses blind to voters' treatment assignment. Canvassers proceeded down the list of houses in the experiment in this order, knocking on one door after another without regard to the household's experimental group. The beginning of the conversation was also identical in each condition: "Hi, are you [subject's name]?" If the subject identified him/herself or came to the door at this point, the canvasser then checked a box called "Voter came to door" on their walk list. The experimental sample for the follow-up surveys consists of those who came to the door at this point. 
Only after canvassers determined whether the voter they were looking for came to the door or not did they begin either implementing the intervention or delivering the placebo. Importantly, nothing was different in the procedure before this point: voters did not know the canvasser intended to have a conversation with them about immigration or the placebo issues before identifying themselves or not; canvassers did not inform voters about the topic of the conversation before this point.

These procedures guarantee an unbiased experimental comparison among voters who came to the door and then were delivered the intervention or were then not delivered the intervention based on their random assignment (Nickerson 2005; Broockman, Kalla and Sekhon 2017).

One strength of this study's research design is that we are able to sensitively test the placebo design's key assumption: the kinds of voters who identify themselves at their doors before the placebo starts and before the intervention starts are similar. Our tests support this assumption. We describe these tests for each experiment below.

\section{Estimating Average Treatment Effects}

Consistent with our pre-analysis plans, to estimate treatment effects we use ordinary least squares (OLS) regressions with cluster-robust standard errors, clustering on household and also including the pre-treatment covariates from the baseline survey and voter list named in our pre-analysis plan. This procedure and these covariates were pre-specified in advance and produce unbiased estimates of causal effects (Broockman, Kalla and Sekhon 2017). Note that there is no reclassification of treatment based on what occurs at the door and we do not exclude any subjects who came to the door; we compare all subjects who came to the door and were pre-assigned to the treatment conversation to all subjects who came to the door and were pre-assigned to the placebo conversation.

Procedure for Combining Outcomes into Indices. We pre-specified that we would create the indices by using factor analysis and rescaling the factors to have mean 0 and standard deviation 1 . 


\section{Online Appendix for Experiment 1}

This experiment was pre-registered at https://osf.io/2gfqc/?view_only=dbdc723b79bc4ef0a1d4f6a89eb51f1e.

Training, implementation, and intervention procedures (including scripts) for the Full Intervention, Intervention without Analogic Perspective-Taking, and Placebo conditions are available at https://osf.io/nf968/?view_onl $\mathrm{y}=53950517 \mathrm{dcac} 4 \mathrm{~b} 9 \mathrm{ab} 3 \mathrm{bcfc} 2 \mathrm{ca} 94 \mathrm{eb} 433$.

\section{Follow-Up Surveys}

We conducted multiple waves of follow-up surveys for voters who came to the door in any condition. These follow-up surveys began around 1 week (average of 9.5 days and standard deviation of 4.4 days), 7 weeks (average of 50.6 days and standard deviation of 4.1 days), and 4.5 months (average of 133.5 days and standard deviation of 20.1 days, unlike the prior surveys this was launched for all respondents at the same time rather than on a rolling basis) after the day each voter was canvassed. We solicited voters to complete these re-surveys at the email addresses they provided in the baseline survey and sent three reminders. Note that to the extent any voters answered the wrong surveys or did not answer the surveys carefully, this measurement error would lead us to underestimate the true effects of treatment (Gerber and Green, 2012).

The below table shows how the representativeness of those who responded to the survey differ from those mailed an invitation to participate in the survey. These data come from the voter file. Note that except where otherwise noted, no weighting is used in the analysis; the aim of the estimation is to test for the existence of treatment effects within this sample, not to generalize to the population of invited respondents.

Table OA1: Representativeness of Experiment at Each Stage

\begin{tabular}{|c|c|c|c|c|c|c|c|c|c|c|c|}
\hline Sample & Female & Age & AfAm & White & Voted 18 & Voted 16 & Voted 14 & Voter 12 & Reg Democrat & Reg Republican & $\mathrm{N}$ \\
\hline Starting & 0.53 & 51.07 & 0.06 & 0.57 & 0.64 & 0.75 & 0.46 & 0.66 & 0.23 & 0.28 & 369317 \\
\hline Baseline Resp. & 0.54 & 52.62 & 0.03 & 0.65 & 0.82 & 0.86 & 0.62 & 0.77 & 0.24 & 0.29 & 8925 \\
\hline Canvassed & 0.53 & 55.82 & 0.03 & 0.61 & 0.85 & 0.88 & 0.66 & 0.8 & 0.23 & 0.27 & 2838 \\
\hline 1 Wk Resp. & 0.52 & 56.76 & 0.02 & 0.64 & 0.88 & 0.89 & 0.69 & 0.82 & 0.24 & 0.26 & 1738 \\
\hline 7 Wk Resp. & 0.53 & 55.99 & 0.02 & 0.65 & 0.88 & 0.89 & 0.69 & 0.82 & 0.24 & 0.27 & 1707 \\
\hline 5 Mo Resp. & 0.52 & 56.14 & 0.02 & 0.65 & 0.88 & 0.89 & 0.69 & 0.82 & 0.24 & 0.27 & 1592 \\
\hline
\end{tabular}

\section{Outcomes}

The survey included dozens of political, social, and cultural questions, only some of which were related to immigration and healthcare. In our pre-analysis plan, we indicate which items constituted experimental outcomes. Below we list these items and give their full text.

The below items appeared on multiple surveys; the \# sign will be replaced with the survey number in our analysis: the baseline survey is survey 0 ; the 1 -week survey is survey 1 ; the 7 -week survey is survey 2 , and; the 4.5-month survey is survey 3 . The variable name for each item is written using in-line code. For the remainder of the paper, we will refer to these items by their variable names.

- Immigrant Prejudice Index. This index consisted of 8 items related to prejudice towards unauthorized immigrants. In addition to an overall immigrant prejudice index consisting of all 8 items, we also examined three subindices.

- Subindex: Common ingroup identity (e.g., immigrants are part of our community). The first set of questions are five point scales where respondents were asked: "Do you agree or disagree with the below statements about undocumented or illegal immigrants?" Response options were: Strongly agree, Somewhat agree, Neither agree nor disagree, Somewhat disagree, Strongly disagree. 
* t\#_immprej_partoflocal: "I would consider any illegal immigrants who live in my neighborhood as part of our local community."

* t\#_immprej_dontwanttofit: "Too many undocumented immigrants just don't want to fit into American society."

* t\#_immprej_holdsamevalues: "Undocumented immigrants hold the same values as me and my family."

* t\#_immprej_foreignersvs: "There are many unauthorized immigrants to the United States who have been living here for many years. When you think about these immigrants, do you think about them as members of your community, or as foreigners?" The response option was a 1-10 scale ranging from "Foreigners" to "Members of my community".

- Subindex: Negative sentiment. These questions used the same five point scale as above:

* t\#_immprej_noproblemlivingn: "I would have no problem living in areas where undocumented immigrants live."

* t\#_immprej_burdenoncomm: "Undocumented immigrants are a burden on our community."

- Subindex: Empathic Concern (e.g., concern with their suffering) (also reactive empathy)

* t\#_immprej_suffering: "The suffering of some illegal immigrants concerns me."

* t\#_immprej_deservecare: "Undocumented immigrants deserve our care and support."

- Immigrant Policy Index. This index consisted of 8 items related to policy towards unauthorized immigrants. In addition to an overall immigrant policy index consisting of all 8 items, we also examined three subindices.

- Subindex: Health care. These questions used the same five point scale as above:

* t\#_immpolicy_hc_under_uhc: "Politicians have been talking about creating a new government healthcare program that would provide all Americans healthcare coverage. Do you think the government should provide illegal immigrants healthcare coverage under any such program?"

* t\#_immpolicy_hc_available: "Do you think health insurance coverage provided by the government should be available to unauthorized immigrants living in the United States?"

* t\#_immpolicy_medicaid: "Medicaid is a state-run program that provides health insurance to poor people in [STATE]. Should undocumented immigrants in [STATE] who would otherwise qualify be allowed to receive Medicaid from [STATE]?"

- Subindex: General attitudes. These questions used the same five point scale as above:

* t\#_immpolicy_donotdeserve: "Illegal immigrants have not contributed enough to deserve government assistance."

* t\#_immpolicy_govdowhatcan: "The government should do what it can to help undocumented immigrants living in the United States."

- Subindex: Non-healthcare policies. This index asked: "The government has a number of programs to help people. Do you think these programs should be available to immigrants currently living in the United States illegally?" Response options are Definitely available to illegal immigrants; probably available to illegal immigrants; Not sure; Probably not available to illegal immigrants; Definitely available to illegal immigrants:

* t\#_immpolicy_foodstamps: Money that can be used to buy food (sometimes called SNAP or food stamps)

* t\#_immpolicy_k12schools: Public schools (Kindergarten through 12th grades)

* t\#_immpolicy_instatetuition: In-state college tuition at [STATE] state colleges

- Potential Mechanisms.

- Parallel empathy. We do not test this; see Pre-Analysis Plan for a discussion.

- Reactive empathy. We consider reactive empathy (called Empathic Concern above) a dimension of prejudice in itself in addition to being mechanisms for why other attitudes might change.

- Shifts in attributional thinking. "Undocumented immigrants face big challenges that are no fault of their own" (t\#_imm_attrib_thinking).

- Self-outgroup merging. "I think I have a lot in common with undocumented immigrants" (t\#_imm_self_out_merge). 


\section{Outcome Indices}

In our pre-analysis plan, we specified that we would combine multiple items into indices to test hypotheses. Combining outcomes into an index increases precision by decreasing survey measurement error and limits the potential for biases from multiple hypothesis testing (Broockman, Kalla and Sekhon, 2017).

The indices are as follows:

- t\#_factor_imm_all_all: An index of all primary outcomes (i.e., all the items in the prejudice and policy indicies), created to test the omnibus hypothesis that the treatment had any effects.

- t\#_factor_imm_prej_all: An index of outcomes from t\#_factor_imm_all_all capturing the Immigrant Prejudice Index.

- t\#_factor_imm_policy_all: An index of outcomes from t\#_factor_imm_all_all capturing the Immigrant Policy Index.

In addition to an outcome index at each time period, we also present some results from a pooled outcome index - tALL_factor _ - taking the average of each outcome index across time periods. If a respondent did not take a particular post-treatment survey, that time period is excluded from the average. Note that this pooled outcome was not pre-specified in our pre-analysis plan. We use this pooled outcome index to increase the precision of our treatment effect estimates through further reductions in measurement error. This pooled outcome is also a useful brief summary of the overall effects.

\section{Contact Rate}

Contact is defined as the voter coming to the door and being identified before the topics of the placebo or immigration begin. Across the three conditions among voters who responded to the baseline survey and were then randomly assigned to an experimental condition, the contact rates were: Placebo: 0.32. Intervention without APT: 0.32. Full Intervention: 0.32 .

In the two intervention conditions, we asked the voters to first answer a rating question about healthcare The share of voters who answered this question provides an indication of how often voters actually began the conversation. Conditional on having come to the door, the proportion of voters who provided this first rating is: Intervention without APT: 0.83. Full Intervention: 0.83 .

Across the three conditions, among the voters who came to the door, the canvass completion rates were: Placebo: 0.95. Intervention without APT: 0.79. Full Intervention: 0.78.

On average, the conversations lasted: Placebo: 2.58 minutes (standard deviation of 3.2 minutes). Intervention without APT: 13.21 minutes (standard deviation of 9.74 minutes). Among those who at least provided the first rating, thee conversations lasted an average of 15.52 minutes and had a standard deviation of 8.97 minutes. Full Intervention: 15.59 minutes (standard deviation of 11.05 minutes). Among those who at least provided the first rating, thee conversations lasted an average of 18.45 minutes and had a standard deviation of 9.86 minutes.

\section{Tests of Design Assumptions}

\section{Covariate Balance among All Subjects, Compliers, and Reporters}

The below tables demonstrate that balance on pre-treatment observable attributes is maintained among the original universe of pre-survey respondents randomized to each group, the sub-sample that was canvassed, and the sub-sample that was both canvassed and successfully re-interviewed. Each table shows the mean value for the covariate under each condition as well as the $p$-value from a one-way ANOVA test. The first table considers all voters who were randomly assigned after having taken the pre-survey (all subjects); the second table considers all voters who were successfully contacted (compliers); the remaining tables consider all voters who responded to the first through third post-surveys (reporters). 
Table OA2: Covariate Balance among Pre-Survey Respondents.

\begin{tabular}{l|r|r|r|l}
\hline & Placebo & Intervention w/o APT & Full Intervention & p-value \\
\hline Age & 52.34 & 52.72 & 52.80 & 0.51 \\
\hline Female & 0.55 & 0.54 & 0.55 & 0.55 \\
\hline White & 0.65 & 0.65 & 0.65 & 0.93 \\
\hline Trump Approve t0 & 0.44 & 0.46 & 0.44 & 0.11 \\
\hline College Graduate t0 & 0.45 & 0.46 & 0.46 & 0.64 \\
\hline Baseline Factor of Immigration Support & -0.17 & -0.16 & -0.16 & 0.95 \\
\hline $\mathrm{N}$ & 2977.00 & 2975.00 & 2973.00 & - \\
\hline
\end{tabular}

Table OA3: Covariate Balance among Compliers.

\begin{tabular}{l|r|r|r|l}
\hline & Placebo & Intervention w/o APT & Full Intervention & p-value \\
\hline Age & 55.27 & 56.49 & 55.71 & 0.24 \\
\hline Female & 0.55 & 0.52 & 0.53 & 0.51 \\
\hline White & 0.64 & 0.61 & 0.59 & 0.05 \\
\hline Trump Approve t0 & 0.43 & 0.46 & 0.44 & 0.46 \\
\hline College Graduate t0 & 0.47 & 0.46 & 0.48 & 0.73 \\
\hline Baseline Factor of Immigration Support & -0.12 & -0.14 & -0.14 & 0.86 \\
\hline $\mathrm{N}$ & 953.00 & 938.00 & 947.00 & - \\
\hline
\end{tabular}

Table OA4: Covariate Balance among 1st Post-Survey Respondents.

\begin{tabular}{l|r|r|r|l}
\hline & Placebo & Intervention w/o APT & Full Intervention & p-value \\
\hline Age & 56.64 & 57.16 & 56.50 & 0.76 \\
\hline Female & 0.56 & 0.49 & 0.51 & 0.07 \\
\hline White & 0.65 & 0.64 & 0.63 & 0.81 \\
\hline Trump Approve t0 & 0.40 & 0.43 & 0.41 & 0.54 \\
\hline College Graduate t0 & 0.54 & 0.53 & 0.53 & 0.97 \\
\hline Baseline Factor of Immigration Support & -0.04 & -0.11 & -0.09 & 0.44 \\
\hline $\mathrm{N}$ & 584.00 & 566.00 & 588.00 & - \\
\hline
\end{tabular}

Table OA5: Covariate Balance among 2nd Post-Survey Respondents.

\begin{tabular}{l|r|r|r|l}
\hline & Placebo & Intervention w/o APT & Full Intervention & p-value \\
\hline Age & 56.02 & 55.62 & 56.34 & 0.75 \\
\hline Female & 0.55 & 0.53 & 0.51 & 0.31 \\
\hline White & 0.66 & 0.64 & 0.64 & 0.72 \\
\hline Trump Approve t0 & 0.41 & 0.42 & 0.41 & 0.87 \\
\hline College Graduate t0 & 0.51 & 0.53 & 0.54 & 0.73 \\
\hline Baseline Factor of Immigration Support & -0.07 & -0.06 & -0.08 & 0.93 \\
\hline $\mathrm{N}$ & 581.00 & 572.00 & 554.00 & - \\
\hline
\end{tabular}


Table OA6: Covariate Balance among 3rd Post-Survey Respondents.

\begin{tabular}{l|r|r|r|l}
\hline & Placebo & Intervention w/o APT & Full Intervention & p-value \\
\hline Age & 55.68 & 56.66 & 56.09 & 0.61 \\
\hline Female & 0.54 & 0.51 & 0.50 & 0.45 \\
\hline White & 0.67 & 0.65 & 0.64 & 0.69 \\
\hline Trump Approve t0 & 0.41 & 0.41 & 0.41 & 0.99 \\
\hline College Graduate t0 & 0.53 & 0.53 & 0.54 & 0.91 \\
\hline Baseline Factor of Immigration Support & -0.08 & -0.06 & -0.10 & 0.81 \\
\hline $\mathrm{N}$ & 539.00 & 529.00 & 524.00 & - \\
\hline
\end{tabular}

\section{Survey Attrition}

An important design assumption is that the treatment does not affect the composition of the individuals who take each follow-up survey (Broockman, Kalla and Sekhon, 2017). We investigate this by regressing an indicator for responding to a post-treatment survey on indicators of treatment assignment. Across the three survey waves, we find no evidence of differential attrition.

Table OA7: Test for differential attrition

\begin{tabular}{l|r|r|r|r}
\hline & Effect & SE & t.stat & p-value \\
\hline 1 Week & \multicolumn{5}{|c}{} \\
\hline W/o APT & -0.01 & 0.02 & -0.42 & 0.68 \\
\hline Full & 0.01 & 0.02 & 0.36 & 0.72 \\
\hline 7 Weeks \\
\hline W/o APT & 0.00 & 0.02 & 0.01 & 1.00 \\
\hline Full & -0.03 & 0.02 & -1.10 & 0.27 \\
\hline 4.5 Months \\
\hline W/o APT & 0.00 & 0.02 & -0.07 & 0.94 \\
\hline Full & -0.01 & 0.02 & -0.54 & 0.59 \\
\hline
\end{tabular}

\section{Test of Differential Attrition by Covariates}

The above subsection demonstrated that there was no average differential attrition; now, we test for whether the treatment caused attrition to differ by covariates (for example, whether it encouraged already-supportive subjects to complete the post-survey but also discouraged unsupportive subjects from doing so) (Gerber and Green, 2012). To test whether attrition patterns are similar by covariates in treatment and placebo, we use a linear regression of whether or not an individual responded to the follow-up survey on treatment, baseline covariates, and treatment-covariate interactions. We then perform a heteroskedasticity-robust F-test of the hypothesis that all the interaction coefficients are zero. This procedure was pre-specified in our pre-analysis plan and is standard practice (Gerber and Green, 2012). Below we report the p-value of this F-test. Based on the results presented in the Table below, there does not appear to be evidence of asymmetrical attrition.

Table OA8: p-value by Survey Wave Test of Differential Attrition by Covariates.

\begin{tabular}{l|l}
\hline 1 Week Survey (t1) & 0.07 \\
\hline 7 Weeks Survey (t2) & 0.28 \\
\hline 4.5 Month Survey (t3) & 0.38 \\
\hline
\end{tabular}

\section{Results}

Below we report the results in tabular form at each time period and for each outcome measure. In each section, the first table shows the results by the average treatment effect. Each table includes two models: 
one in which we adjust for the pre-specified pre-treatment covariates to improve precision and a second unadjusted model.

Below we estimate the ATE on the overall index. Note that we pre-registered a focus on the estimates with covariates (which were also pre-registered) since we expected these to be much more precise; the experimental design was intended to draw significant statistical power from the baseline survey. However, we also present results without covariates for completeness.

Table OA9: ATE effects on overall index

\begin{tabular}{|c|c|c|c|c|c|c|c|c|}
\hline & \multicolumn{4}{|c|}{ With Covariates } & \multicolumn{4}{|c|}{ Without Covariates } \\
\hline & Effect & $\mathrm{SE}$ & t.stat & p-value & Effect & $\mathrm{SE}$ & t.stat & p-value \\
\hline \multicolumn{9}{|l|}{1 Week } \\
\hline Full vs. Placebo & 0.096 & 0.023 & 4.241 & 0.000 & 0.046 & 0.060 & 0.765 & 0.444 \\
\hline w/o APT vs. Placebo & 0.133 & 0.022 & 5.919 & 0.000 & 0.053 & 0.060 & 0.887 & 0.375 \\
\hline Full vs. w/o APT & -0.038 & 0.023 & -1.608 & 0.108 & -0.007 & 0.061 & -0.119 & 0.905 \\
\hline \multicolumn{9}{|l|}{7 Weeks } \\
\hline Full vs. Placebo & 0.097 & 0.024 & 4.043 & 0.000 & 0.075 & 0.061 & 1.234 & 0.218 \\
\hline w/o APT vs. Placebo & 0.104 & 0.023 & 4.440 & 0.000 & 0.103 & 0.060 & 1.714 & 0.087 \\
\hline Full vs. w/o APT & -0.006 & 0.026 & -0.234 & 0.815 & -0.028 & 0.062 & -0.447 & 0.655 \\
\hline \multicolumn{9}{|l|}{ 4.5 Months } \\
\hline Full vs. Placebo & 0.097 & 0.023 & 4.170 & 0.000 & 0.068 & 0.063 & 1.082 & 0.279 \\
\hline w/o APT vs. Placebo & 0.110 & 0.023 & 4.823 & 0.000 & 0.116 & 0.062 & 1.847 & 0.065 \\
\hline Full vs. w/o APT & -0.013 & 0.024 & -0.524 & 0.600 & -0.047 & 0.064 & -0.744 & 0.457 \\
\hline \multicolumn{9}{|l|}{ Pooled } \\
\hline Full vs. Placebo & 0.089 & 0.020 & 4.543 & 0.000 & 0.054 & 0.056 & 0.965 & 0.335 \\
\hline w/o APT vs. Placebo & 0.118 & 0.019 & 6.192 & 0.000 & 0.084 & 0.055 & 1.529 & 0.126 \\
\hline Full vs. w/o APT & -0.030 & 0.021 & -1.461 & 0.144 & -0.031 & 0.057 & -0.538 & 0.591 \\
\hline
\end{tabular}

Below we estimate the ATE on the overall prejudice index.

Table OA10: ATE effects on prejudice index

\begin{tabular}{|c|c|c|c|c|c|c|c|c|}
\hline & \multicolumn{4}{|c|}{ With Covariates } & \multicolumn{4}{|c|}{ Without Covariates } \\
\hline & Effect & $\mathrm{SE}$ & t.stat & p-value & Effect & SE & t.stat & p-value \\
\hline \multicolumn{9}{|l|}{1 Week } \\
\hline Full vs. Placebo & 0.075 & 0.024 & 3.085 & 0.002 & 0.013 & 0.061 & 0.207 & 0.836 \\
\hline w/o APT vs. Placebo & 0.110 & 0.024 & 4.698 & 0.000 & 0.026 & 0.060 & 0.432 & 0.666 \\
\hline Full vs. w/o APT & -0.037 & 0.025 & -1.492 & 0.136 & -0.013 & 0.060 & -0.220 & 0.826 \\
\hline \multicolumn{9}{|l|}{7 Weeks } \\
\hline Full vs. Placebo & 0.051 & 0.027 & 1.907 & 0.057 & 0.012 & 0.061 & 0.199 & 0.842 \\
\hline w/o APT vs. Placebo & 0.054 & 0.026 & 2.068 & 0.039 & 0.048 & 0.060 & 0.804 & 0.422 \\
\hline Full vs. w/o APT & -0.004 & 0.027 & -0.147 & 0.883 & -0.036 & 0.061 & -0.594 & 0.553 \\
\hline \multicolumn{9}{|l|}{ 4.5 Months } \\
\hline Full vs. Placebo & 0.082 & 0.026 & 3.128 & 0.002 & 0.045 & 0.063 & 0.705 & 0.481 \\
\hline w/o APT vs. Placebo & 0.101 & 0.026 & 3.895 & 0.000 & 0.107 & 0.062 & 1.712 & 0.087 \\
\hline Full vs. w/o APT & -0.022 & 0.027 & -0.795 & 0.427 & -0.062 & 0.063 & -0.987 & 0.324 \\
\hline \multicolumn{9}{|l|}{ Pooled } \\
\hline Full vs. Placebo & 0.066 & 0.022 & 3.062 & 0.002 & 0.015 & 0.056 & 0.267 & 0.789 \\
\hline w/o APT vs. Placebo & 0.096 & 0.021 & 4.608 & 0.000 & 0.056 & 0.055 & 1.022 & 0.307 \\
\hline Full vs. w/o APT & -0.033 & 0.022 & -1.491 & 0.136 & -0.041 & 0.056 & -0.739 & 0.460 \\
\hline
\end{tabular}

Below we estimate the ATE on the policy index. 
Table OA11: ATE effects on policy index

\begin{tabular}{|c|c|c|c|c|c|c|c|c|}
\hline & \multicolumn{4}{|c|}{ With Covariates } & \multicolumn{4}{|c|}{ Without Covariates } \\
\hline & Effect & $\mathrm{SE}$ & t.stat & $\mathrm{p}$-value & Effect & SE & t.stat & p-value \\
\hline \multicolumn{9}{|l|}{1 Week } \\
\hline Full vs. Placebo & 0.107 & 0.026 & 4.064 & 0.000 & 0.073 & 0.059 & 1.229 & 0.219 \\
\hline w/o APT vs. Placebo & 0.146 & 0.027 & 5.431 & 0.000 & 0.077 & 0.060 & 1.284 & 0.199 \\
\hline Full vs. w/o APT & -0.038 & 0.027 & -1.394 & 0.164 & -0.004 & 0.062 & -0.070 & 0.944 \\
\hline \multicolumn{9}{|l|}{7 Weeks } \\
\hline Full vs. Placebo & 0.135 & 0.028 & 4.879 & 0.000 & 0.132 & 0.060 & 2.200 & 0.028 \\
\hline w/o APT vs. Placebo & 0.148 & 0.027 & 5.411 & 0.000 & 0.152 & 0.060 & 2.548 & 0.011 \\
\hline Full vs. w/o APT & -0.011 & 0.030 & -0.358 & 0.721 & -0.020 & 0.062 & -0.319 & 0.750 \\
\hline \multicolumn{9}{|l|}{4.5 Months } \\
\hline Full vs. Placebo & 0.103 & 0.026 & 3.967 & 0.000 & 0.085 & 0.062 & 1.369 & 0.171 \\
\hline w/o APT vs. Placebo & 0.111 & 0.026 & 4.232 & 0.000 & 0.117 & 0.063 & 1.864 & 0.062 \\
\hline Full vs. w/o APT & -0.005 & 0.027 & -0.190 & 0.849 & -0.031 & 0.064 & -0.488 & 0.626 \\
\hline \multicolumn{9}{|l|}{ Pooled } \\
\hline Full vs. Placebo & 0.104 & 0.022 & 4.745 & 0.000 & 0.088 & 0.055 & 1.591 & 0.112 \\
\hline w/o APT vs. Placebo & 0.134 & 0.022 & 6.047 & 0.000 & 0.109 & 0.055 & 1.971 & 0.049 \\
\hline Full vs. w/o APT & -0.029 & 0.024 & -1.213 & 0.225 & -0.021 & 0.057 & -0.367 & 0.714 \\
\hline
\end{tabular}

\section{Complier Average Causal Effects}

In the pre-analysis plan, we noted that we planned to adjust for the complier average causal effect (CACE) by dividing the average treatment effect (ATE) by the proportion of conversations where the voter answered the first rating question. This CACE assumes that 1) there was no effect of the intervention for the voters who immediately refused to talk, and 2) there are no defiers; that is, no voters only received the intervention if they were assigned to the placebo group yet would not have received it were they actually in the treatment group (Gerber and Green, 2012). Reporting these point estimates would not change the experimental comparison we conduct, but would increase point estimates to account for the measurement error in the treatment indicator.

Some readers may be interested in a CACE. To compute a CACE, we use a conservative definition of compliance, whether subjects got to the "first rating" part of the conversation where they initially told canvassers how they felt about the policy. Using this definition of compliance, the compliance rate in the Full Intervention condition was $81 \%$ and the compliance rate in the Intervention without Analogic Perspective-Taking condition was $82 \%$. The ITT point estimates should therefore be multiplied by 1.24 and 1.23 in the Full and Without Analogic Perspective-Taking interventions, respectively, to compute the CACE. That is, given a true effect on compliers of 1.24 and 1.23 times the size of the ATEs we observed, we would on average estimate ATEs of the magnitude that we did. These imply CACE estimates in the Full and Without Analogic Perspective-Taking intervention conditions of, respectively, $\mathrm{d}=0.11$ and $\mathrm{d}=0.145$ on the overall index pooled across all time periods.

\section{Heterogeneous Treatment Effects}

In this section we present heterogeneous treatment effects by pre-specified subgroups. For each result, we present the conditional average treatment effect, adjusting for covariates, within each subgroup. As the outcome in these analyses we use the index of all the items in the prejudice and policy indices as measured in the first post-treatment survey.

We pre-specified that we would investigate heterogeneous treatment effects by voter and canvasser traits. We will investigate these by comparing the ATEs within the pre-specified subgroups.

Canvasser Immigration Status Below are results by the immigration status of the canvasser. All canvassers completed a demographic survey in which they were asked "Do you consider yourself to be an 
immigrant?" Responses are coded as 1 for yes and 0 for all other responses. $16 \%$ of canvassers identified as immigrants.

Table OA12: Heterogeneous treatment effects by Canvasser being an immigrant

\begin{tabular}{l|r|r|r|r|r|r|r|r}
\hline & \multicolumn{6}{|c|}{ Canvasser being an immigrant $=1$} & \multicolumn{3}{|c}{ Canvasser being an immigrant $=0$} \\
\cline { 2 - 9 } & Effect & SE & t.stat & p-value & Effect & SE & t.stat & p-value \\
\hline Full & 0.09 & 0.06 & 1.61 & 0.11 & 0.10 & 0.03 & 3.91 & 0 \\
\hline Without APT & 0.10 & 0.06 & 1.54 & 0.12 & 0.14 & 0.03 & 5.52 & 0 \\
\hline
\end{tabular}

Canvasser Race Below are results by the race of the canvasser. All canvassers completed a demographic survey in which they were asked "What is your race?" Responses are coded as 1 for White self-identification and 0 for all other responses. $56 \%$ of canvassers identified as white

Table OA13: Heterogeneous treatment effects by Canvasser being white

\begin{tabular}{l|r|r|r|r|r|r|r|r}
\hline & \multicolumn{4}{|c|}{ Canvasser being white $=1$} & \multicolumn{4}{c}{ Canvasser being white $=0$} \\
\cline { 2 - 9 } & Effect & SE & t.stat & p-value & Effect & SE & t.stat & p-value \\
\hline Full & 0.10 & 0.03 & 3.09 & 0 & 0.09 & 0.04 & 2.56 & 0.01 \\
\hline Without APT & 0.11 & 0.03 & 3.43 & 0 & 0.15 & 0.03 & 4.57 & 0.00 \\
\hline
\end{tabular}

By voter's baseline partisanship Below are the results by the voter's baseline partisanship. $30 \%$ of voters identified as Democrats (excluding leaners). $34 \%$ of voters identified as Republicans (excluding leaners). $36 \%$ of voters identified as Independents or others.

Table OA14: Heterogeneous treatment effects by partisanship

\begin{tabular}{|c|c|c|c|c|c|c|c|c|c|c|c|c|}
\hline & \multicolumn{4}{|c|}{ Democrat } & \multicolumn{4}{|c|}{ Republican } & \multicolumn{4}{|c|}{ Independent/Other } \\
\hline & Effect & $\mathrm{SE}$ & t.stat & p-value & Effect & SE & t.stat & p-value & Effect & $\mathrm{SE}$ & t.stat & p-value \\
\hline Full & 0.10 & 0.04 & 2.55 & 0.01 & 0.04 & 0.04 & 1.11 & 0.27 & 0.13 & 0.04 & 3.25 & 0 \\
\hline Without APT & 0.18 & 0.04 & 4.26 & 0.00 & 0.08 & 0.04 & 2.32 & 0.02 & 0.14 & 0.04 & 3.75 & 0 \\
\hline
\end{tabular}

By voter's baseline ideology Below are the results by the voter's baseline ideology $30 \%$ of voters identified as liberals. $43 \%$ of voters identified as conservatives. $27 \%$ of voters identified as moderators or others.

Table OA15: Heterogeneous treatment effects by ideology

\begin{tabular}{|c|c|c|c|c|c|c|c|c|c|c|c|c|}
\hline & \multicolumn{4}{|c|}{ Liberals } & \multicolumn{4}{|c|}{ Conservatives } & \multicolumn{4}{|c|}{ Moderates } \\
\hline & Effect & $\mathrm{SE}$ & t.stat & p-value & Effect & SE & t.stat & $\mathrm{p}$-value & Effect & $\mathrm{SE}$ & t.stat & p-value \\
\hline Full & 0.13 & 0.04 & 3.34 & 0 & 0.03 & 0.03 & 0.96 & 0.34 & 0.16 & 0.05 & 3.04 & 0 \\
\hline Without APT & 0.18 & 0.04 & 4.25 & 0 & 0.08 & 0.03 & 2.61 & 0.01 & 0.18 & 0.05 & 3.72 & 0 \\
\hline
\end{tabular}

By voter's baseline education Below are results by the education level of voters at baseline. $53 \%$ of voters identified as receiving a college degree. All other responses are coded together.

Table OA16: Heterogeneous treatment effects by College educated

\begin{tabular}{l|r|r|r|r|r|r|r|r}
\hline & \multicolumn{4}{|c|}{ College educated $=1$} & \multicolumn{4}{c}{ College educated =0 } \\
\cline { 2 - 9 } & Effect & SE & t.stat & p-value & Effect & SE & t.stat & p-value \\
\hline Full & 0.11 & 0.03 & 3.60 & 0 & 0.07 & 0.03 & 1.98 & 0.05 \\
\hline Without APT & 0.14 & 0.03 & 4.61 & 0 & 0.13 & 0.04 & 3.88 & 0.00 \\
\hline
\end{tabular}


By voter's gender Below are results by the gender of voters according to the voter file. $52 \%$ of voters are coded as female on the voter file.

Table OA17: Heterogeneous treatment effects by Female

\begin{tabular}{l|r|r|r|r|r|r|r|r}
\hline & \multicolumn{4}{|c|}{ Female $=1$} & \multicolumn{4}{c}{ Female $=0$} \\
\cline { 2 - 9 } & Effect & SE & t.stat & p-value & Effect & SE & t.stat & p-value \\
\hline Full & 0.15 & 0.03 & 4.68 & 0 & 0.04 & 0.03 & 1.16 & 0.24 \\
\hline Without APT & 0.19 & 0.03 & 5.89 & 0 & 0.07 & 0.03 & 2.24 & 0.03 \\
\hline
\end{tabular}

By voter's baseline Trump approval Below are results by the approval of Donald Trump by voters at baseline. $41 \%$ of voters approved of Trump in the baseline survey. All other responses are coded together.

Table OA18: Heterogeneous treatment effects by Trump approval

\begin{tabular}{l|r|r|r|r|r|r|r|r}
\hline & \multicolumn{4}{|c|}{ Trump approval $=1$} & \multicolumn{4}{c}{ Trump approval =0 } \\
\cline { 2 - 9 } & Effect & SE & t.stat & p-value & Effect & SE & t.stat & p-value \\
\hline Full & 0.07 & 0.03 & 2.12 & 0.03 & 0.12 & 0.03 & 3.81 & 0 \\
\hline Without APT & 0.10 & 0.03 & 2.83 & 0.00 & 0.16 & 0.03 & 5.19 & 0 \\
\hline
\end{tabular}

\section{Results with Weights}

To assess the generalizability of our results, we compare our main results - a sample average treatment effect (SATE) - to an estimate of the population average treatment effect (PATE). To estimate the PATE, we first construct weights of who was canvassed and took the survey relative to the starting universe. We construct these weights using entropy balancing (Hainmueller, 2012) and weight on gender, age, race, and vote history. Below are results with and without these weights, showing that the estimated SATEs and PATEs are similar. If anything, the estimated PATEs are larger than the estimated SATEs, suggesting that the set of individuals who are canvassed and respond to surveys are perhaps slightly more difficult to persuade than the broader universe. Note that this analysis was not pre-registered but follows the same procedure as used in previous work by Kalla and Broockman (2020).

Table OA19: ATE Effects on Overall Index with Weights

\begin{tabular}{|c|c|c|c|c|c|c|c|c|}
\hline & \multicolumn{4}{|c|}{ Unweighted } & \multicolumn{4}{|c|}{ Weighted } \\
\hline & Effect & $\mathrm{SE}$ & t.stat & p-value & Effect & $\mathrm{SE}$ & t.stat & p-value \\
\hline \multicolumn{9}{|l|}{1 Week } \\
\hline Full vs. Placebo & 0.096 & 0.023 & 4.241 & 0 & 0.120 & 0.030 & 3.994 & 0.000 \\
\hline APT vs. Placebo & 0.133 & 0.022 & 5.919 & 0 & 0.137 & 0.029 & 4.797 & 0.000 \\
\hline \multicolumn{9}{|l|}{7 Week } \\
\hline Full vs. Placebo & 0.097 & 0.024 & 4.043 & 0 & 0.094 & 0.032 & 2.940 & 0.003 \\
\hline APT vs. Placebo & 0.103 & 0.023 & 4.440 & 0 & 0.084 & 0.030 & 2.814 & 0.005 \\
\hline \multicolumn{9}{|l|}{ 4.5 Months } \\
\hline Full vs. Placebo & 0.097 & 0.023 & 4.170 & 0 & 0.119 & 0.032 & 3.698 & 0.000 \\
\hline APT vs. Placebo & 0.110 & 0.023 & 4.823 & 0 & 0.094 & 0.030 & 3.092 & 0.002 \\
\hline
\end{tabular}

\section{Estimates by Individual Policy Items}

It may be difficult for readers to interpret the magnitude of an effect presented in terms of standard deviation change. We therefore dichotomize each variable to record whether participants registered any support (not only strong agreement). These new dichotomized variables are coded to 1 if a participant agreed at all with the policy (Somewhat or Strongly agree) and 0 otherwise (indicating stated indifference or opposition). Again, we reverse code t1_immpolicy_donotdeserve. 
All results below are based on answers to the first follow-up survey. Note that all estimates are intent-to-treat effects; as described above, these estimates can be multiplied by approximately 1.23 for CACE estimates under the assumptions described above in the Complier Average Causal Effects section.

Table OA20: Effect on individual policy items (t1, at all)

\begin{tabular}{|c|c|c|c|c|}
\hline & \multicolumn{4}{|c|}{ With Covariates } \\
\hline & Effect & $\mathrm{SE}$ & t.stat & p-value \\
\hline \multicolumn{5}{|l|}{ immpolicy_hc_under_uhc } \\
\hline Full vs. Placebo & 0.051 & 0.018 & 2.797 & 0.005 \\
\hline Without APT vs. Placebo & 0.080 & 0.018 & 4.355 & 0.000 \\
\hline Either Treatment vs. Placebo & 0.065 & 0.016 & 4.080 & 0.000 \\
\hline Full vs. Without APT & -0.030 & 0.018 & -1.689 & 0.092 \\
\hline \multicolumn{5}{|l|}{ immpolicy_hc_available } \\
\hline Full vs. Placebo & 0.061 & 0.019 & 3.274 & 0.001 \\
\hline Without APT vs. Placebo & 0.068 & 0.019 & 3.615 & 0.000 \\
\hline Either Treatment vs. Placebo & 0.064 & 0.016 & 3.942 & 0.000 \\
\hline Full vs. Without APT & -0.005 & 0.018 & -0.294 & 0.769 \\
\hline \multicolumn{5}{|l|}{ immpolicy_medicaid } \\
\hline Full vs. Placebo & 0.046 & 0.018 & 2.537 & 0.011 \\
\hline Without APT vs. Placebo & 0.084 & 0.019 & 4.478 & 0.000 \\
\hline Either Treatment vs. Placebo & 0.065 & 0.016 & 4.013 & 0.000 \\
\hline Full vs. Without APT & -0.035 & 0.018 & -1.951 & 0.051 \\
\hline \multicolumn{5}{|c|}{ immpolicy_donotdeserve (rev. coded) } \\
\hline Full vs. Placebo & 0.012 & 0.026 & 0.471 & 0.638 \\
\hline Without APT vs. Placebo & 0.008 & 0.026 & 0.298 & 0.765 \\
\hline Either Treatment vs. Placebo & 0.010 & 0.023 & 0.442 & 0.659 \\
\hline Full vs. Without APT & 0.004 & 0.025 & 0.160 & 0.873 \\
\hline \multicolumn{5}{|l|}{ immpolicy_govdowhatcan } \\
\hline Full vs. Placebo & 0.022 & 0.020 & 1.079 & 0.281 \\
\hline Without APT vs. Placebo & 0.045 & 0.020 & 2.266 & 0.024 \\
\hline Either Treatment vs. Placebo & 0.033 & 0.018 & 1.892 & 0.059 \\
\hline Full vs. Without APT & -0.025 & 0.020 & -1.255 & 0.210 \\
\hline \multicolumn{5}{|l|}{ immpolicy_foodstamps } \\
\hline Full vs. Placebo & 0.038 & 0.020 & 1.931 & 0.054 \\
\hline Without APT vs. Placebo & 0.065 & 0.020 & 3.293 & 0.001 \\
\hline Either Treatment vs. Placebo & 0.051 & 0.017 & 3.004 & 0.003 \\
\hline Full vs. Without APT & -0.027 & 0.020 & -1.371 & 0.171 \\
\hline \multicolumn{5}{|l|}{ immpolicy_k12schools } \\
\hline Full vs. Placebo & -0.004 & 0.020 & -0.219 & 0.827 \\
\hline Without APT vs. Placebo & 0.025 & 0.020 & 1.243 & 0.214 \\
\hline Either Treatment vs. Placebo & 0.010 & 0.017 & 0.577 & 0.564 \\
\hline Full vs. Without APT & -0.031 & 0.020 & -1.569 & 0.117 \\
\hline \multicolumn{5}{|l|}{ immpolicy_instatetuition } \\
\hline Full vs. Placebo & 0.034 & 0.020 & 1.734 & 0.083 \\
\hline Without APT vs. Placebo & 0.043 & 0.020 & 2.184 & 0.029 \\
\hline Either Treatment vs. Placebo & 0.039 & 0.017 & 2.234 & 0.026 \\
\hline Full vs. Without APT & -0.004 & 0.019 & -0.227 & 0.821 \\
\hline
\end{tabular}




\section{Online Appendix for Experiment 2}

This experiment was pre-registered at the Open Science Framework at https://osf.io/wnf4y/?view_only=f4 e15299b3b6490aab5f466feb5dd8e4.

Training, implementation, and intervention procedures (including scripts) for the Full Intervention, PerspectiveGetting Only, and Placebo conditions are available at https://osf.io/a53pf/?view_only=d8c8308061834f73b1 $4 \mathrm{dd} 40 \mathrm{~b} 30 \mathrm{cb} 5 \mathrm{f} 3 \mathrm{~d}$.

\section{Follow-Up Surveys}

Following the placebo design described above, we conducted multiple waves of follow-up surveys for voters who came to the door in any condition. These follow-up surveys began around 1 week (the $t 2$ survey; median 8 days, SD 2.6 days), 11 weeks (the $t 3$ survey; median 79 days, SD 20.0 days), and approximately 4.5 months (the $t 4$ survey; median 146 days, SD 3.0 days) after the day each voter was canvassed. We solicited voters to complete these re-surveys at the email addresses they provided in the baseline survey. Three reminders to complete the follow-up surveys were sent for each survey wave.

Note that to the extent any voters answered the wrong surveys or did not answer the surveys carefully, this measurement error would lead us to underestimate the true effects of treatment (Gerber and Green, 2012).

The below table shows how the representativeness of those who responded to the survey differ from those mailed an invitation to participate in the survey. These data come from the voter file. Note that except where otherwise noted, no weighting is used in the analysis; the aim of the estimation is to test for the existence of treatment effects within this sample, not to generalize to the population of invited respondents. We do not have access to data on the racial composition of voters in the starting universe and so we only report racial self-identification beginning with the survey on which voters were asked their race.

Table OA22: Representativeness of Experiment at Each Stage

\begin{tabular}{l|l|l|l|l|l}
\hline Sample & Female & Age & Race / Ethnicity is Non-Hispanic White & State $=$ TN & N \\
\hline Starting & 0.52 & 49.93 & NA & 0.51 & 336023 \\
\hline 1st Baseline Resp. & 0.5 & 52.01 & NA & 0.56 & 9340 \\
\hline 2nd Baseline Resp. & 0.49 & 53.04 & 0.81 & 0.56 & 6163 \\
\hline Canvassed & 0.47 & 55.19 & 0.82 & 0.51 & 650 \\
\hline 1 Wk Resp. & 0.47 & 55.23 & 0.85 & 0.52 & 529 \\
\hline 11 Wk Resp. & 0.48 & 55.36 & 0.84 & 0.53 & 518 \\
\hline 4.5 Mo Resp. & 0.47 & 55.18 & 0.84 & 0.53 & 513 \\
\hline
\end{tabular}

\section{Outcomes}

The survey included dozens of political, social, and cultural questions, only some of which were related to immigration and healthcare. In our pre-analysis plan, we indicate which items constituted experimental outcomes. Below we list these items and give their full text.

The below items appeared on multiple surveys; the \# sign below will be replaced with the survey number in our analysis: The first baseline survey is survey 0 ; The second baseline survey is survey 1; the 1-week survey is survey 2 ; the 11 -week survey is survey 3 , and; the 4.5 -month survey is survey 4 . 
The variable name for each item is written using in-line code. For the remainder of the paper, we will refer to these items by their variable names.

- Immigrant Prejudice Index. This index consisted of 8 items related to prejudice towards unauthorized immigrants. In addition to an overall immigrant prejudice index consisting of all 8 items, we also examined three subindices.

- Subindex: Common ingroup identity (e.g., immigrants are part of our community). The first set of questions are five point scales where respondents were asked: "Do you agree or disagree with the below statements about undocumented or illegal immigrants?" Response options were: Strongly agree, Somewhat agree, Neither agree nor disagree, Somewhat disagree, Strongly disagree:

* t\#_immprej_partoflocal: "I would consider any illegal immigrants who live in my neighborhood as part of our local community."

* t\#_immprej_holdsamevalues: "Undocumented immigrants hold the same values as me and my family."

* t\#_immprej_foreignersvs: "There are many unauthorized immigrants to the United States who have been living here for many years. When you think about these immigrants, do you think about them as members of your community, or as foreigners?" The response option was a 1-10 scale ranging from "Foreigners" to "Members of my community".

- Subindex: Negative sentiment. These questions used the same five point scale as above:

* t\#_immprej_noproblemlivingn: "I would have no problem living in areas where undocumented immigrants live."

* t\#_immprej_burdenoncomm: "Undocumented immigrants are a burden on our community."

- Subindex: Empathic Concern (e.g., concern with their suffering) (also reactive empathy)

* t\#_immprej_suffering: "The suffering of some illegal immigrants concerns me."

* t\#_immprej_deservecare: "Undocumented immigrants deserve our care and support."

- Immigrant Policy Index. This index consisted of items related to policy towards unauthorized immigrants. In addition to an overall immigrant policy index consisting of all the items, we also examined four subindices.

- Subindex: Health care (primary subindex in CA site)

* t\#_immpolicy_hc_available: "Health insurance coverage provided by the government should be available to unauthorized immigrants living in the United States."

* t\#_immpolicy_medicaid: "Medicaid is a state-run program that provides health insurance to poor people in [STATE]. Low-income undocumented immigrants in [STATE] should be allowed to receive Medicaid from the state of [STATE]"

- Subindex: Education (primary subindex in TN site)

* t\#_immpolicy_instatetuition: Undocumented immigrants living in [STATE] should be eligible for in-state college tuition at [STATE] state colleges.

* t\#_immpolicy_scholarship: Illegal immigrants who have graduated from a [STATE] high school should be eligible to receive the same scholarships as other [STATE] residents to attend [STATE] state colleges.

- Subindex: Non-healthcare policies

* t\#_immpolicy_foodstamps: Illegal immigrants should be allowed to receive food stamps, a government program that helps low-income people pay for food.

- Subindex: General attitudes

* t\#_immpolicy_donotdeserve: Illegal immigrants have not contributed enough to deserve government assistance.

* t\#_immpolicy_govdowhatcan: The government should do what it can to help undocumented immigrants living in the United States.

* t\#_immpolicy_deportall: The government should work to identify and deport all illegal immigrants.

* t\#_immpolicy_legalstatus: The federal government should grant legal status to people who were brought to the US illegally as children and who have graduated from a U.S. high school.

- Immigrant Action Taking

* t\#_immaction: These days people are busy and often don't have time to do many of the 
things they would like to. Suppose in the next month someone asked you to engage in the following activities. How likely would you be to say yes? [Contact a politician to express my support for undocumented immigrants.] [Extremely likely, Very likely, Somewhat likely, A little likely, Not at all likely].

\section{Outcome Indices}

In our pre-analysis plan, we specified that we would combine multiple items into indices to test hypotheses. Combining outcomes into an index increases precision by decreasing survey measurement error and limits the potential for biases from multiple hypothesis testing (Broockman, Kalla and Sekhon, 2017).

The indices are as follows:

- t\#_overall_factor: An index of all primary outcomes (i.e., all the items in the prejudice and policy indicies), created to test the omnibus hypothesis that the treatment had any effects. We did not pre-register that we would combine all the items across prejudice and policy indicies but we do so to summarize the overall results.

- t\#_prejudice_factor: An index of outcomes from t\#_factor_imm_all_all capturing the Immigrant Prejudice Index.

- t\#_policy_factor: An index of outcomes from t\#_factor_imm_all_all capturing the Immigrant Policy Index.

In addition to an outcome index at each time period, we also present the results of a pooled outcome index tALL_factor_ - taking the average of each outcome index across time periods. If a respondent did not take a particular post-treatment survey, that time period is excluded from the average. Note that this pooled outcome was not pre-specified in our pre-analysis plan. We use this pooled outcome index to increase the precision of our treatment effect estimates through further reductions in measurement error. This pooled outcome is also a useful brief summary of the overall effects.

\section{Estimation Procedures}

\section{Contact Rate}

Contact is defined as the voter coming to the door and being identified before the topics of the placebo or immigration begin. Across the three conditions among voters who responded to the baseline survey and were then randomly assigned to an experimental condition, the contact rates were: Placebo: 0.12 , Perspective-Getting Only Intervention: 0.09, Full Intervention: 0.11.

In the two intervention conditions, we asked the voters to first answer a rating question about healthcare The share of voters who answered this question provides an indication of how often voters actually began the conversation. Conditional on having come to the door, the proportion of voters who provided this first rating is: Perspective-Getting Only Intervention: 0.85, Full Intervention: 0.8.

Across the three conditions, among the voters who came to the door, the canvass completion rates were: Placebo: 0.92, Perspective-Getting Only Intervention: 0.73, Full Intervention: 0.7.

On average, the conversations lasted: Placebo: 2.03 minutes (standard deviation of 4.49 minutes), PerspectiveGetting Only Intervention: 6.44 minutes (standard deviation of 5.08 minutes). Among those who at least provided the first rating, these conversations lasted an average of 7.28 minutes and had a standard deviation of 5.01 minutes, Full Intervention: 14.49 minutes (standard deviation of 11.38 minutes). Among those who at least provided the first rating, these conversations lasted an average of 17.1 minutes and had a standard deviation of 10.7 minutes. 


\section{Tests of Design Assumptions}

\section{Covariate Balance among All Subjects, Compliers, and Reporters}

The below tables demonstrate that balance on pre-treatment observable attributes is maintained among the original universe of pre-survey respondents randomized to each group, the sub-sample that was canvassed, and the sub-sample that was both canvassed and successfully re-interviewed. Each table shows the mean value for the covariate under each condition as well as the $p$-value from a one-way ANOVA test. The first table considers all voters who were randomly assigned after having taken the pre-survey (all subjects); the second table considers all voters who were successfully contacted (compliers); the remaining tables consider all voters who responded to the first through third post-surveys (reporters). There are slight imbalances on age and state among compliers and post-treatment survey responders. However, there is covariate balance on all of the lagged dependent variables gathered in the first and second baseline surveys.

Table OA23: Covariate Balance among 1st and 2nd Baseline Respondents.

\begin{tabular}{l|r|r|r|l}
\hline & Placebo & PG-Only & Full Intervention & p-value \\
\hline Age & 52.64 & 53.18 & 53.29 & 0.4 \\
\hline Female & 0.49 & 0.51 & 0.48 & 0.17 \\
\hline State: TN & 0.56 & 0.56 & 0.56 & 1 \\
\hline 1st Baseline Trump Feeling Therm & 36.78 & 37.24 & 36.57 & 0.86 \\
\hline 1st Baseline Immigration Policy Factor & -0.06 & -0.06 & -0.07 & 0.96 \\
\hline 1st Baseline Immigration Prejudice Factor & -0.05 & -0.04 & -0.06 & 0.82 \\
\hline 2nd Baseline Immigration Policy Factor & -0.05 & -0.06 & -0.06 & 0.88 \\
\hline 2nd Baseline Immigration Prejudice Factor & -0.05 & -0.05 & -0.06 & 0.99 \\
\hline $\mathrm{N}$ & 2053.00 & 2054.00 & 2056.00 & - \\
\hline
\end{tabular}

Table OA24: Covariate Balance among Compliers.

\begin{tabular}{l|r|r|r|l}
\hline & Placebo & PG-Only & Full Intervention & p-value \\
\hline Age & 53.58 & 54.75 & 57.39 & 0.04 \\
\hline Female & 0.45 & 0.50 & 0.46 & 0.57 \\
\hline State: TN & 0.46 & 0.56 & 0.52 & 0.08 \\
\hline 1st Baseline Trump Feeling Therm & 36.99 & 36.16 & 36.79 & 0.98 \\
\hline 1st Baseline Immigration Policy Factor & -0.02 & -0.09 & -0.07 & 0.76 \\
\hline 1st Baseline Immigration Prejudice Factor & 0.05 & -0.05 & -0.07 & 0.38 \\
\hline 2nd Baseline Immigration Policy Factor & 0.01 & -0.13 & -0.07 & 0.33 \\
\hline 2nd Baseline Immigration Prejudice Factor & 0.04 & -0.12 & -0.05 & 0.21 \\
\hline $\mathrm{N}$ & 245.00 & 188.00 & 217.00 & - \\
\hline
\end{tabular}

Table OA25: Covariate Balance among 1st (1 Week) Post-Survey Respondents.

\begin{tabular}{l|r|r|r|l}
\hline & Placebo & PG-Only & Full Intervention & p-value \\
\hline Age & 53.46 & 54.50 & 57.85 & 0.02 \\
\hline Female & 0.45 & 0.48 & 0.48 & 0.77 \\
\hline State: TN & 0.46 & 0.62 & 0.52 & 0.01 \\
\hline 1st Baseline Trump Feeling Therm & 35.30 & 36.79 & 36.57 & 0.93 \\
\hline 1st Baseline Immigration Policy Factor & 0.00 & -0.06 & -0.06 & 0.83 \\
\hline 1st Baseline Immigration Prejudice Factor & 0.07 & -0.04 & -0.07 & 0.31 \\
\hline 2nd Baseline Immigration Policy Factor & 0.04 & -0.07 & -0.06 & 0.5 \\
\hline 2nd Baseline Immigration Prejudice Factor & 0.07 & -0.11 & -0.06 & 0.19 \\
\hline $\mathrm{N}$ & 197.00 & 156.00 & 176.00 & - \\
\hline
\end{tabular}


Table OA26: Covariate Balance among 2nd (11 Week) Post-Survey Respondents.

\begin{tabular}{l|r|r|r|l}
\hline & Placebo & PG-Only & Full Intervention & p-value \\
\hline Age & 53.73 & 54.82 & 57.78 & 0.05 \\
\hline Female & 0.44 & 0.52 & 0.49 & 0.34 \\
\hline State: TN & 0.47 & 0.61 & 0.53 & 0.04 \\
\hline 1st Baseline Trump Feeling Therm & 35.60 & 34.17 & 36.17 & 0.9 \\
\hline 1st Baseline Immigration Policy Factor & -0.01 & 0.00 & -0.09 & 0.66 \\
\hline 1st Baseline Immigration Prejudice Factor & 0.05 & 0.01 & -0.09 & 0.36 \\
\hline 2nd Baseline Immigration Policy Factor & 0.02 & -0.03 & -0.10 & 0.48 \\
\hline 2nd Baseline Immigration Prejudice Factor & 0.05 & -0.05 & -0.08 & 0.38 \\
\hline $\mathrm{N}$ & 197.00 & 154.00 & 167.00 & - \\
\hline
\end{tabular}

Table OA27: Covariate Balance among 3rd (4.5 Month) Post-Survey Respondents.

\begin{tabular}{l|r|r|r|l}
\hline & Placebo & PG-Only & Full Intervention & p-value \\
\hline Age & 53.42 & 54.25 & 58.00 & 0.02 \\
\hline Female & 0.43 & 0.52 & 0.47 & 0.27 \\
\hline State: TN & 0.47 & 0.60 & 0.53 & 0.06 \\
\hline 1st Baseline Trump Feeling Therm & 36.02 & 33.10 & 36.01 & 0.75 \\
\hline 1st Baseline Immigration Policy Factor & 0.00 & -0.01 & -0.08 & 0.7 \\
\hline 1st Baseline Immigration Prejudice Factor & 0.06 & 0.01 & -0.07 & 0.45 \\
\hline 2nd Baseline Immigration Policy Factor & 0.02 & -0.04 & -0.09 & 0.54 \\
\hline 2nd Baseline Immigration Prejudice Factor & 0.05 & -0.05 & -0.05 & 0.46 \\
\hline $\mathrm{N}$ & 189.00 & 155.00 & 169.00 & - \\
\hline
\end{tabular}

\section{Survey Attrition}

An important design assumption is that the treatment does not affect the composition of the individuals who take each follow-up survey (Broockman, Kalla and Sekhon, 2017). We investigate this by regressing an indicator for responding to a post-treatment survey on indicators of treatment assignment. Across the three survey waves, we find some evidence of differential attrition relative to the placebo condition. However, there is no evidence of differential attrition when comparing the two treatments to each other.

Table OA28: Test for differential attrition

\begin{tabular}{l|r|r|r|r}
\hline & Effect & SE & t.stat & p-value \\
\hline 1 Week & -0.02 & 0.01 & -2.29 & 0.02 \\
\hline PG-Only & -0.01 & 0.01 & -1.19 & 0.24 \\
\hline Full Intervention & 0.01 & 0.01 & 1.14 & 0.26 \\
\hline Full vs. PG-Only & \multicolumn{5}{|l}{} \\
\hline 11 Weeks & -0.02 & 0.01 & -2.42 & 0.01 \\
\hline PG-Only & -0.01 & 0.01 & -1.70 & 0.09 \\
\hline Full Intervention & 0.01 & 0.01 & 0.75 & 0.46 \\
\hline Full vs. PG-Only & 0.01 & \\
\hline 4.5 Months & -0.02 & 0.01 & -1.93 & 0.05 \\
\hline PG-Only & -0.01 & 0.01 & -1.14 & 0.25 \\
\hline Full Intervention & 0.01 & 0.01 & 0.80 & 0.42 \\
\hline Full vs. PG-Only & 0
\end{tabular}




\section{Test of Differential Attrition by Covariates}

The above subsection demonstrated that there was some average differential attrition; now, we test for whether the treatment caused attrition to differ by covariates (for example, whether it encouraged already-supportive subjects to complete the post-survey but also discouraged unsupportive subjects from doing so) (Gerber and Green, 2012). To test whether attrition patterns are similar by covariates in treatment and placebo, we use a linear regression of whether or not an individual responded to the follow-up survey on treatment, baseline covariates, and treatment-covariate interactions. We then perform a heteroskedasticity-robust F-test of the hypothesis that all the interaction coefficients are zero. This procedure was pre-specified in our pre-analysis plan and is standard practice (Gerber and Green, 2012). Below we report the p-value of this F-test. Based on the results presented in the Table below, there does not appear to be evidence of asymmetrical attrition.

Table OA29: p-value by Survey Wave Test of Differential Attrition by Covariates.

\begin{tabular}{l|l}
\hline 1 Week Survey (t2) & 0.11 \\
\hline 11 Weeks Survey (t3) & 0.35 \\
\hline 4.5 Month Survey (t4) & 0.12 \\
\hline
\end{tabular}

\section{Results}

Below we report the results in tabular form at each time period and for each outcome measure. In each section, the first table shows the results by the average treatment effect. Each table includes two models: one in which we adjust for the pre-specified pre-treatment covariates to improve precision and a second unadjusted model. Our main specification comes from results with the pre-specified pre-treatment covariates.

\section{Overall Index of Exclusionary Attitudes}

Below we estimate the ATE on the overall index. Note that we pre-registered a focus on the estimates with covariates (which were also pre-registered) since we expected these to be much more precise; the experimental design was intended to draw significant statistical power from the baseline survey. However, we also present results without covariates for completeness.

Table OA30: ATE effects on overall index

\begin{tabular}{|c|c|c|c|c|c|c|c|c|}
\hline & \multicolumn{4}{|c|}{ With Covariates } & \multicolumn{4}{|c|}{ Without Covariates } \\
\hline & Effect & $\mathrm{SE}$ & t.stat & p-value & Effect & $\mathrm{SE}$ & t.stat & $\mathrm{p}$-value \\
\hline \multicolumn{9}{|l|}{1 Week } \\
\hline PG-Only vs. Placebo & 0.120 & 0.036 & 3.351 & 0.001 & 0.014 & 0.111 & 0.128 & 0.898 \\
\hline Full Intervention vs. Placebo & 0.091 & 0.030 & 2.986 & 0.003 & -0.012 & 0.109 & -0.109 & 0.913 \\
\hline Full Intervention vs. PG-Only & -0.029 & 0.039 & -0.750 & 0.454 & -0.026 & 0.114 & -0.229 & 0.819 \\
\hline \multicolumn{9}{|l|}{11 Weeks } \\
\hline PG-Only vs. Placebo & 0.064 & 0.038 & 1.690 & 0.092 & 0.019 & 0.110 & 0.173 & 0.863 \\
\hline Full Intervention vs. Placebo & 0.108 & 0.039 & 2.740 & 0.006 & -0.010 & 0.110 & -0.093 & 0.926 \\
\hline Full Intervention vs. PG-Only & 0.032 & 0.046 & 0.706 & 0.481 & -0.029 & 0.112 & -0.261 & 0.794 \\
\hline \multicolumn{9}{|l|}{ 4.5 Months } \\
\hline PG-Only vs. Placebo & 0.045 & 0.039 & 1.170 & 0.242 & -0.012 & 0.113 & -0.110 & 0.912 \\
\hline Full Intervention vs. Placebo & 0.066 & 0.036 & 1.816 & 0.070 & -0.039 & 0.112 & -0.349 & 0.727 \\
\hline Full Intervention vs. PG-Only & 0.012 & 0.043 & 0.286 & 0.775 & -0.026 & 0.113 & -0.234 & 0.816 \\
\hline \multicolumn{9}{|l|}{ Pooled } \\
\hline PG-Only vs. Placebo & 0.069 & 0.032 & 2.168 & 0.031 & -0.012 & 0.106 & -0.115 & 0.909 \\
\hline Full Intervention vs. Placebo & 0.094 & 0.029 & 3.237 & 0.001 & 0.008 & 0.104 & 0.075 & 0.940 \\
\hline Full Intervention vs. PG-Only & 0.020 & 0.037 & 0.549 & 0.583 & 0.020 & 0.107 & 0.187 & 0.852 \\
\hline
\end{tabular}




\section{Prejudice Index}

Below we estimate the ATE on the overall prejudice index.

Table OA31: ATE effects on prejudice index

\begin{tabular}{|c|c|c|c|c|c|c|c|c|}
\hline & \multicolumn{4}{|c|}{ With Covariates } & \multicolumn{4}{|c|}{ Without Covariates } \\
\hline & Effect & $\mathrm{SE}$ & t.stat & p-value & Effect & $\mathrm{SE}$ & t.stat & p-value \\
\hline \multicolumn{9}{|l|}{1 Week } \\
\hline PG-Only vs. Placebo & 0.118 & 0.043 & 2.764 & 0.006 & -0.018 & 0.111 & -0.158 & 0.874 \\
\hline Full Intervention vs. Placebo & 0.071 & 0.039 & 1.820 & 0.069 & -0.059 & 0.110 & -0.539 & 0.590 \\
\hline Full Intervention vs. PG-Only & -0.052 & 0.047 & -1.102 & 0.271 & -0.042 & 0.114 & -0.365 & 0.716 \\
\hline \multicolumn{9}{|l|}{11 Weeks } \\
\hline PG-Only vs. Placebo & 0.104 & 0.048 & 2.187 & 0.029 & 0.050 & 0.110 & 0.455 & 0.649 \\
\hline Full Intervention vs. Placebo & 0.095 & 0.048 & 1.959 & 0.051 & -0.029 & 0.111 & -0.261 & 0.794 \\
\hline Full Intervention vs. PG-Only & -0.019 & 0.054 & -0.347 & 0.729 & -0.079 & 0.112 & -0.705 & 0.481 \\
\hline \multicolumn{9}{|l|}{4.5 Months } \\
\hline PG-Only vs. Placebo & 0.067 & 0.044 & 1.525 & 0.128 & -0.002 & 0.112 & -0.018 & 0.986 \\
\hline Full Intervention vs. Placebo & 0.070 & 0.046 & 1.518 & 0.130 & -0.040 & 0.112 & -0.354 & 0.723 \\
\hline Full Intervention vs. PG-Only & -0.020 & 0.048 & -0.416 & 0.678 & -0.038 & 0.113 & -0.333 & 0.739 \\
\hline \multicolumn{9}{|l|}{ Pooled } \\
\hline PG-Only vs. Placebo & 0.082 & 0.038 & 2.183 & 0.029 & -0.012 & 0.106 & -0.116 & 0.907 \\
\hline Full Intervention vs. Placebo & 0.084 & 0.036 & 2.313 & 0.021 & -0.021 & 0.104 & -0.205 & 0.837 \\
\hline Full Intervention vs. PG-Only & -0.004 & 0.042 & -0.087 & 0.931 & -0.009 & 0.106 & -0.086 & 0.932 \\
\hline
\end{tabular}

\section{Policy Index}

Below we estimate the ATE on the policy index.

Table OA32: ATE effects on policy index

\begin{tabular}{|c|c|c|c|c|c|c|c|c|}
\hline & \multicolumn{4}{|c|}{ With Covariates } & \multicolumn{4}{|c|}{ Without Covariates } \\
\hline & Effect & $\mathrm{SE}$ & t.stat & $\mathrm{p}$-value & Effect & $\mathrm{SE}$ & t.stat & $\mathrm{p}$-value \\
\hline \multicolumn{9}{|l|}{1 Week } \\
\hline PG-Only vs. Placebo & 0.113 & 0.040 & 2.799 & 0.005 & 0.036 & 0.111 & 0.328 & 0.743 \\
\hline Full Intervention vs. Placebo & 0.102 & 0.034 & 2.969 & 0.003 & 0.024 & 0.108 & 0.222 & 0.825 \\
\hline Full Intervention vs. PG-Only & -0.008 & 0.041 & -0.197 & 0.844 & -0.012 & 0.113 & -0.109 & 0.913 \\
\hline \multicolumn{9}{|l|}{11 Weeks } \\
\hline PG-Only vs. Placebo & 0.029 & 0.043 & 0.687 & 0.492 & -0.006 & 0.110 & -0.056 & 0.955 \\
\hline Full Intervention vs. Placebo & 0.106 & 0.042 & 2.514 & 0.012 & -0.001 & 0.109 & -0.009 & 0.993 \\
\hline Full Intervention vs. PG-Only & 0.066 & 0.052 & 1.266 & 0.207 & 0.005 & 0.113 & 0.046 & 0.964 \\
\hline \multicolumn{9}{|l|}{4.5 Months } \\
\hline PG-Only vs. Placebo & 0.029 & 0.043 & 0.681 & 0.496 & -0.017 & 0.112 & -0.155 & 0.877 \\
\hline Full Intervention vs. Placebo & 0.061 & 0.039 & 1.555 & 0.120 & -0.035 & 0.111 & -0.312 & 0.755 \\
\hline Full Intervention vs. PG-Only & 0.032 & 0.049 & 0.653 & 0.514 & -0.017 & 0.113 & -0.153 & 0.879 \\
\hline \multicolumn{9}{|l|}{ Pooled } \\
\hline PG-Only vs. Placebo & 0.056 & 0.035 & 1.601 & 0.110 & -0.012 & 0.106 & -0.110 & 0.912 \\
\hline Full Intervention vs. Placebo & 0.097 & 0.031 & 3.086 & 0.002 & 0.028 & 0.103 & 0.268 & 0.789 \\
\hline Full Intervention vs. PG-Only & 0.036 & 0.041 & 0.885 & 0.377 & 0.039 & 0.106 & 0.370 & 0.712 \\
\hline
\end{tabular}

\section{Complier Average Causal Effects}

We understand some readers will be interested in a CACE. To compute a CACE, we use a conservative definition of compliance, whether subjects got to the "first rating" part of the conversation where they initially 
told canvassers how they felt about the policy. Using this definition of compliance, the compliance rate in the Full Intervention condition was $78 \%$ and the contact rate in the PG-Only Intervention condition was $86 \%$. The ITT point estimates should therefore be multiplied by 1.28 and 1.16 in the Full and PG-Only interventions, respectively, to compute the CACE. That is, given a true effect on compliers of 1.28 and 1.16 times the size of the ATEs we observed, we would on average estimate ATEs of the magnitude that we did. These imply CACE estimates in the Full and PG-Only intervention conditions of, respectively, $d=0.088$ and $\mathrm{d}=0.109$ on the overall index pooled across all time periods.

\section{Heterogeneous Treatment Effects}

In this section we present heterogeneous treatment effects by pre-specified subgroups. For each result, we present the conditional average treatment effect, adjusting for covariates, within each subgroup. As the outcome in these analyses we use the index of all the items in the prejudice and policy indices as measured in the first post-treatment survey.

Canvasser Immigration Status Below are results by the immigration status of the canvasser. All canvassers completed a demographic survey in which they were asked "Do you consider yourself to be an immigrant?" Responses are coded as 1 for yes and 0 for all other responses. $9 \%$ of canvassers identified as immigrants.

Table OA33: Heterogeneous treatment effects by Canvasser is an immigrant

\begin{tabular}{l|r|r|r|r|r|r|r|r}
\hline & \multicolumn{4}{|c|}{ Canvasser is an immigrant $=1$} & \multicolumn{4}{c}{ Canvasser is an immigrant $=0$} \\
\cline { 2 - 9 } & Effect & SE & t.stat & p-value & Effect & SE & t.stat & p-value \\
\hline PG-Only & 0.04 & 0.34 & 0.12 & 0.91 & 0.10 & 0.04 & 2.73 & 0.01 \\
\hline Full Intervention & 0.44 & 0.30 & 1.43 & 0.20 & 0.07 & 0.03 & 2.40 & 0.02 \\
\hline
\end{tabular}

Canvasser Race Below are results by the race of the canvasser. All canvassers completed a demographic survey in which they were asked "What is your race?" Responses are coded as 1 for any non-White selfidentification and 0 for all other responses. $75 \%$ of canvassers identified as people of color. The differences between the effects for canvassers of color and white canvassers are too imprecise to conclusively determine whether their effects are either identical or meaningfully different.

Table OA34: Heterogeneous treatment effects by Canvasser identifies as a person of color

\begin{tabular}{l|r|r|r|r|r|r|r|r}
\hline & \multicolumn{4}{|c|}{ Canvasser identifies as a person of color $=1$} & \multicolumn{4}{|c}{ Canvasser identifies as a person of color $=0$} \\
\cline { 2 - 8 } & Effect & SE & t.stat & p-value & Effect & SE & t.stat & p-value \\
\hline PG-Only & 0.14 & 0.04 & 3.27 & 0.00 & 0.07 & 0.09 & 0.74 & 0.46 \\
\hline Full Intervention & 0.09 & 0.04 & 2.44 & 0.01 & 0.09 & 0.07 & 1.30 & 0.20 \\
\hline
\end{tabular}

By voter's baseline partisanship Below are the results by the voter's baseline partisanship. 33\% of voters identified as Democrats (excluding leaners). $32 \%$ of voters identified as Republicans (excluding leaners). $35 \%$ of voters identified as Independents or others.

Table OA35: Heterogeneous treatment effects by Voter Partisanship

\begin{tabular}{l|r|r|r|r|r|r|r|r|r|r|r|r}
\hline & \multicolumn{4}{|c|}{ Democrat } & \multicolumn{4}{c|}{ Republican } & \multicolumn{4}{c}{ Independent/Other } \\
\cline { 2 - 29 } & Effect & SE & t.stat & p-value & Effect & SE & t.stat & p-value & Effect & SE & t.stat & p-value \\
\hline PG-Only & 0.09 & 0.05 & 1.65 & 0.1 & 0.13 & 0.07 & 1.92 & 0.06 & 0.12 & 0.06 & 1.91 & 0.06 \\
\hline Full Intervention & 0.05 & 0.05 & 1.04 & 0.3 & 0.10 & 0.06 & 1.62 & 0.11 & 0.12 & 0.07 & 1.74 & 0.08 \\
\hline
\end{tabular}

By voter's baseline ideology Below are the results by the voter's baseline ideology $34 \%$ of voters identified as liberals. $40 \%$ of voters identified as conservatives. $26 \%$ of voters identified as moderators or others. 
Table OA36: Heterogeneous treatment effects by Voter Ideology

\begin{tabular}{l|r|r|r|r|r|r|r|r|r|r|r|r}
\hline & \multicolumn{4}{|c|}{ Liberals } & \multicolumn{4}{c|}{ Conservatives } & \multicolumn{4}{c}{ Moderates } \\
\cline { 2 - 27 } & Effect & SE & t.stat & p-value & Effect & SE & t.stat & p-value & Effect & SE & t.stat & p-value \\
\hline PG-Only & 0.17 & 0.05 & 3.36 & 0.00 & 0.13 & 0.06 & 2.45 & 0.01 & -0.02 & 0.09 & -0.21 & 0.83 \\
\hline Full Intervention & 0.06 & 0.05 & 1.37 & 0.17 & 0.06 & 0.05 & 1.32 & 0.19 & 0.14 & 0.08 & 1.74 & 0.09 \\
\hline
\end{tabular}

By voter's baseline 2020 Presidential vote intention Below are results by 2020 Presidential vote intention at baseline. $52 \%$ of voters identified as likely Trump voters, $10 \%$ of voters identified as undecided voters, and $38 \%$ of voters identified as likely Democratic voters (at the time of the survey, Biden had not yet won the 2020 Democratic presidential nomination). We combine Democratic and undecided voters because there are so few undecided voters.

Table OA37: Heterogeneous treatment effects by 2020 Vote Choice $=$ Trump

\begin{tabular}{l|r|r|r|r|r|r|r|r}
\hline & \multicolumn{4}{|c|}{2020 Vote Choice $=$ Trump $=1$} & \multicolumn{4}{|c}{ 2020 Vote Choice $=$ Trump $=0$} \\
\cline { 2 - 9 } & Effect & SE & t.stat & p-value & Effect & SE & t.stat & p-value \\
\hline PG-Only & 0.14 & 0.05 & 3.17 & 0 & 0.11 & 0.05 & 2.08 & 0.04 \\
\hline Full Intervention & 0.11 & 0.04 & 2.80 & 0 & 0.07 & 0.05 & 1.47 & 0.14 \\
\hline
\end{tabular}

By voter's baseline education Below are results by the education level of voters at baseline. $68 \%$ of voters identified as receiving a college degree. All other responses are coded together.

Table OA38: Heterogeneous treatment effects by College educated

\begin{tabular}{l|r|r|r|r|r|r|r|r}
\hline & \multicolumn{4}{|c|}{ College educated $=1$} & \multicolumn{4}{c}{ College educated =0 } \\
\cline { 2 - 9 } & Effect & SE & t.stat & p-value & Effect & SE & t.stat & p-value \\
\hline PG-Only & 0.04 & 0.04 & 1.00 & 0.32 & 0.14 & 0.06 & 2.19 & 0.03 \\
\hline Full Intervention & 0.09 & 0.04 & 2.31 & 0.02 & 0.02 & 0.06 & 0.27 & 0.79 \\
\hline
\end{tabular}

By voter's prior contact with undocumented immigrants Below are results by whether the voter self-reported having "any close friends, colleagues, or family members who are illegal or undocumented immigrants". $13 \%$ of voters identified as knowing an undocumented immigrant. All other responses (No, Not sure, Would rather not say) are coded together.

Table OA39: Heterogeneous treatment effects by Prior contact

\begin{tabular}{l|r|r|r|r|r|r|r|r}
\hline & \multicolumn{4}{|c|}{ Prior contact $=1$} & \multicolumn{4}{c}{ Prior contact $=0$} \\
\cline { 2 - 9 } & Effect & SE & t.stat & p-value & Effect & SE & t.stat & p-value \\
\hline PG-Only & 0.17 & 0.10 & 1.76 & 0.09 & 0.11 & 0.04 & 2.83 & 0 \\
\hline Full Intervention & -0.03 & 0.12 & -0.22 & 0.83 & 0.11 & 0.03 & 3.19 & 0 \\
\hline
\end{tabular}

Site-specific subindex, by site The script in California discussed healthcare policy (including undocumented immigrants in Medicaid) while the script in Tennessee discussed education policy (in-state tuition for undocumented immigrants at state colleges). As a result, the PAP indicated that we would test a healthcare and education subindex, respectively, in California and Tennessee, respectively.

Table OA40: Heterogeneous treatment effects by California (on CA Subindex)

\begin{tabular}{l|r|r|r|r|r|r|r|r}
\hline & \multicolumn{4}{|c|}{ California (on CA Subindex) $=1$} & \multicolumn{4}{c}{ California (on CA Subindex) $=0$} \\
\cline { 2 - 9 } & Effect & SE & t.stat & p-value & Effect & SE & t.stat & p-value \\
\hline PG-Only & 0.08 & 0.08 & 1.03 & 0.30 & 0.11 & 0.07 & 1.46 & 0.15 \\
\hline Full Intervention & 0.05 & 0.07 & 0.71 & 0.48 & 0.09 & 0.07 & 1.26 & 0.21 \\
\hline
\end{tabular}


Table OA41: Heterogeneous treatment effects by Tennessee (on TN Subindex)

\begin{tabular}{l|r|r|r|r|r|r|r|r}
\hline & \multicolumn{4}{|c|}{ Tennessee (on TN Subindex) $=1$} & \multicolumn{4}{|c}{ Tennessee (on TN Subindex) $=0$} \\
\cline { 2 - 9 } & Effect & SE & t.stat & p-value & Effect & SE & t.stat & p-value \\
\hline PG-Only & 0.34 & 0.09 & 3.98 & 0 & 0.00 & 0.08 & 0.06 & 0.95 \\
\hline Full Intervention & 0.32 & 0.08 & 4.12 & 0 & 0.08 & 0.07 & 1.12 & 0.26 \\
\hline
\end{tabular}

\section{Results with Weights}

To estimate the PATE, we first construct weights of who was canvassed and took the survey relative to the starting universe. We construct these weights using entropy balancing (Hainmueller, 2012) and weight on gender, age, and state. Below are results with and without these weights, showing that the estimated SATEs and PATEs are similar. Note that this analysis was not pre-registered but follows the same procedure as used in previous work by Kalla and Broockman (2020).

Table OA42: ATE Effects on Overall Index with Weights

\begin{tabular}{|c|c|c|c|c|c|c|c|c|}
\hline & \multicolumn{4}{|c|}{ Unweighted } & \multicolumn{4}{|c|}{ Weighted } \\
\hline & Effect & $\mathrm{SE}$ & t.stat & $\mathrm{p}$-value & Effect & $\mathrm{SE}$ & t.stat & $\mathrm{p}$-value \\
\hline \multicolumn{9}{|l|}{1 Week } \\
\hline PG-Only vs. Placebo & 0.120 & 0.036 & 3.351 & 0.001 & 0.123 & 0.036 & 3.383 & 0.001 \\
\hline Full vs. Placebo & 0.091 & 0.031 & 2.986 & 0.003 & 0.090 & 0.031 & 2.904 & 0.004 \\
\hline \multicolumn{9}{|l|}{11 Weeks } \\
\hline PG-Only vs. Placebo & 0.064 & 0.038 & 1.690 & 0.092 & 0.071 & 0.038 & 1.840 & 0.066 \\
\hline Full vs. Placebo & 0.107 & 0.039 & 2.741 & 0.006 & 0.109 & 0.040 & 2.750 & 0.006 \\
\hline \multicolumn{9}{|l|}{4.5 Months } \\
\hline PG-Only vs. Placebo & 0.045 & 0.039 & 1.170 & 0.243 & 0.053 & 0.038 & 1.405 & 0.161 \\
\hline Full vs. Placebo & 0.066 & 0.036 & 1.817 & 0.070 & 0.067 & 0.036 & 1.853 & 0.064 \\
\hline
\end{tabular}

\section{Estimates by Individual Policy Items}

We dichotomize each variable to record whether participants registered any support (not only strong agreement). These new dichotomized variables are coded to 1 if a participant agreed at all with the policy (Somewhat or Strongly agree) and 0 otherwise (indicating stated indifference or opposition). We reverse code immolicy_donotdeserve and immpolicy_deportall. 
Table OA43: Effect on individual policy items (t2, at all)

\begin{tabular}{|c|c|c|c|c|}
\hline & \multicolumn{4}{|c|}{ With Covariates } \\
\hline & Effect & $\mathrm{SE}$ & t.stat & p-value \\
\hline \multicolumn{5}{|l|}{ immpolicy_scholarship } \\
\hline Full vs. Placebo & 0.127 & 0.037 & 3.436 & 0.001 \\
\hline PG-Only vs. Placebo & 0.080 & 0.033 & 2.422 & 0.016 \\
\hline Either Treatment vs. Placebo & 0.102 & 0.030 & 3.393 & 0.001 \\
\hline Full vs. PG-Only & -0.034 & 0.036 & -0.940 & 0.348 \\
\hline \multicolumn{5}{|l|}{ immpolicy_donotdeserve } \\
\hline Full vs. Placebo & 0.078 & 0.041 & 1.891 & 0.059 \\
\hline PG-Only vs. Placebo & -0.033 & 0.036 & -0.900 & 0.369 \\
\hline Either Treatment vs. Placebo & 0.019 & 0.032 & 0.585 & 0.559 \\
\hline Full vs. PG-Only & -0.112 & 0.045 & -2.509 & 0.013 \\
\hline \multicolumn{5}{|l|}{ immpolicy_govdowhatcan } \\
\hline Full vs. Placebo & 0.052 & 0.040 & 1.306 & 0.192 \\
\hline PG-Only vs. Placebo & 0.074 & 0.034 & 2.147 & 0.032 \\
\hline Either Treatment vs. Placebo & 0.064 & 0.031 & 2.032 & 0.043 \\
\hline Full vs. PG-Only & 0.029 & 0.040 & 0.722 & 0.471 \\
\hline \multicolumn{5}{|l|}{ immpolicy_instatetuition } \\
\hline Full vs. Placebo & 0.074 & 0.039 & 1.919 & 0.056 \\
\hline PG-Only vs. Placebo & 0.077 & 0.034 & 2.259 & 0.024 \\
\hline Either Treatment vs. Placebo & 0.075 & 0.030 & 2.484 & 0.013 \\
\hline Full vs. PG-Only & 0.008 & 0.039 & 0.213 & 0.831 \\
\hline \multicolumn{5}{|l|}{ immpolicy_foodstamps } \\
\hline Full vs. Placebo & 0.005 & 0.034 & 0.144 & 0.885 \\
\hline PG-Only vs. Placebo & 0.012 & 0.032 & 0.389 & 0.697 \\
\hline Either Treatment vs. Placebo & 0.009 & 0.028 & 0.322 & 0.748 \\
\hline Full vs. PG-Only & 0.010 & 0.037 & 0.283 & 0.778 \\
\hline \multicolumn{5}{|l|}{ immpolicy_deportall } \\
\hline Full vs. Placebo & 0.023 & 0.039 & 0.607 & 0.544 \\
\hline PG-Only vs. Placebo & 0.050 & 0.037 & 1.348 & 0.178 \\
\hline Either Treatment vs. Placebo & 0.037 & 0.032 & 1.174 & 0.241 \\
\hline Full vs. PG-Only & 0.036 & 0.040 & 0.888 & 0.375 \\
\hline \multicolumn{5}{|l|}{ immpolicy_legalstatus } \\
\hline Full vs. Placebo & 0.035 & 0.039 & 0.904 & 0.366 \\
\hline PG-Only vs. Placebo & 0.042 & 0.039 & 1.068 & 0.286 \\
\hline Either Treatment vs. Placebo & 0.039 & 0.034 & 1.136 & 0.257 \\
\hline Full vs. PG-Only & 0.017 & 0.038 & 0.432 & 0.666 \\
\hline \multicolumn{5}{|l|}{ immpolicy_hc_available } \\
\hline Full vs. Placebo & 0.048 & 0.033 & 1.473 & 0.141 \\
\hline PG-Only vs. Placebo & 0.024 & 0.031 & 0.777 & 0.438 \\
\hline Either Treatment vs. Placebo & 0.035 & 0.027 & 1.308 & 0.191 \\
\hline Full vs. PG-Only & -0.027 & 0.035 & -0.771 & 0.441 \\
\hline \multicolumn{5}{|l|}{ immpolicy_medicaid } \\
\hline Full vs. Placebo & 0.041 & 0.033 & 1.252 & 0.211 \\
\hline PG-Only vs. Placebo & 0.055 & 0.030 & 1.792 & 0.074 \\
\hline Either Treatment vs. Placebo & 0.048 & 0.026 & 1.828 & 0.068 \\
\hline Full vs. PG-Only & 0.007 & 0.036 & 0.189 & 0.850 \\
\hline
\end{tabular}




\section{References}

Broockman, David E, Joshua L Kalla and Jasjeet S Sekhon. 2017. "The design of field experiments with survey outcomes: A framework for selecting more efficient, robust, and ethical designs." Political Analysis $25(4): 435-464$.

Gerber, Alan S and Donald P Green. 2012. Field experiments: Design, analysis, and interpretation. WW Norton.

Hainmueller, Jens. 2012. "Entropy balancing for causal effects: A multivariate reweighting method to produce balanced samples in observational studies." Political Analysis 20(1):25-46.

Kalla, Joshua L and David E Broockman. 2020. "Reducing Exclusionary Attitudes through Interpersonal Conversation: Evidence from three field experiments." American Political Science Review . 


\section{Online Appendix C. Online Appendix for Study 3: Phone Difference-in-Differences Study}

This experiment was pre-registered at https://osf.io/uwafr/?view only=2bb216db90374578bc99f98d254d5999.

\section{Background and Implementation}

Due to the COVID-19 pandemic, we had to stop the in-person canvassing in Experiment 2 early and conducted a new phone study instead. Due to a limited budget and sample size, this phone study uses a difference-in-differences design. In Study 3, we included the uncontacted voters from Experiment 2 who had completed both baseline surveys and had a phone number on the voter file in this study ( $\mathrm{n}=$ 3,438 ). All of these voters were attempted with a phone call. 97 had a partial conversation and 274 had a completed conversation. The remainder were not reached.

To implement the study, we first randomly assigned voters into four equally sized lists. Lists were contacted over a course of a week. After a week, voters both reached and not reached in that list were contacted for two post-conversations surveys. On average, the post-call surveys were conducted 6 days (standard deviation of 3 days; median of 5.5 days; $\mathrm{N}=2,460$ ) and 45 days (standard deviation of 3 days; median of 44 days; $\mathrm{N}=2,484$ ) after the calling took place. The scripts used are available at https://osf.io/uwafr/?view_only=2bb216db90374578bc99f98d254d5999. Of the 274 completed conversations, we have data on the length of 265 of the conversations; the completed conversations lasted an average of 15.6 minutes with a median of 14 minutes.

\section{Outcome Measures}

As stated in the pre-analysis plan, we have two main outcome measures for this experiment: agreement with the following two statements (coded on a 5-point scale):

- Medicaid is a state-run program that provides health insurance to low-income people in [STATE]. Low-income undocumented immigrants in [STATE] should be allowed to receive Medicaid from the state of [STATE].

- Health insurance coverage provided by the government should be available to unauthorized immigrants living in the United States.

We also create a policy index, in which we combine these two items with the following additional statements:

- Illegal immigrants have not contributed enough to deserve access to government programs.

- The government should do what it can to help undocumented immigrants living in the United States.

We create the index by taking the first-dimension from a factor analysis based on the data from the two baseline surveys. We then standardize this index to have mean 0, SD 1 across all of the data.

We also create a prejudice index, in which we use the same procedure to combine the following statements:

- The suffering of some illegal immigrants concerns me.

- Undocumented immigrants deserve our care and support.

Finally, we also create an overall index based on a factor analysis of all of the above six statements.

\section{Test of Design Assumptions: No Pre-Treatment Trends}

We first investigate whether parallel trends hold in the pre-call period by investigating whether there is an effect of being called after the second baseline survey on second baseline survey attitudes. As we show in the below table, we estimate no meaningful treatment effects in the baseline period. 
Table OA44: Testing for Pre-Treatment Trends

\begin{tabular}{|c|c|c|c|c|c|}
\hline & $\begin{array}{c}\text { (1) } \\
\text { Medicaid } \\
\text { DV }\end{array}$ & $\begin{array}{c}\text { (2) } \\
\text { Health } \\
\text { Insurance DV }\end{array}$ & $\begin{array}{c}\text { (3) } \\
\text { Overall } \\
\text { Factor }\end{array}$ & $\begin{array}{c}(4) \\
\text { Policy } \\
\text { Factor } \\
\end{array}$ & $\begin{array}{c}(5) \\
\text { Prejudice } \\
\text { Factor }\end{array}$ \\
\hline Wave \#1 & $\begin{array}{c}0.01 \\
(0.02)\end{array}$ & $\begin{array}{c}0.11 * * * \\
(0.02)\end{array}$ & $\begin{array}{c}0.03 * * * \\
(0.01)\end{array}$ & $\begin{array}{c}0.03 * * * \\
(0.01)\end{array}$ & $\begin{array}{c}0.05 * * * \\
(0.01)\end{array}$ \\
\hline Wave*Reached & $\begin{array}{c}0.04 \\
(0.07)\end{array}$ & $\begin{array}{c}0.04 \\
(0.06)\end{array}$ & $\begin{array}{c}0.01 \\
(0.03)\end{array}$ & $\begin{array}{c}0.02 \\
(0.03)\end{array}$ & $\begin{array}{l}-0.04 \\
(0.04)\end{array}$ \\
\hline Constant & $\begin{array}{c}2.45^{* * * *} \\
(0.01)\end{array}$ & $\begin{array}{c}2.44 * * * \\
(0.01)\end{array}$ & $\begin{array}{c}-0.05 * * * \\
(0.00)\end{array}$ & $\begin{array}{c}-0.05 * * * \\
(0.00)\end{array}$ & $\begin{array}{c}-0.03 * * * \\
(0.01)\end{array}$ \\
\hline $\begin{array}{l}\text { Respondent X Time } \\
\text { Observations }\end{array}$ & 5,450 & 5,450 & 5,450 & 5,450 & 5,450 \\
\hline R-squared & 0.00 & 0.01 & 0.01 & 0.01 & 0.01 \\
\hline $\begin{array}{l}\text { Number of Unique } \\
\text { Respondents }\end{array}$ & 2,725 & 2,725 & 2,725 & 2,725 & 2,725 \\
\hline
\end{tabular}

$$
\text { Cluster-robust standard errors in parentheses. }{ }^{* * *} \mathrm{p}<0.01,{ }^{* *} \mathrm{p}<0.05,{ }^{*} \mathrm{p}<0.1
$$

Test of Design Assumptions: No Effect on Placebo Outcomes

We investigate whether being called has an effect on the likelihood of stating one would take political action on unrelated issues. Given the intervention is about immigration, we do not expect to find an effect on these other outcomes. Indeed, as we show in the below table, we find no effect on any of these placebo outcomes. The placebo outcomes we look at are: Contact a politician to express my support for renewable energy.; Contact a politician to express my support for lowering taxes; Contact a politician to express my support for the right to buy and own guns.; Marriages between same-sex couples should be recognized as valid, with the same rights as traditional marriages.; Gay and lesbian relations between consenting adults should be legal.; Same-sex couples should be banned from adopting children.

Table OA45: Testing for Effects on Placebo Outcomes

\begin{tabular}{|c|c|c|c|c|c|c|}
\hline & $\begin{array}{c}(1) \\
\text { Contact: } \\
\text { Energy }\end{array}$ & $\begin{array}{c}(2) \\
\text { Contact: } \\
\text { Taxes }\end{array}$ & $\begin{array}{c}\text { (3) } \\
\text { Contact: } \\
\text { Guns }\end{array}$ & $\begin{array}{c}(4) \\
\text { LGBT: } \\
\text { Marriage }\end{array}$ & $\begin{array}{c}(5) \\
\text { LGBT: } \\
\text { Legal }\end{array}$ & $\begin{array}{c}(6) \\
\text { LGBT: } \\
\text { Adoption }\end{array}$ \\
\hline Wave \#1 & $\begin{array}{c}-0.09 * * * \\
(0.02)\end{array}$ & $\begin{array}{c}0.04 \\
(0.02)\end{array}$ & $\begin{array}{c}0.10 * * * \\
(0.02)\end{array}$ & $\begin{array}{c}0.05^{* * * *} \\
(0.01)\end{array}$ & $\begin{array}{l}-0.00 \\
(0.02)\end{array}$ & $\begin{array}{c}0.04 * * * \\
(0.02)\end{array}$ \\
\hline Wave \#2 & $\begin{array}{l}0.04^{*} \\
(0.02)\end{array}$ & $\begin{array}{c}0.01 \\
(0.02)\end{array}$ & $\begin{array}{c}0.01 \\
(0.02)\end{array}$ & $\begin{array}{l}-0.02 \\
(0.02)\end{array}$ & $\begin{array}{l}-0.01 \\
(0.02)\end{array}$ & $\begin{array}{c}-0.03^{* * *} \\
(0.02)\end{array}$ \\
\hline Post & $\begin{array}{c}-0.29 * * * \\
(0.02)\end{array}$ & $\begin{array}{c}-0.14 * * * \\
(0.02)\end{array}$ & $\begin{array}{c}0.07 * * * \\
(0.02)\end{array}$ & $\begin{array}{c}0.05^{* * *} \\
(0.02)\end{array}$ & $\begin{array}{l}-0.02 \\
(0.02)\end{array}$ & $\begin{array}{c}0.05 * * * \\
(0.02)\end{array}$ \\
\hline Post*Reached & $\begin{array}{l}-0.02 \\
(0.06)\end{array}$ & $\begin{array}{l}-0.06 \\
(0.07)\end{array}$ & $\begin{array}{c}0.02 \\
(0.06)\end{array}$ & $\begin{array}{l}-0.04 \\
(0.04)\end{array}$ & $\begin{array}{l}-0.02 \\
(0.04)\end{array}$ & $\begin{array}{l}0.01 \\
(0.05)\end{array}$ \\
\hline Constant & $\begin{array}{c}2.76^{* * *} \\
(0.01)\end{array}$ & $\begin{array}{c}2.57 * * * \\
(0.01)\end{array}$ & $\begin{array}{c}2.03 * * * \\
(0.01)\end{array}$ & $\begin{array}{c}3.89 * * * \\
(0.01)\end{array}$ & $\begin{array}{c}4.28 * * * \\
(0.01)\end{array}$ & $\begin{array}{c}1.96 * * * \\
(0.01)\end{array}$ \\
\hline $\begin{array}{l}\text { Respondent X Time } \\
\text { Observations }\end{array}$ & 10,334 & 10,334 & 10,334 & 10,353 & 10,353 & 10,353 \\
\hline R-squared & 0.03 & 0.01 & 0.00 & 0.00 & 0.00 & 0.00 \\
\hline $\begin{array}{l}\text { Number of Unique } \\
\text { Respondents }\end{array}$ & 2,725 & 2,725 & 2,725 & 2,725 & 2,725 & 2,725 \\
\hline
\end{tabular}


Results

The below table shows our primary results. Across the two individual policy outcome measures and the three factors, we consistently estimate large and statistically significant effects of the calls on immigration attitudes. To improve the interpretability of these results, we can recode the Medicaid and health insurance DVs to reflect a support margin: -1 for opposing the policy; 0 for being unsure; 1 for supporting the policy. On this trichotomized measure reflecting a vote margin, we estimate a treatment effect of 11.9 percentage points on the Medicaid outcome $(\mathrm{SE}=4.6 ; \mathrm{p}=0.01)$ and 10.9 percentage points on the health insurance outcome $(\mathrm{SE}=4.4 ; \mathrm{p}=0.01)$.

Table OA46: Main Results from Study 3

\begin{tabular}{|c|c|c|c|c|c|}
\hline & $\begin{array}{c}(1) \\
\text { Medicaid } \\
(1-5 \text { scale }) \\
\end{array}$ & $\begin{array}{c}(2) \\
\text { Health Ins. } \\
(1-5 \text { scale })\end{array}$ & $\begin{array}{c}\text { (3) } \\
\text { Overall } \\
\text { Factor }\end{array}$ & $\begin{array}{c}(4) \\
\text { Policy } \\
\text { Factor }\end{array}$ & $\begin{array}{c}(5) \\
\text { Prejudice } \\
\text { Factor }\end{array}$ \\
\hline Wave \#1 & $\begin{array}{c}0.01 \\
(0.02)\end{array}$ & $\begin{array}{c}0.11 * * * \\
(0.02)\end{array}$ & $\begin{array}{c}0.03 * * * \\
(0.01)\end{array}$ & $\begin{array}{c}0.03 * * * \\
(0.01)\end{array}$ & $\begin{array}{c}0.05 * * * \\
(0.01)\end{array}$ \\
\hline Wave \#2 & $\begin{array}{c}0.01 \\
(0.02)\end{array}$ & $\begin{array}{c}0.00 \\
(0.02)\end{array}$ & $\begin{array}{c}0.01 \\
(0.01)\end{array}$ & $\begin{array}{c}0.01 \\
(0.01)\end{array}$ & $\begin{array}{l}-0.00 \\
(0.01)\end{array}$ \\
\hline Post & $\begin{array}{c}0.10^{* * *} \\
(0.02)\end{array}$ & $\begin{array}{c}0.07 * * * \\
(0.02)\end{array}$ & $\begin{array}{c}0.07 * * * \\
(0.01)\end{array}$ & $\begin{array}{c}0.07 * * * \\
(0.01)\end{array}$ & $\begin{array}{c}0.02 \\
(0.01)\end{array}$ \\
\hline Post*Reached & $\begin{array}{c}0.19 * * * \\
(0.06)\end{array}$ & $\begin{array}{c}0.18 * * * \\
(0.06)\end{array}$ & $\begin{array}{c}0.12 * * * \\
(0.03)\end{array}$ & $\begin{array}{c}0.13 * * * \\
(0.03)\end{array}$ & $\begin{array}{c}0.09 * * * \\
(0.03)\end{array}$ \\
\hline Constant & $\begin{array}{c}2.45^{* * *} * \\
(0.01)\end{array}$ & $\begin{array}{c}2.44 * * * \\
(0.01)\end{array}$ & $\begin{array}{c}-0.05 * * * \\
(0.01)\end{array}$ & $\begin{array}{c}-0.05 * * * \\
(0.01)\end{array}$ & $\begin{array}{c}-0.02 * * * \\
(0.01)\end{array}$ \\
\hline $\begin{array}{l}\text { Observations } \\
\text { R-squared } \\
\text { Number of Unique } \\
\text { Observations }\end{array}$ & $\begin{array}{c}10,342 \\
0.01 \\
2,725\end{array}$ & $\begin{array}{c}10,342 \\
0.01 \\
2,725\end{array}$ & $\begin{array}{c}10,342 \\
0.02 \\
2,725\end{array}$ & $\begin{array}{c}10,342 \\
0.02 \\
2,725\end{array}$ & $\begin{array}{c}10,347 \\
0.00 \\
2,725\end{array}$ \\
\hline
\end{tabular}

Cluster-robust standard errors in parentheses. ${ }^{* * *} \mathrm{p}<0.01,{ }^{* *} \mathrm{p}<0.05, * \mathrm{p}<0.1$ 
Figure OA2: Main Results from Study 3
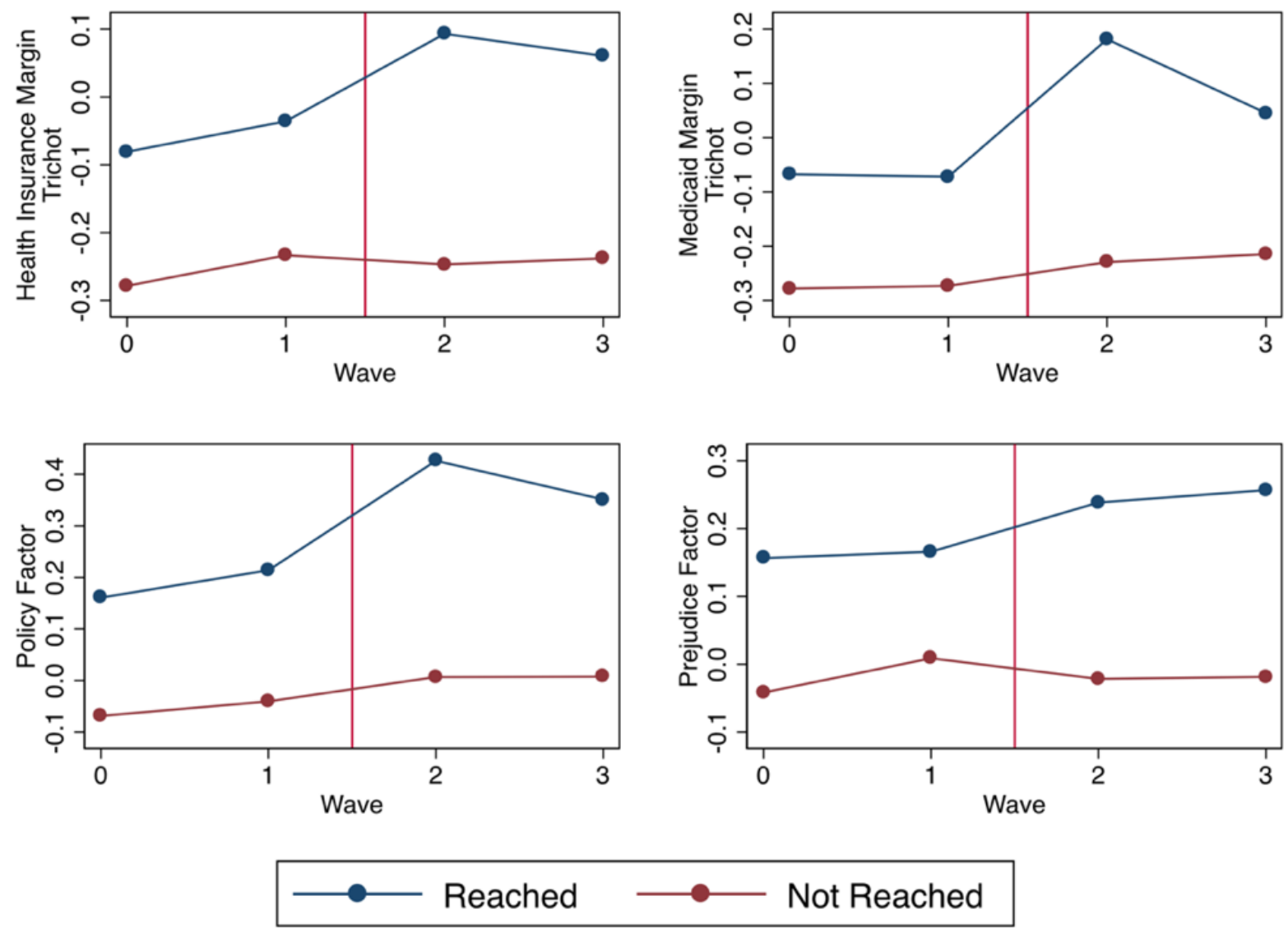